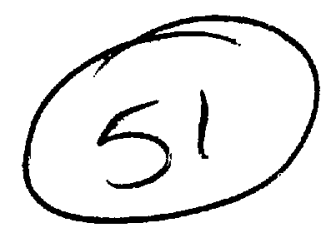

\title{
Structural Analysis of a Mechanized LHD Trench Undercut Caving System
}

UNITED STATES DEPARTMENT OF THE INTERIOR

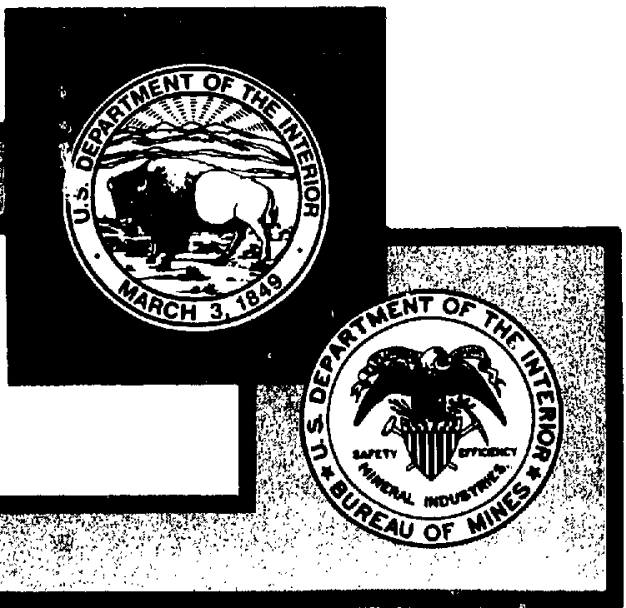




\section{U.S. Department of the Interior Mission Statement}

As the Nation's principal conservation agency, the Department of the Interior has responsibility for most of our nationally-owned public lands and natural resources. This includes fostering sound use of our land and water resources; protecting our fish, wildlife, and biological diversity; preserving the environmental and cultural values of our national parks and historical places; and providing for the enjoyment of life through outdoor recreation. The Department assesses our energy and mineral resources and works to ensure that their development is in the best interests of all our people by encouraging stewardship and citizen participation in their care. The Department also has a major responsibility for American Indian reservation communities and for people who live in island territories under U.S. administration. 
Report of investigations 9542

Structural Analysis of a Mechanized
LHD Trench Undercut Caving System

By C. V. Jude

UNITED STATES DEPARTMENT OF THE INTERIOR

Bruce Babbitt, Secretary

BUREAU OF MINES

Rhea L. Graham, Director 
International Standard Serial Number ISSN 1066-5552 


\section{CONTENTS}

Abstract $\ldots \ldots \ldots \ldots \ldots \ldots \ldots \ldots \ldots \ldots \ldots \ldots \ldots \ldots \ldots \ldots \ldots \ldots \ldots \ldots \ldots \ldots \ldots \ldots \ldots$

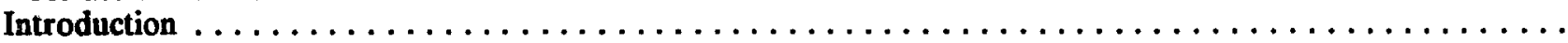

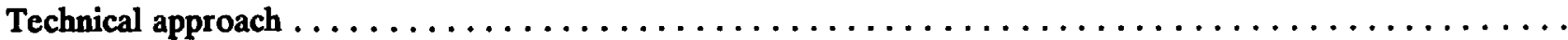

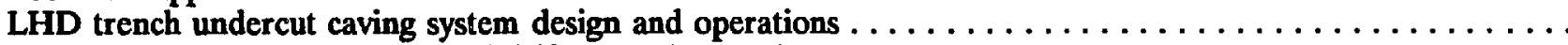

Plan and section views of panel drifts, trenches, and caves $\ldots \ldots \ldots \ldots \ldots \ldots \ldots \ldots \ldots \ldots$

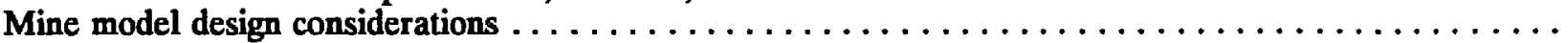

Oblique section for mine stress model $\ldots \ldots \ldots \ldots \ldots \ldots \ldots \ldots \ldots \ldots \ldots \ldots \ldots \ldots \ldots$

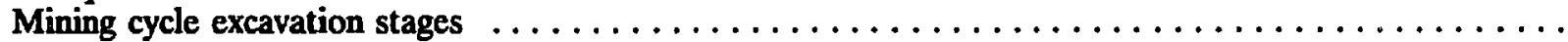

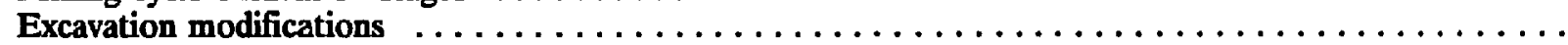

Determination of rock mass and intact rock shear-failure criteria parameter values $\ldots \ldots \ldots \ldots \ldots \ldots$

Results from rock strength data analyses $\ldots \ldots \ldots \ldots \ldots \ldots \ldots \ldots \ldots \ldots \ldots \ldots \ldots \ldots$

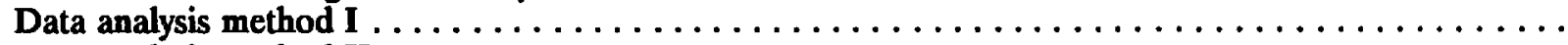

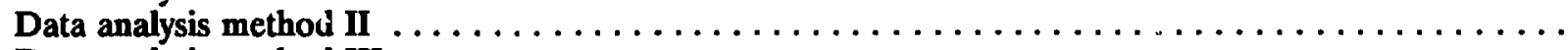

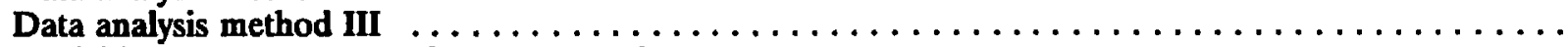

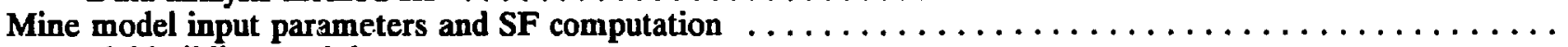

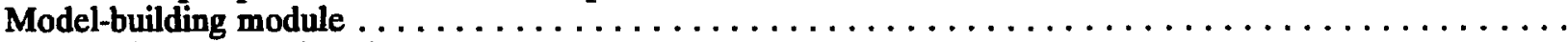

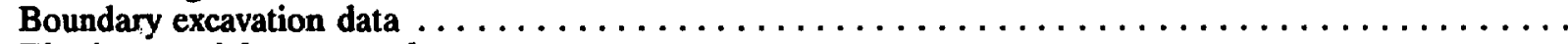

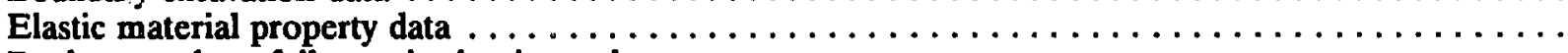

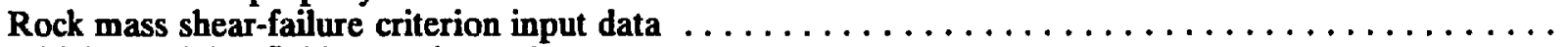

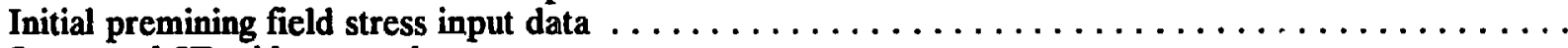

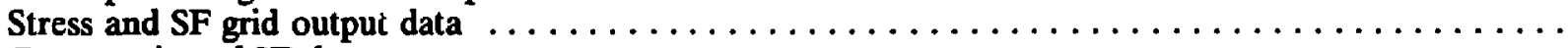

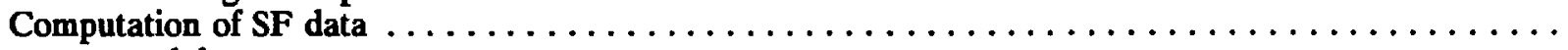

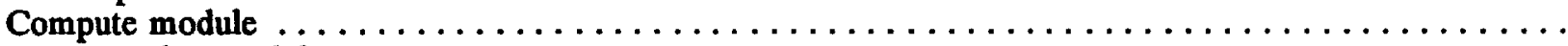

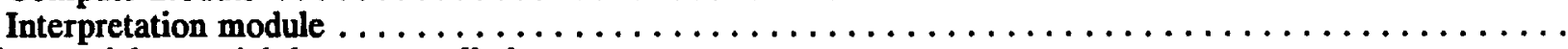

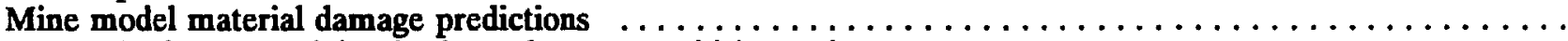

Results from premining horizontal stress sensitivity analyses $\ldots \ldots \ldots \ldots \ldots \ldots \ldots \ldots \ldots \ldots$

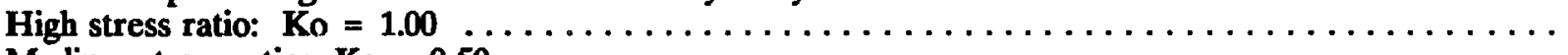

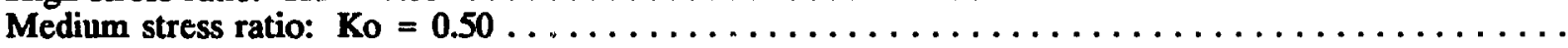

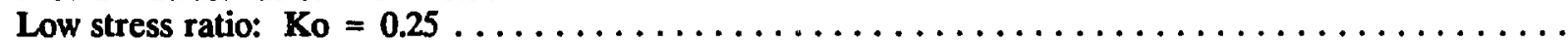

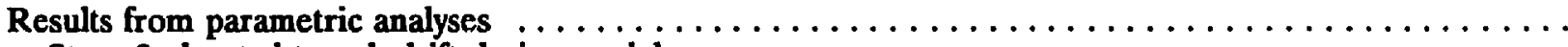

Stage 2 elevated trench drift design model cases $\ldots \ldots \ldots \ldots \ldots \ldots \ldots \ldots \ldots \ldots \ldots \ldots$

Modified stage 2 delayed excavation of trench drift model case $\ldots \ldots \ldots \ldots \ldots \ldots \ldots \ldots \ldots$

Field survey site results

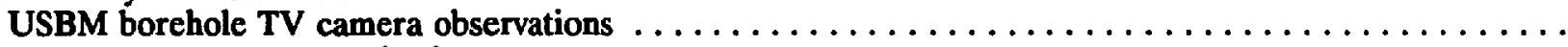

Magma convergence monitoring measurements

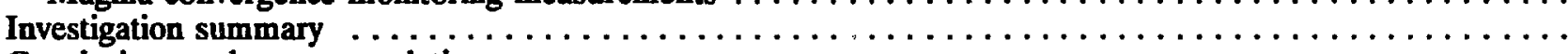

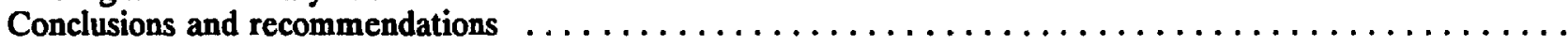

Acknowledgments

References

\section{ILUSTRATIONS}

1. Isometric view of conventional gravity draw caving system at San Manuel Mine $\ldots \ldots \ldots \ldots \ldots$

2. Isometric view of mechanized LHD trench undercut caving system at San Manuel Mine $\ldots \ldots \ldots \ldots$

3. Isometric view of elevated and nonelevated trench drift designs $\ldots \ldots \ldots \ldots \ldots \ldots \ldots \ldots \ldots$

4. Observed displacement pattern around LHD production draw drift $\ldots \ldots \ldots \ldots \ldots \ldots \ldots \ldots \ldots$

5. Locations of TV camera and convergence boreholes at field survey site $\ldots \ldots \ldots \ldots \ldots \ldots \ldots \ldots$

6. Boundary-element mine model for simulating mining cycle caving stages $\ldots \ldots \ldots \ldots \ldots \ldots \ldots \ldots$

7. Section view of elevated trench drift design with apex drifts added $\ldots \ldots \ldots \ldots \ldots \ldots \ldots \ldots \ldots \ldots \ldots$

8. Mohr-Coulomb rock mass shear-failure parameter values from borehole shear tests $\ldots \ldots \ldots \ldots \ldots \ldots$

9. Hoek-Brown shear-failure parameter values for intact rock and rock mass conditions . . . . . . . . .

10. Mine model stage 2 excavation geometry for original nonelevated trench drift design $\ldots \ldots \ldots \ldots \ldots \ldots$

11. Mine model stage 2 excavation geometry for alternative elevated trench drift design . . . . . . . . . . .

12. Stage $\mathbf{2}$ material damage predictions for nonelevated trenches as function of high stress ratio and

13. Stage 2 material damage predictions for nonelevated trenches as function of high stress ratio and Mohr-Cculomb rock mass failure criterion 


\section{ILLUSTRATIONS-Continued}

14. Stage $\mathbf{2}$ material damage predictions for nonelevated trenches as function of high stress ratio and

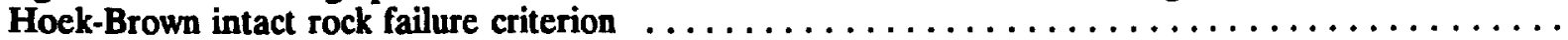

15. Stage 2 material damage predictions for nonelevated trenches as function of medium stress ratio and

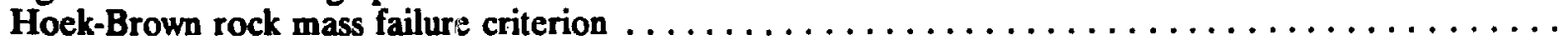

16. Stage 2 material damage predictions for nonelevated trenches as function of medium stress ratio and

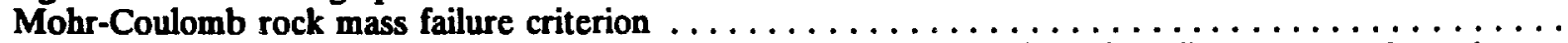

17. Stage 2 material damage predictions for noneivated trenches as function of medium stress ratio and

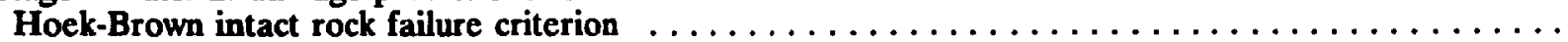

18. Stage 2 material damage predictions for nonelevated trenches as function of low stress ratio and

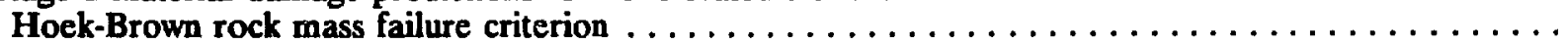

19. Stage 2 material damage predictions for nonelevated trenches as function of low stress ratio and

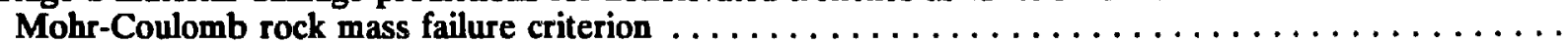

20. Stage 2 material damage predictions for nonelevated trenches as function of low stress ratio and

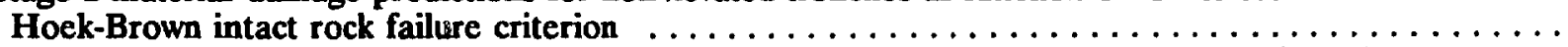

21. Stage $\mathbf{2}$ material damage predictions for elevated trenches as function of low stress ratio and

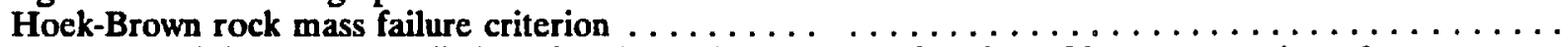

22. Stage 2 material damage predictions for elevated trenches as function of low stress ratio and

Mohr-Coulomb rock mass failure criterion . . . . . . . . . . . . . . . . . . . . .

23. Stage 2 material damage predictions for elevated trenches as function of low stress ratio, average

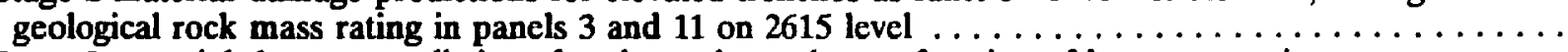

24. Stage 2 material damage predictions for elevated trenches as function of low stress ratio, average geological rock mass rating in panel 3 on 2615 level . . . . . . . . . . . . . . . . .

25. Stage 2 material damage predictions for elevated trenches as function of low stress ratio, geological rock mass rating in panel 11 on 2615 level . . . . . . . . . . . . . . . . . . . . . . .

26. Stage 2 material damage predictions for hypothetical elevated trench drift design as function of low stress ratio and Hoek-Brown rock mass strength parameter values $\ldots \ldots \ldots \ldots \ldots \ldots \ldots \ldots$

27. Stage $\mathbf{2}$ material damage predictions for hypothetical elevated trench drift design as function of low stress ratio and Mohr-Coulomb rock mass strength parameter values $\ldots \ldots \ldots \ldots \ldots \ldots \ldots$

28. Modified stage 2 material damage predictions around chamber drift brow for delayed excavation of right trench drift as function of low stress ratio and Hock-Brown rock mass strength parameters . . . . . . .

29. Modified stage 2 material damage predictions around chamber drift brow for delayed excavation of right trench drift as function of low stress ratio and Mohr-Coulomb rock mass strength parameters .......

30. Modified stage 2 material damage predictions around chamber drift brow for delayed excavation of right trench drift as function of low stress ratio, average geological rock mass rating in panel 3 on 2615

level, and estimated Hoek-Brown rock mass strength parameters $\ldots \ldots \ldots \ldots \ldots \ldots \ldots \ldots$

31. Location of TV camera boreholes and convergence extensometers at survey site in panel 3 on 2615 level

\section{TABLES}

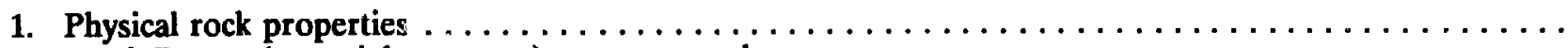

2. Hoek-Brown (material constants) parameter values $\ldots \ldots \ldots \ldots \ldots \ldots \ldots \ldots \ldots \ldots \ldots \ldots$

\section{UNIT OF MEASURE ABBREVIATIONS USED IN THIS REPORT}

$\begin{array}{llll}\text { deg } & \text { degree } & \mathrm{MN} / \mathrm{m}^{3} & \text { meganewton per cubic meter } \\ \mathbf{f t} & \text { foot } & \mathrm{MPa} & \text { megapascal } \\ \text { in } & \text { inch } & \mathrm{MPa} / \mathrm{m} & \text { megapascal per meter } \\ \mathbf{l b} / \mathrm{ft}^{\mathbf{3}} & \text { pound per cubic foot } & \mathrm{psi} & \text { pound per square inch } \\ \mathbf{m} & \text { meter } & \mathrm{psi} / \mathrm{ft} & \text { pound per square inch per foot } \\ \mathbf{m m} & \text { millimeter } & & \end{array}$

Reference to specific products does not imply endorsement by the U.S. Bureau of Mines. 


\title{
STRUCTURAL ANALYSIS OF A MECHANIZED LHD TRENCH UNDERCUT CAVING SYSTEM
}

\author{
By C. V. Jude'
}

\begin{abstract}
This U. S. Bureau of Mines (USBM) report presents results of stress analyses and field observations to investigate the effects of elevated trench drifts on the structural stability of rock mass zones surrounding a production draw drift in a mine utilizing a mechanized load-haul-dump (LHD) trench undercut panel caving system. A two-dimensional boundary-element mine stress model was developed to predict the locations and extent of damaged rock mass zones surrounding draw drifts where adjacent, parallel trench drifts are either elevated or not elevated above the LHD production draw drift level. A Mohr-Coulomb shear-failure criterion was obtained directly from in situ borehole shear test data. Hoek-Brown shear-failure parameter values were computed from borehole-shear and triaxial test data. A procedure is described to estimate these parameters when a rock mass rating (RMR) value and triaxial data on intact samples exist, and no borehole shear test data exist.

Results indicate that trench drifts, elevated to the level equal to the height of the LHD production draw drift, would not minimize material damage nor significantly enhance the stability of rib and crown pillar zones surrounding production draw drifts in the mechanized LHD trench undercut caving panel investigated at this mine.
\end{abstract}

${ }^{1}$ Mining arigineer, Denver Research Center, U.S. Bureau of Mines, Denver, CO. 


\section{INTRODUCTION}

A dilemma common to many block caving systems is the existence of two opposing ground control requirements. The in situ rock mass must experience sufficient material damage during undercutting to initiate caving, while the unmined rock mass that surrounds the production level drifts must provide stable rib and crown pillars during all stages of mine development and production. Major geomechanical problems affecting block caving operations are predicting cavability, defining size distribution of broken ore, and designing stable production openings (I)..$^{23}$

In an effort to advance the U.S. Bureau of Mines (USBM) mission to ensure an adequate, dependable supply of minerals, USBM researchers have investigated mine design parameters, rock mass rating (RMR) characteristics, and sequential operating procedures critical to the success of block caving systems (2). Research in this area included development of a generic finite-element stress model to investigate how premining stresses, rock fractures, and block boundary weakening zones may influence caving (3), and a finite-element model to predict redistribution of stresses and potential zones of weakness in a particular orebody to be block caved (4).

In 1988, the USBM entered into a cooperative research agreement with the Magma Copper Co., Tucson, AZ, to obtain relevant information on block caving ground control problems and consider alternative solutions. This investigation, conducted at the San Manuel Mine located 40 miles northwest of Tucson, AZ, used a two-dimensional boundary-element structural stress analysis model to evaluate whether or not elevated trench drifts could minimize material damage and significantly enhance the stability of rock mass zones surrounding production draw drifts in this particular load-haul-dump (LHD) trench undercut panel caving mine.

Prior to 1984, the San Manuel Mine had used a conventional gravity draw horizontal undercut block caving system shown in figure $1(5)$. In late 1984, Magma began testing new mining methods using mechanized equipment. The new longhole horizontal undercut method focused on driving undercut drifts with rubber-tired jumbo drills and diesel-powered LHD units (6). Longholes, drilled from these drifts, were blasted to complete the development of the horizontal undercut located $4.5 \mathrm{~m}(15 \mathrm{ft})$ above the

\footnotetext{
2Italic numbers in parentheses refer to items in the list of references at the end of this report.

${ }^{3}$ OFR 79-81. A Study of the Behavior of Underground Openings During Block Caving Operations by G. B. Barla and S. H. Boshkov. USBM Contract J0275005, H. Krumb School of Mines, 1979, 542 pp.
}

production draw level. Caving ore flowed through draw raises to a neiwork of grizzly drifts, where it continued to move by gravity down closely spaced orepasses into loading chutes, located $18 \mathrm{~m}$ ( $60 \mathrm{ft}$ ) below on the train haulage level (figure 1). This design decreased undercut drift footage and reduced the cost to complete the undercut.

Experience and knowledge gained from the longhole undercut project led to the design and development of a new mechanized LHD trench drift undercut panel caving system in 1985 in test panels 18 and 19 on the 2315 level. The new trench drift undercut caving system consisted of parallel LHD production draw and trench drifts alternating across a panel area (figure 2). Chamber draw drifts were driven $45^{\circ}$ from LHD production draw drifts to the the trench drift. Figure 2 shows the locations of nonelevated trench drifts (dashed profile) tested in panels 18 and 19 and elevated trench drifts used in production panels 3 and 11 on 2615 level. Figure 3 shows the relative locations of production and chamber draw drifts and rib pillars for the original nonelevated trench and subsequent alternative elevated trench drift designs. Longholes, inclined $60^{\circ}$, were ring drilled upward in a fan-shaped pattern from the trench drift and extended $18 \mathrm{~m}$ (60 ft) over the LHD draw drifts. Longholes were loaded with powder and shot to initiate undercutting, followed by full-production caving (figure 2). The caved ore was drawn by the LHD unit from the loading chamber draw drift that accessed the trench drift muck pile from the production draw drift. After the LHD loaded in the chamber drift, it trammed through the production draw drift and dumped the ore into the nearest orepass. The effect of this design was to increase draw efficiency by replacing the work force with high-capacity mobile equipment. The design reduced haulage development footage and required fewer orepasses, resulting in lower capital costs. Magma engineers (7) reported some areas in the 2315 level test panels experienced few ground control overpressure problems. However, other areas experienced rib pillar failures with subsequent convergence of the roof rock-arch (crown pillar) zone located directly above the LHD draw drifts. Figure 4 depicts observed displacement patterns in trench drift panels, resulting in rib failure and subsequent displacement of the crown pillar. Areas containing joints and faults showed early sloughing along the ribs of LHD production and chamber draw drifts.

Full tonnage extraction was not achieved in test panels 18 and 19, compared to production from adjacent panels using the conventional gravity draw caving system. 
Figure 1



Isometric view of conventional gravity draw caving system at San Manuel Mare 


\section{KEY}

ELTD Elevated trench drift

NELTD

LHD DD

LHD

C DD

CDB

CAVE

RNGDRL

PNL AD

PROLVL

TRN HD

OP
Nonelevated trench drift Load haul dump draw drift Load haul dump draw unit Chamber draw drift Chamber drift brow Production cave Ring drill pattern Panel access drift Production level Train haulage drift Orepass

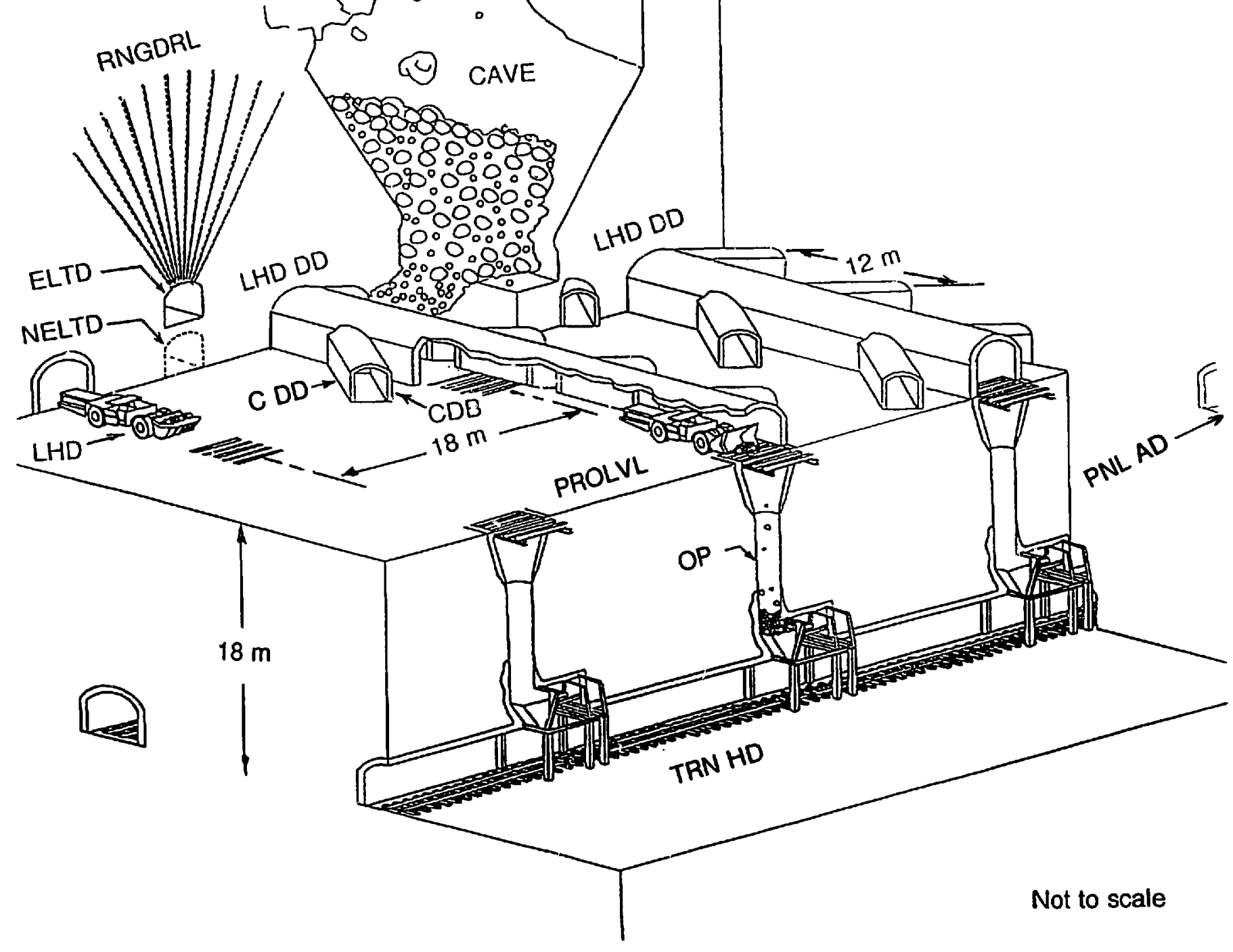

Isomutric view of mechanized load houl dump (LHD) trench undercut caving system at San Manuel Mine with locations of elevated and nonelenated (dashed projile) bench drifts. 
Figure 3
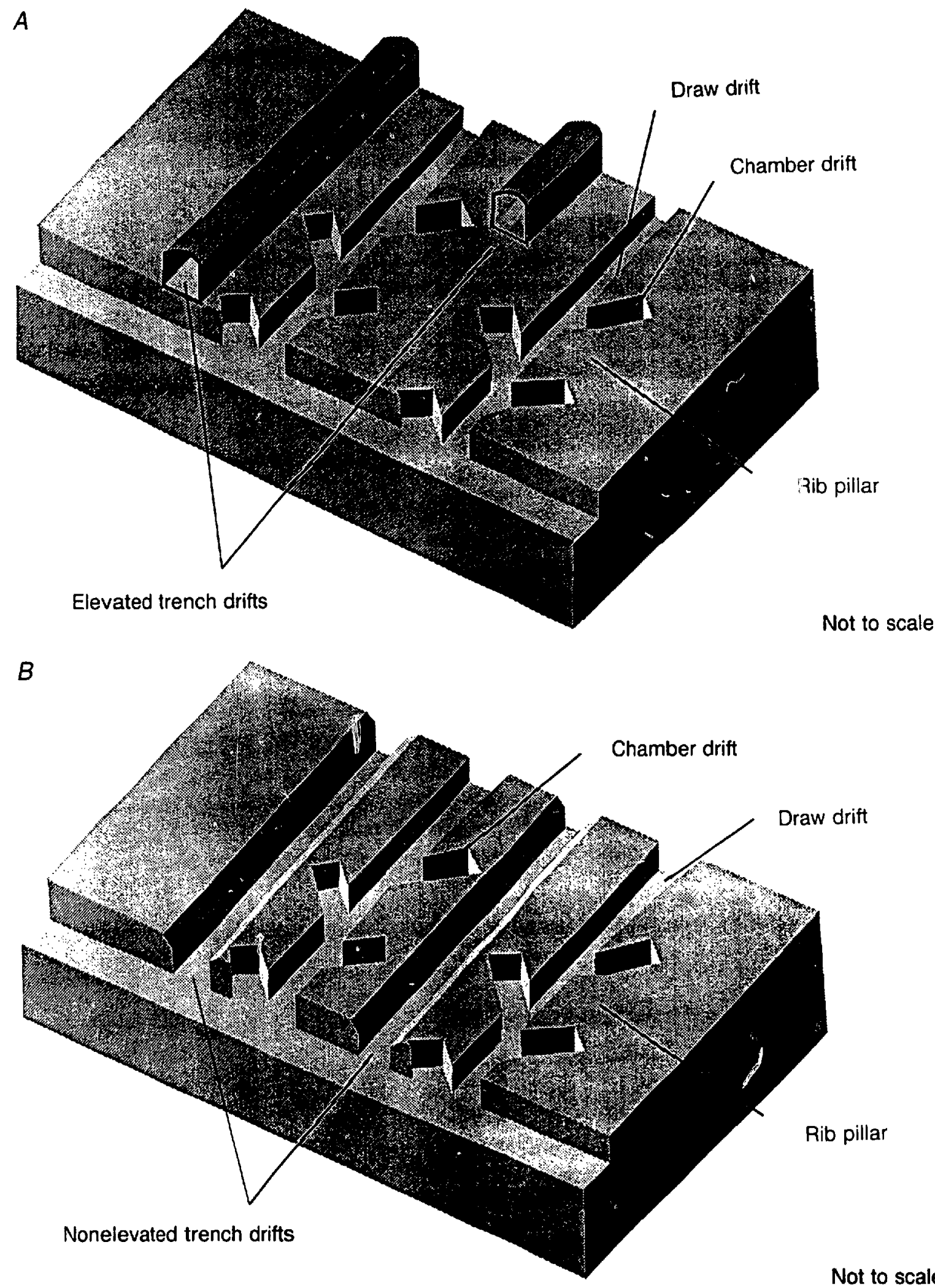

Not to scale

Isometric view of elevated and nonelevated trench diff desigrs. A, Elevated trench drifts implemented in production panels 3 and 11 on 2615 level; B, original nonelevated trench difts tested in panels 18 and 19 on 2315 level. 
Figure 4

A

Crown pillar

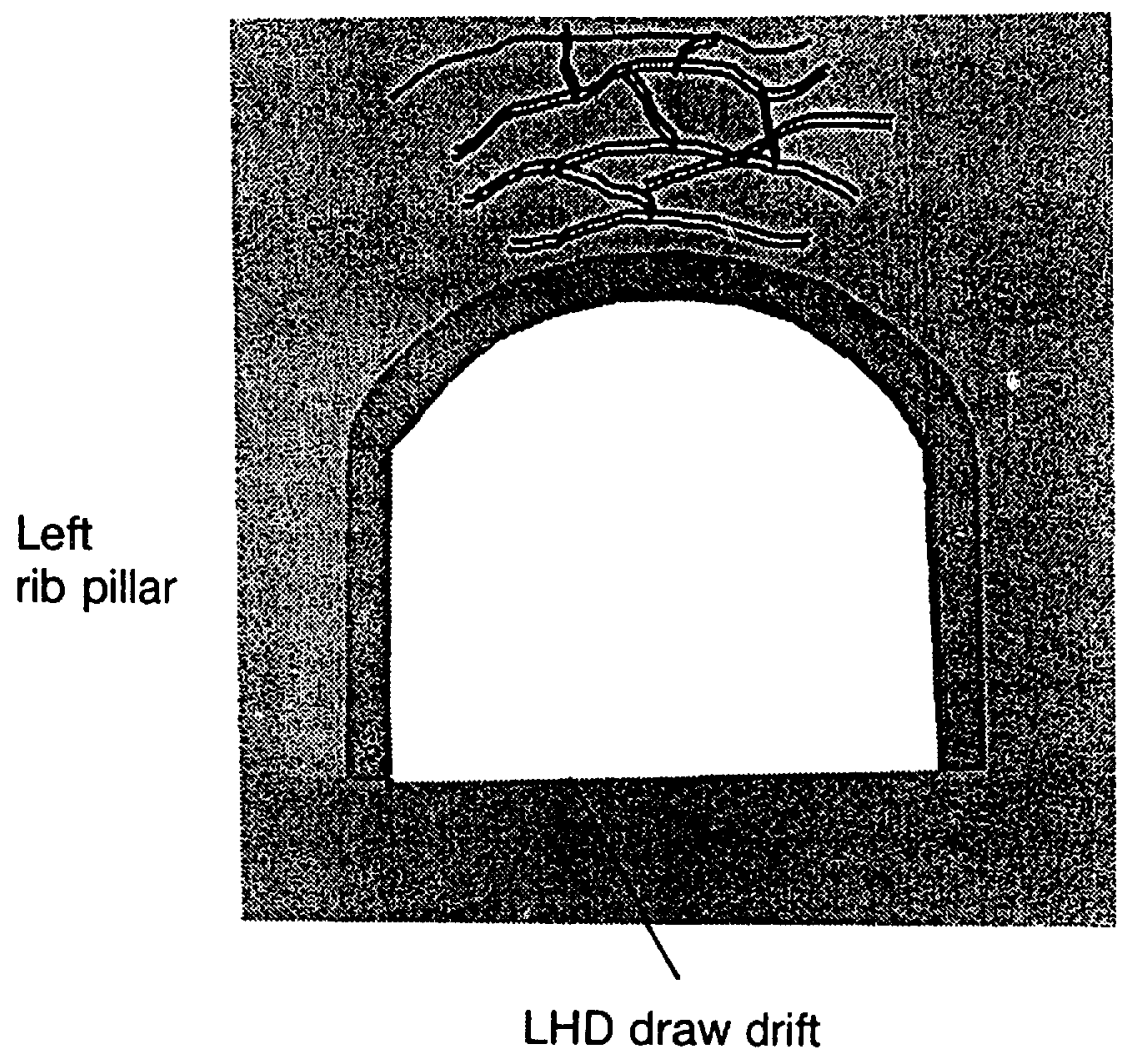

Right

rib pillar

B

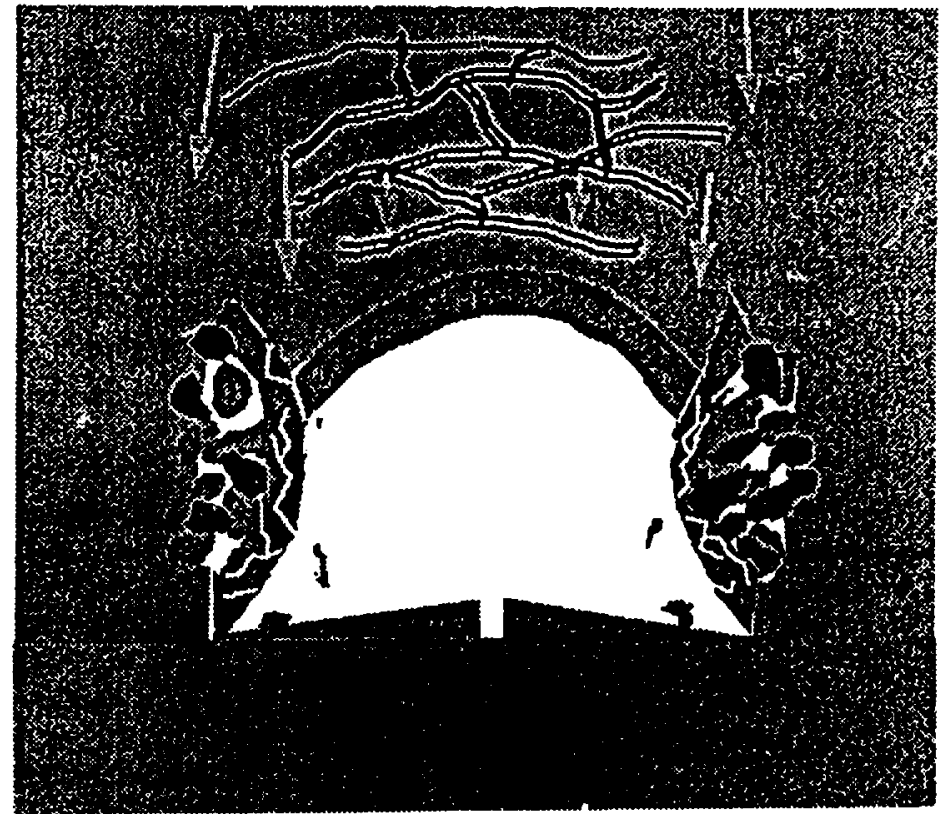

Not to scale

Obsenved displacement pattem around LHD production draw dijt A, Original rock-arch shape before failune; $B$, rock-arch movement and shope after failure. 
In 1987, further modifications of drift spacing (in plan view) were incorporated into the design and implemented in two full-scale production panels (3 and 11) on the 2615 LHD production level, located $90 \mathrm{~m}$ ( $300 \mathrm{ft}$ ) below the 2315 level. A principal design change included increasing the height of the LHD drifts from $3 \mathrm{~m}(10 \mathrm{ft})$ to $3.6 \mathrm{~m}(12 \mathrm{ft})$ to accommodate larger, higher capacity LHD production equipment. Before this cooperative project started, trench drifts had already been elevated $3.6 \mathrm{~m}$ (12 ft) above the production draw drift elevation to create larger supporting rib pillars (figure $5 B$ ). This was done in an effort to reduce rock mass damage from trench blasting and more effectively sustain overpressure loads created during initial stages of undercutting (stage 2) and fullproduction caving (stage 3) (figure 6). Spacings between LHD and chamber liaw drifts were increased, and ground support rock bolting systems were modified to help mitigate ground movement. Concurrently, Magma engineers documented results from RMR and joint and fault field surveys ( 8 ) conducted near Magma's convergence monitoring survey site in panel 3 on 2615 LHD production level (figure $5 A$ ).

In addition to the design changes already noted, parallel apex drifts (figure 7) were driven $18 \mathrm{~m}$ (60 ft) above and over the draw drifts to ensure that the trench cave initiation blasts would not leave unbroken load-bearing, rock-column stubs over the draw drifts (figure 6). Stress analyses assisted in investigating the potential adverse effects these stubs might impose on the mining operation. Incomplete caving overlap between adjacent trenches could result in overpressure, causing either rib pillar and/or roof damage. These apex drifts were not included in the original mine design. Should apex drifts be necessary, the total capital cost for this design would increase. A generic mine stress model geometry was created to simulate this worse case situation hy increasing the trench slope angle from $60^{\circ}$ to $75^{\circ}$ and omitting the anex drifts (figure 6).

Production efficiencies in panels 3 and 11 (2615 level) were reported good in certain areas where the effect of ground pressure was not apparent. Regions containing large intersecting faults and altered material sustained severe damage to ribs and subsequent convergence of the crown pillar. Some of these difficult ground conditions eventually led to production delays and increased maintenance costs. Ground instability problems, including some floor beaving, continued to occur in the mechanized LHD trench drift production panels.

In 1988, Magma announced this mechanized LHD trench undercut caving system would be limited to the San Manuel orebody, scheduled for depletion in 3 years (9).

\section{TECHNICAL APPROACH}

The investigation of rib and crown pillar instabilities, identified with the LHD trench undercut caving system at the San Manuel Mine, was conducted in four phases.

The first phase involved a field trip to the mine to meet the geological and mining engineers cooperating in the 24-month project and collect geotechnical and other mine reports relevant to this ground instability problem. Underground sites were inspected where the original nonelevated trench drift mine design was tested and spacings were later modified because of rib failures and subsequent displacement of the crown pillar directly over the LHD production drift. Project members observed the repeating mining cycle, which consisted of panel drift development, trench undercutting, and full-production caving stages. Production panels, where $3.6-\mathrm{m}(12-\mathrm{ft})$ elevated trench drifts were currently being implemented, were examined so that size, shape, and spacings (in section) of drift, trench, and cave openings could be incorporated into a twodimensional, boundary-element stress (material damage) analysis computer modeling program named EXAMINE ${ }^{2 D}$ (10). Magma engineers provided geologic structure and RMR data characterizing the panel area where elevated trench caving was to start and convergence monitoring was in progress. The USBM selected this site to conduct borehole TV camera surveys. Magma engineers would record displacement and USBM personnel would observe crack development in the rock mass surrounding LHD draw drift 7 at chamber draw drift 5 south in panel 3 on 2615 level.

Physical rock property data were derived from in situ borehole shear and laboratory triaxial tests previously conducted by the USBM in panels 2 and 41 on the 2315 level.

In phase two, three rock strength data analysis methods were conducted to determine the Mohr-Coulomb and Hoek-Brown failure criterion parameter values for rock mass and intact rock conditions. The boundary-element stress analysis program EXAMINE ${ }^{20}$ accepts either criterion. Mine stress model case studies were based on the Mohr-Coulomb rock mass shear-failure parameters (friction angle, cohesion, and a user-specified tension cut-off value) and the Hoek-Brown material strength parameters (the unconfined compressive strength of intact rock UCS(i), material friction value, $m$, and inherent strength value, $s$ ). Mohr-Coulomb rock mass shear-failure paramcters were computed by a linear regression analysis program applied to a large suite of borehole shear test data. 
Figure 5

A

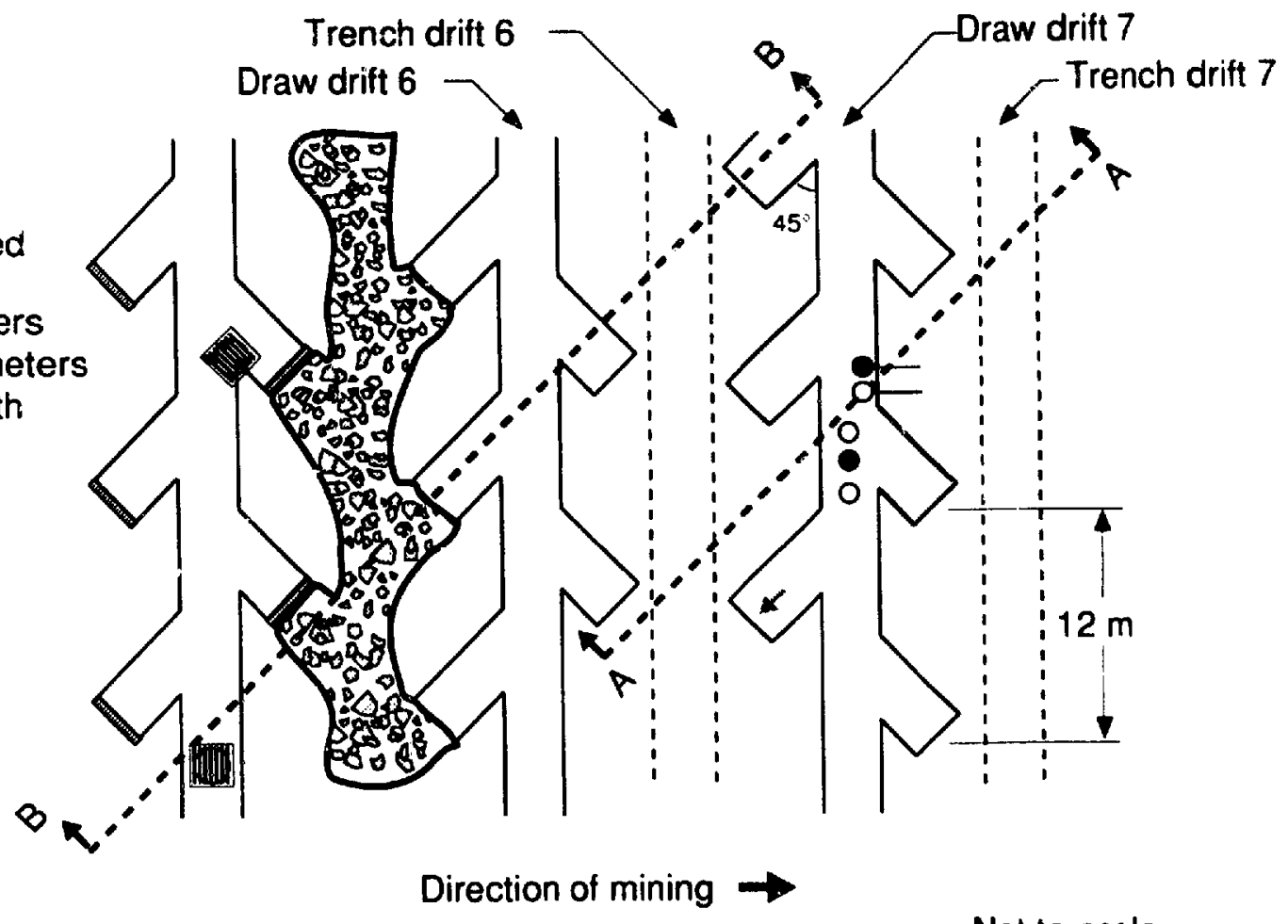

Not to scale

- Vertical TV holes

o- Horizontal and angled TV holes

- Vertical extensometers

- Horizontal extensometers

Chamber drift 5 south Chamber drift 6

$\star \quad$ north up-ramp

[iiiit Orepass

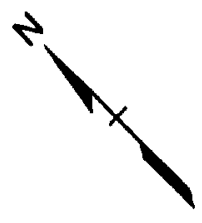

Direction of mining $\rightarrow$

Not to scale

B

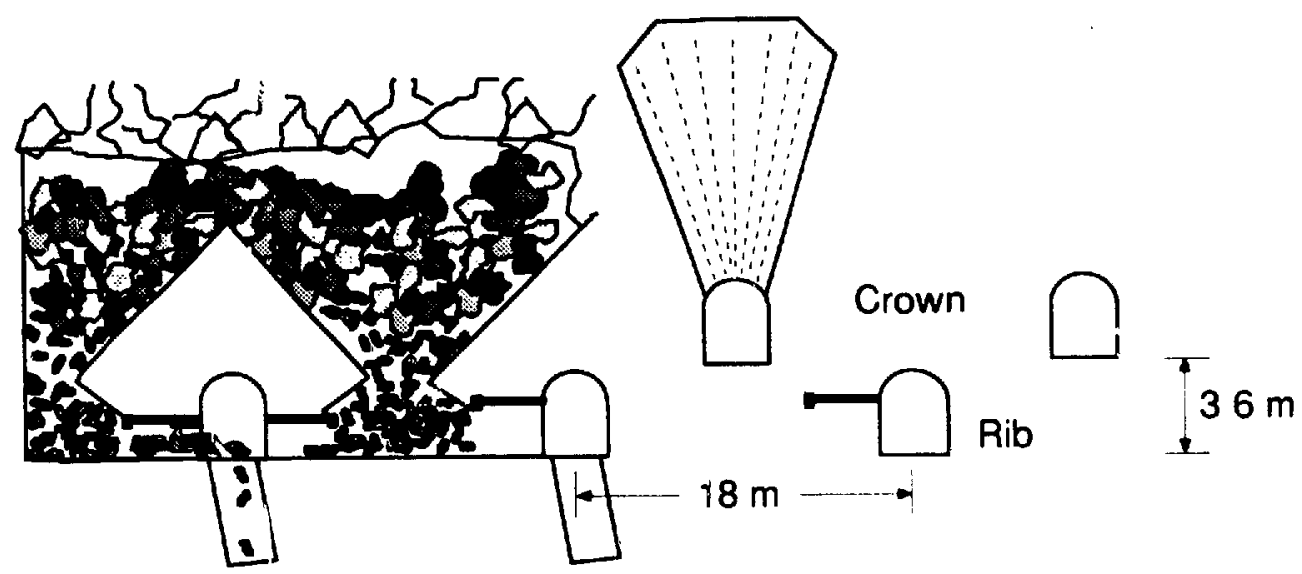

Direction of mining $\rightarrow$

Not to scale

Locations of TV comera and convergence boreholes at field survey site in panel 3 on 2615 level A, Plan view of mine stress model section $A-A ; B$, typical section $B-B$. 
Figure 6

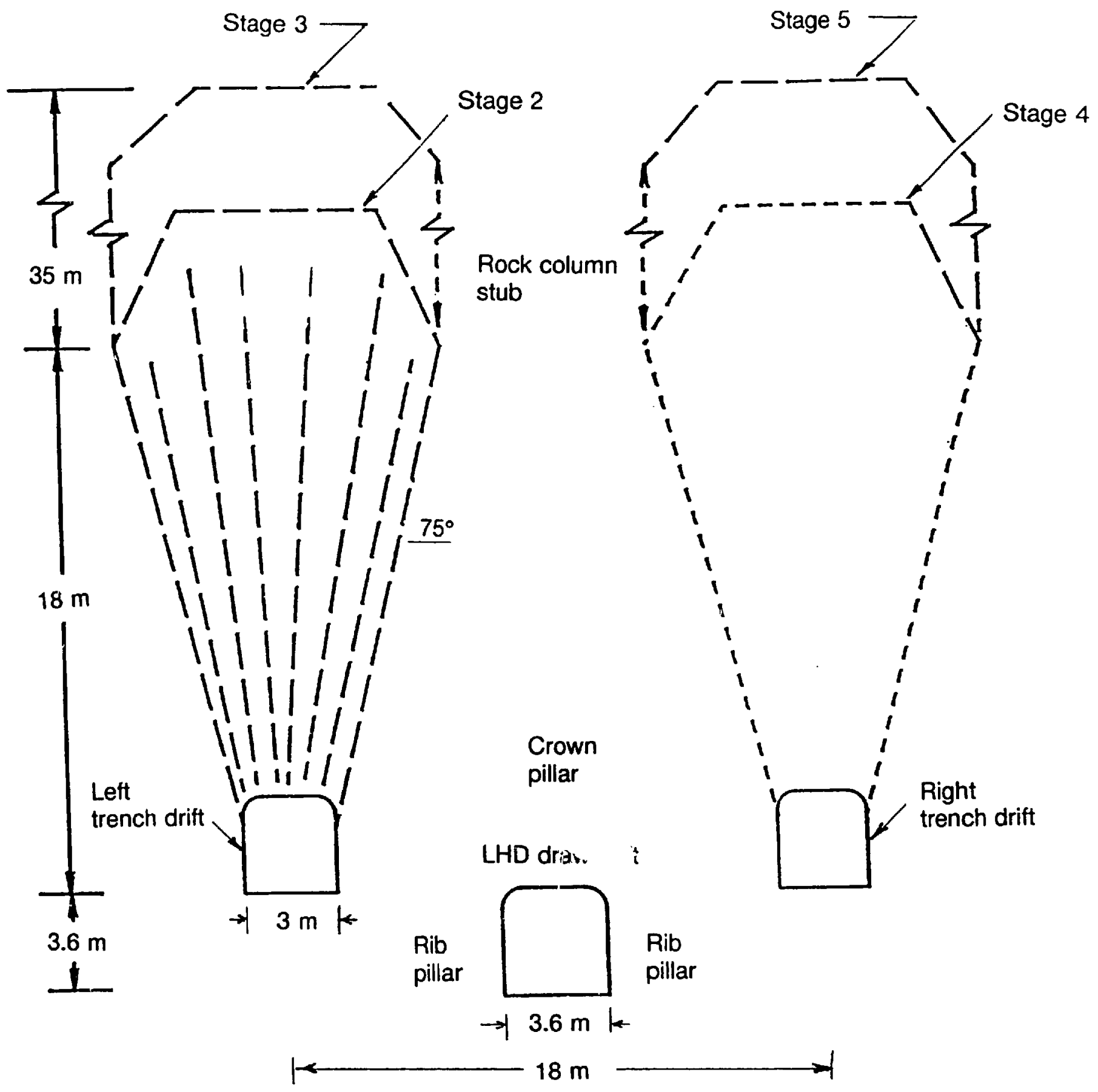

Not to scale

Boundaryelement mine model for simulating mining cycle caving stages (see figure 5, oblique section A-A). 
Figure 7

\begin{aligned} & \multicolumn{1}{c}{ KEY } \\ APXD & Apex drift \\ APXR & Apex access raise \\ CP & Crown pillar \\ CDB & Chamber drift brow \\ C DD & Chamber draiv drift \\ LHD DD & LHD draw drift \\ ELTD & Elevated trench drift \\ OP & Orepass \\ TRN HD & Train haulage drift \end{aligned}

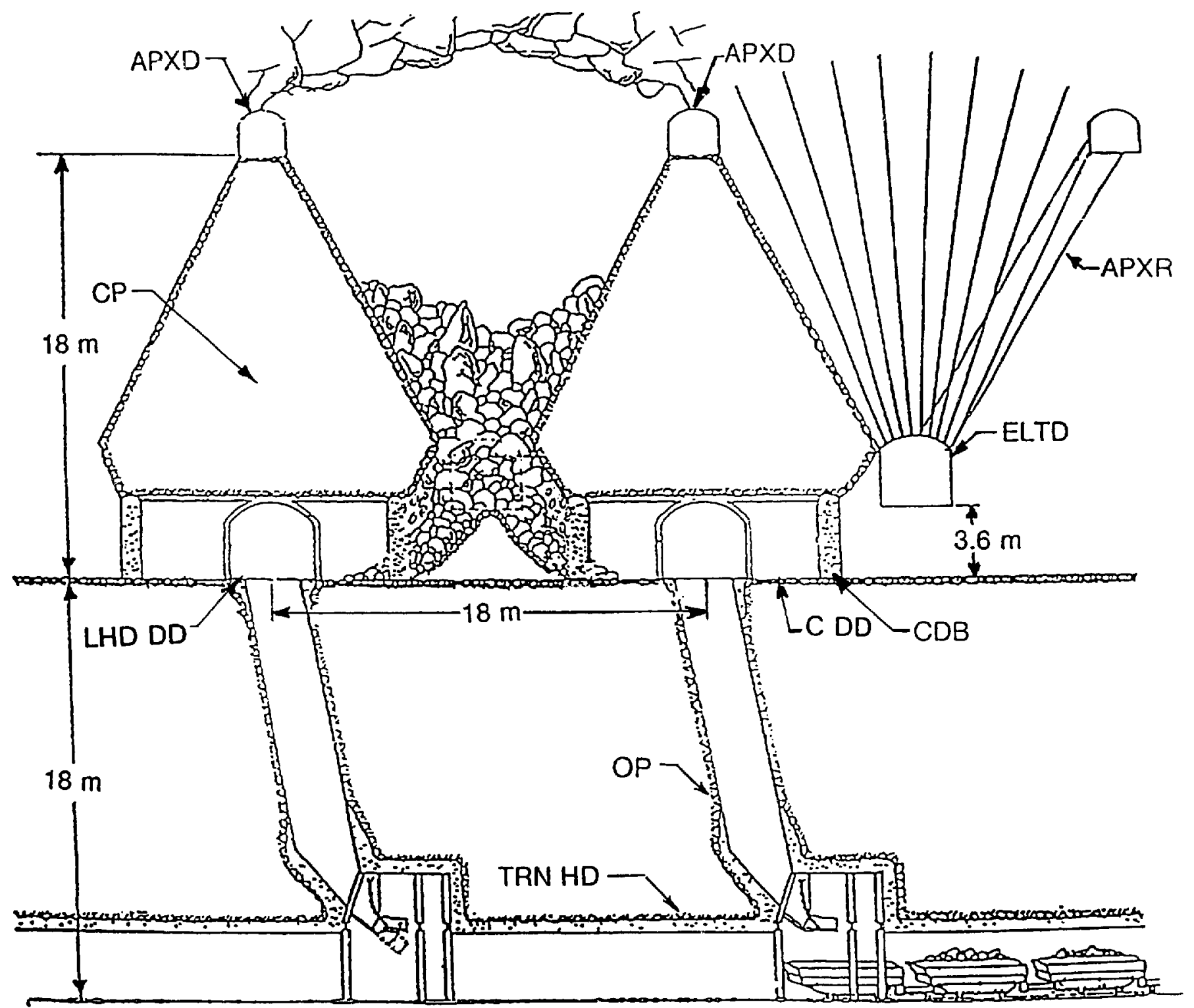

Not to scale 
Hoek-Brown shear-failure parameter values were computed by the ROCKDATA program, using borehole shear test and triaxial compressive strength test data on intact core samples removed from the shear test boreholes. With the rock mass failure criterion specified and the stresses induced around mine excavations computed, EXAMINE $^{2 D}$ computes shear strength factor (strengthstress ratio) values for a multitude of grid points within the model rock zones. The strength factor (SF) output data were used to predict conditions where the rock material may be damaged from high shear stress and becomes unstable. Premining in situ stress values are major input data required by the computer model. However, since initial in situ (premining) stresses had not been obtained in this orebody, the computer stress analysis was performed on a generic and qualitative basis. In the absence of measured premining stress data, a computer stress modeling strategy was formulated to achieve the project objectives. First, a sensitivity analysis was performed using a range of assumed premining stress conditions. The purpose was to search for a model case that simulated the observed rib failures and crown pillar movements that occurred in the original nonelevated trench drift test panels. A range of likely initial principal horizontal stress values (high, medium, and low) was tried, with the principal vertical gravity stress increasing linearly. Mine personnel suggested that the rock mass was generaliy loose and had not exhibited unusually high initial horizontal stress during early stages of panel drift development. The best estimated premining stress values, therefore, focused on the effects of gravity and Poisson's ratio. All mine models were generic and did not represent any specific section in the mine. Once the desired model simulation case was determined from the initial stress candidates above, three parametric stress model cases were performed:

1. For neighboring trench drifts elevated $3.6 \mathrm{~m}$ ( $12 \mathrm{ft}$ ) above the LHD production draw drift level.

2. For a hypothetical alternative design, with neighboring trench drifts elevated $5.5 \mathrm{~m}$ (18 ft) above the LHD production draw drift level.

3. For the modified stage 2 configuration at the survey site, delaying excavation of the right adjacent trench drift.

Phase three focused on the geometric features and stress modeling capability of the computer program EXAMINE $^{2 D}$, used to create the mine stress models. Data entry procedures for constructing the boundaryelement model and computing SF values were identified. Shear SF contour maps were generated for each modeling case, and the pending unstable behavior in the rock mass was interpreted on the basis of indicated material damaged zones. Researchers were aided in reaching a qualitative conclusion on whether or not elevating trench drifts might be advantageous by comparing locations and extent of predicted material damaged zones around the LHD draw drift.

In phase four, two borehole TV camera surveys were performed at the field survey site. The camera system recorded audio descriptions and video tape images at 50-mm (2-in) intervals to document rock surface conditions inside four holes during (modified stage 2) caving and 3 months later when stage 5 full-production caving was achieved. The objective was to determine the actual stage at which cracks first occurred and compare it to the mine model caving stage that first predicted initial material damage.

\section{LHD TRENCH UNDERCUT CAVING SYSTEM DESIGN AND OPERATIONS}

This section describes the layout of panel drifts mined during the initial development stage and the resulting infrastructure of unmined rock mass that provided ground support during cave initiation and subsequent mining cycle excavation stages. Plan and section views describe the geometry of the mine excavations and the operating procedures of the diesel-powered LHD units. Mining cycle excavation stages are defined and mine model design considerations are presented.

\section{PLAN AND SECTION VIEWS OF PANEL DRIFTS, TRENCHES, AND CAVES}

Mine drift development and production stages common to the mechanized LHD trench undercut caving system are described by Magma engineer Crandall (11). Figure 5 shows the location of the field survey site in panel 3 on the 2615 level. LHD production draw drifts, 3.6 by $3.6 \mathrm{~m}$ (12 by $12 \mathrm{ft}$ ), are driven on $18-\mathrm{m}(60-\mathrm{ft})$ centers beneath the ore zone. Staggered chamber draw drifts are driven from the production draw drifts on uniform 12.1-m (40-ft) spacing with an LHD turn-in angle of $45^{\circ}$. Trench undercut drifts driven between the LHD production draw drifts intersect the ends of the chamber drifts that define the chamber draw (loading) point locations. Caving is initiated by ring drilling 75-mm (3-in) diam longholes $18 \mathrm{~m}$ (60 ft) long from the trench drift and blasting sets of rings spaced on $1.5-\mathrm{m}(5-\mathrm{ft})$ centers along the trench drift axis. The drill and blast sequence is repeated along the trench drift while the same sequence is started in the next 
adjacent trench drift. After the initial fragmented rock is extracted, the caving ore moves toward the draw points. Full-production caving is achieved when broken rock continues to gravitate toward the end of the chamber draw drift brow. Near the brow, the LHD unit scoops up the ore, hauls it to the nearest orepass, and dumps it down the transfer raise to the train loading chute station $18 \mathrm{~m}$ (60 ft) below. Chamber drift brows consist of structural steel rupporting segments that are encased in concrete around the chamber drift opening. They are used to control the ore flow into the chamber draw point and are vulnerable to overpressure, which is caused by blasting to initiate caving in the adjacent trench. A major modification to the original nonelevated trench design was to elevate the trench drifts $3.6 \mathrm{~m} \mathrm{(12} \mathrm{ft)} \mathrm{above} \mathrm{the} 2615$ production level (figure $5 B$ ). The rationale for elevating these drifts was to enhance the stability in adjacent rib and crown pillars by retaining more unmined rock mass located directly below the elevated trench drift floor and between the adjacent chamber drifts. Since the caving stage at which the model might predict material damage zones was not known a priori, the model was developed to simulate cave configurations from stage 2 to stage 5 (figure 6). Initial material damage was predicted in the rib pillars at stage 2; therefore, stages 3,4 , and 5 were not simulated, because the material was considered disturbed beyond the linear elastic response assumed by the boundary-element method.

\section{MINE MODEL DESIGN CONSIDERATIONS}

\section{Oblique Section for Mine Stress Model}

Figure $5 \mathrm{~A}$ shows the infrastructure of unmined rock mass that must provide ground support during the productive life of the panel. Boundary panel access drifts were driven around the panel area before the LHD production draw, chamber, and trench drifts were excavated. The formation of this panel drift layout resulted in the extraction of $65 \%$ of the rock mass directly above the 2615 level, leaving $35 \%$ unmined rock mass to support overpressure loads induced during subsequent cave initiation and full-production caving stages. An oblique section (figure $5 A, A-A$ ) was chosen for this investigation so that the model would include unmined rock mass in both the left and right rib pillars (figure 6).

\section{Mining Cycle Excavation Stages}

Repeating mining cycle excavation stages proceed from stage 2 through stage 5 . The excavation geometries for each stage are illustrated in figure 6 , where stage 2 is the excavation configuration created when the left trench has been ring drilled and blasted to initiate the left cave. Stage 3 represents the formation of full-production caving upward. Stage 2 and stage 3 sequences are repeated as stage 4 and stage 5 in the adjacent right trench drift.

\section{Excavation Modifications}

In addition to the elevation of the trench drifts, two other drift excavation modifications were implemented in panel 3 on the 2615 level. Apex drifts (figure 7), located $18 \mathrm{~m}(60 \mathrm{ft})$ above each LHD production draw, were driven to inspect the effects of blasting at the ends of the ring holes and ensure that adjacent caves were interacting so that no rock stubs developed (8). Remnant pillars (rock stubs) may have been a major cause for the instabilities observed around the LHD draw drifts. The apex drifts were omitted from the mine stress model for the following reasons. First, the original nonelevated trench design did not include these drifts, and secondly, modeling the worsecase uverpressure, induced by the caving process, might contribute to understanding the basic causes of the rib and crown pillar instability problem. The generic mine stress model geometry in the oblique section was created to simulate this worse-case situation by increasing the trench slope angle from $60^{\circ}$ to $75^{\circ}$ and omitting the apex drift (figure 6).

Common practice was to develop all trench drifts well ahead of blasting the first (left) trench to initiate caving across the panel (figure 5). Magma had just modified the stage 2 excavation configuration by delaying the excavation of the right elevated trench drift as long as possible so that more unmined rock mass temporarily remained to sustain overpressure caused by blasting and caving in the left trench. To simulate the modified stage 2 configuration, the mine model geometry also included the end of the chamber draw drift at the brow loading point (figure 7). This time-delay procedure was implemented at the field survey site.

\section{DETERMINATION OF ROCK MASS AND INTACT ROCK SHEAR-FAILURE CRITERIA PARAMETER VALUES}

Rock strength data analyses were conducted using the computer program ROCKDATA. This software, and the two-dimensional boundary-element stress analysis program EXAMINE $^{2 D}$, were developed by the Data Visualization
Laboratory and Rock Engineering Group, University of Toronto and Mining Technology Division, Noranda in Pointe-Claire, Quebec (10). The programs belong in the public domain. Computing routines and data analysis 
options in ROCKDATA are presented by Hoek and Brown (12-13) and Hoek (14). This section describes how the ROCKDATA program was used to compute MohrCoulomb and Hoek-Brown rock material shear-failure parameter values required by the EXAMINE ${ }^{2 D}$ mine stress modeling program.

The Mohr-Coulomb rock mass, M-C(rm), failure criterion parameters are-

1. Material friction angle, $\phi(\mathrm{rm})$.

2. Cohesion intercept, $\sigma_{\mathrm{obh}}(\mathrm{rm})$.

3. User-specified tension cut-off value, $\sigma_{t}(\mathrm{rm})$.

The Hoek-Brown intact, H-B(i), rock parameters are defined as-

1. Unconfined compressive strength of intact rock, UCS(i).

2. Material friction constant of intact rock, $m(i)$.

3. Material inherent strength constant of intact rock, s(i), which is equal to 1.0 .

The Hoek-Brown rock mass, $\mathrm{H}-\mathrm{B}(\mathrm{rm})$, parameters are defined as-

1. Unconfined compressive strength of the rock mass, UCS(rm).

2. Material friction constant of the rock mass, $\mathbf{m}(\mathrm{rm})$.

3. Material inherent strength constant of the rock mass, $\mathbf{s}(\mathbf{r m})$.
Three data analysis methods were used in this study. In method I, M-C(rm) parameters were computed from borehole shear test data $\left(\tau, \sigma_{\mathrm{n}}\right)$, previously collected by USBM in panels 2 and 41 on 2315 level. These panels were horizontally offset about $182 \mathrm{~m}(600 \mathrm{ft})$ north and $152 \mathrm{~m}$ (500 ft) southwest, respectively, from the borehole TV camera survey site in panel 3 on the 2615 level. Borehole shear test equipment and test and data analysis procedures are described by Panek (15).

In method II, $\mathbf{H}-\mathrm{B}$ (i) parameters were computed from triaxial test data $\left(\sigma_{1}, \sigma_{3}\right)$ on core samples removed from the shear test boreholes. $H-B(r m)$ parameters were computed from borehole shear test data $\left(\tau, \sigma_{n}\right)$ and unconfined compressive strength UCS(i).

Method III is a procedure that estimates $F[-B(r m)$ parameters for the situation where no borehole shear data exist, but RMR value from fieid surveys and triaxial test data from intact rock samples do exist $(8,16)$. This situation occurred in panels 3 and 11 on 2615 level.

\section{RESULTS FROM ROCK STRENGTH DATA ANALYSES}

\section{Data Analysis Method I}

A linear regression analysis in ROCKDATA computed the $\mathrm{M}-\mathrm{C}(\mathrm{rm})$ parameter values shown in figure 8 and table 1 , where the material friction angle $\phi(\mathrm{rm})=36.5^{\circ}$; the cohesion intercept $c_{\cot }(\mathrm{rm})=4.1 \mathrm{MPa}(592 \mathrm{psi})$.

Table 1. Physlcal rock properties

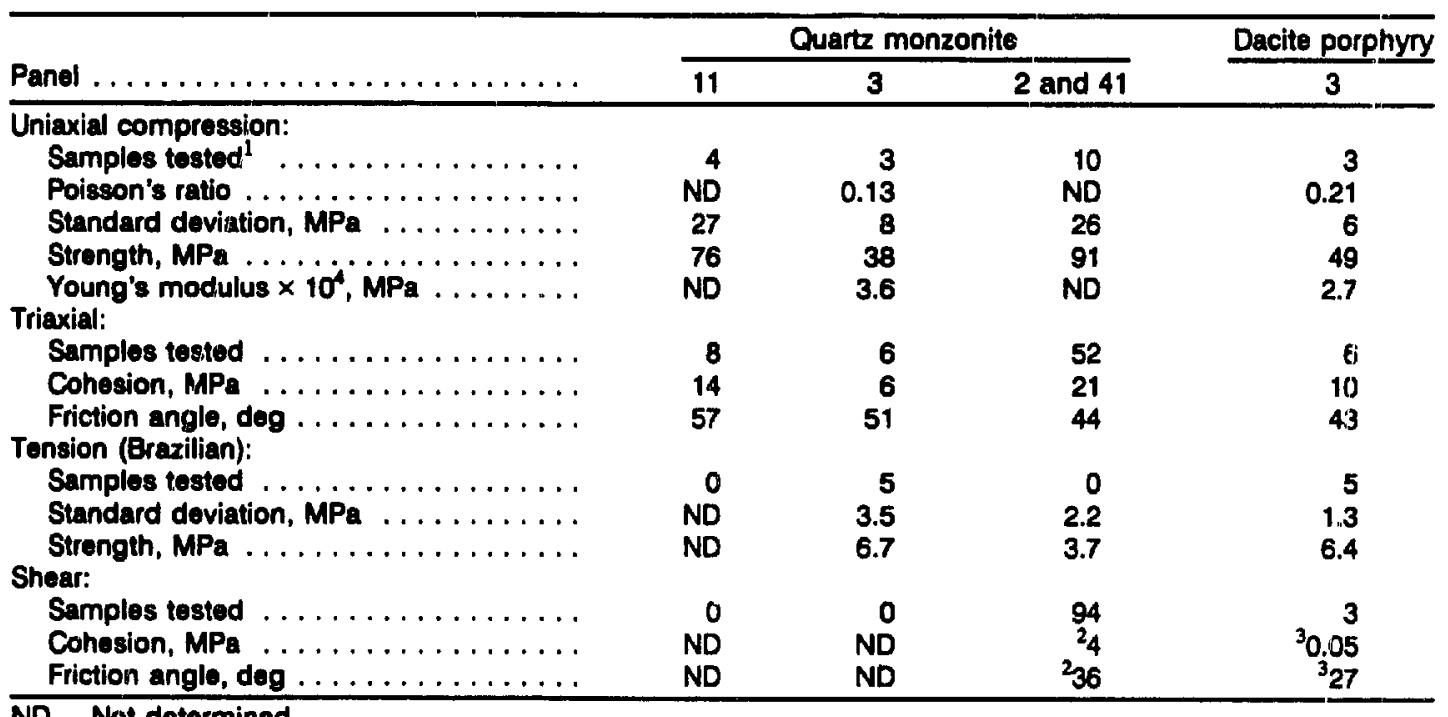

ND Not determined

${ }^{1}$ Panel 2 and 41 samples from 2315 level; others from 2615 level.

${ }^{2}$ USBM borehole shear tests.

3 Laboratory direct shear tests.

NOTE. All data rounded.

Source: Mine reports. 
Figure 8

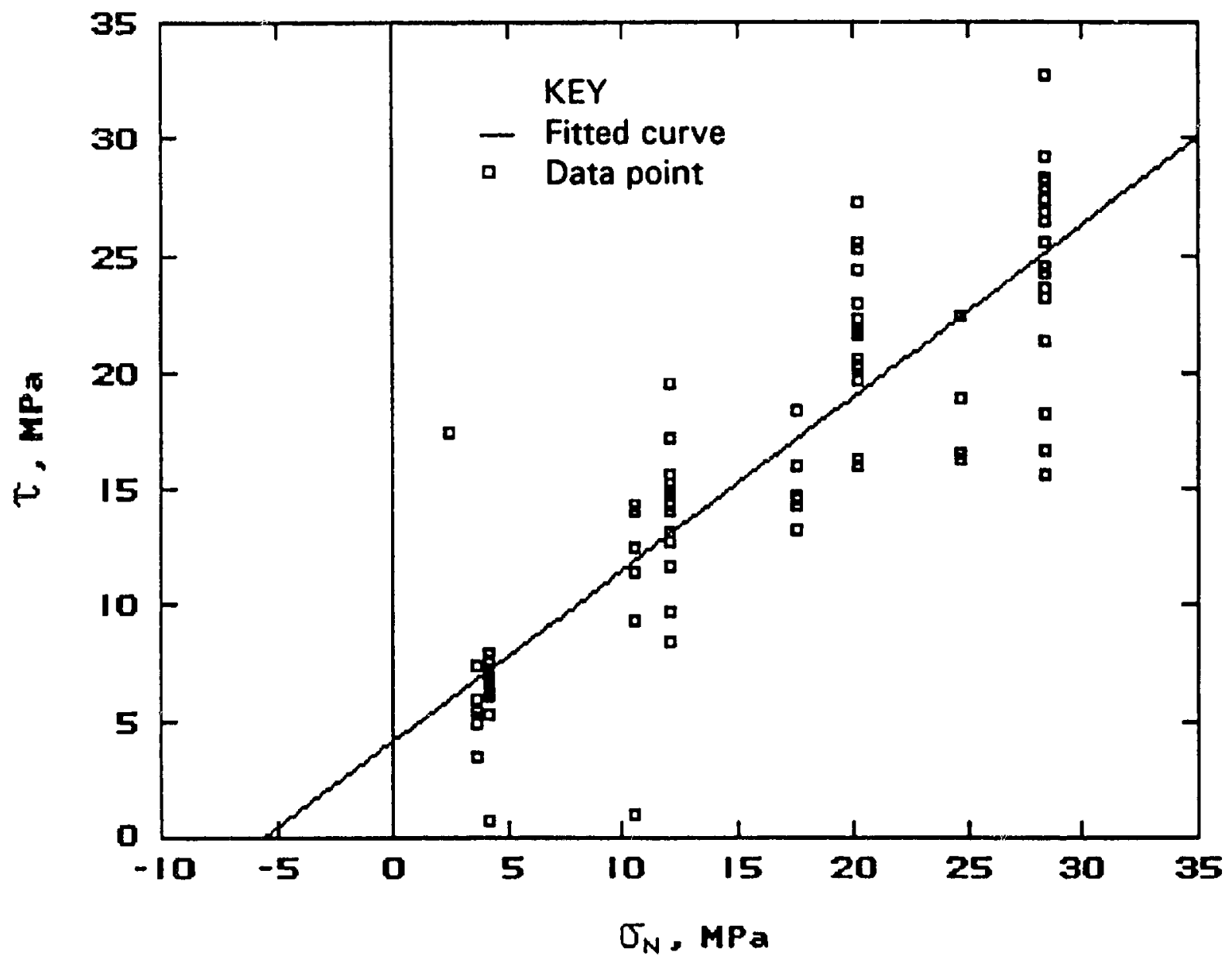

Mohr-Coulomb rock mass shear-faihure parumeter values from borchole shear tests in panels 2 and 41 on 23.15 level and muthod $I t \phi(m)=36.5$ and $\sigma_{\text {ad }}(m)=4.1 \mathrm{MPa}$

\section{Data Analysis Method II}

A nonlinear regression analysis routine in ROCKDATA computed the $\mathrm{H}-\mathrm{B}(\mathrm{i})$ parameter values shown in figure 9 and table 2, where UCS(i) = 91.1 $\mathrm{MPa}(13,210 \mathrm{psi}) ; \mathrm{m}(\mathrm{i})$ $=15.1 ;$ and $\mathrm{s}(\mathrm{i})=1$.

Table 2.Hook-Brown (material constants) parameter values

\begin{tabular}{|c|c|c|c|c|}
\hline \multirow[b]{2}{*}{ Panel } & \multicolumn{3}{|c|}{ Quartz monzonite } & \multirow{2}{*}{$\frac{\text { Dacite porphyry }}{3}$} \\
\hline & 11 & 3 & 2 and 41 & \\
\hline 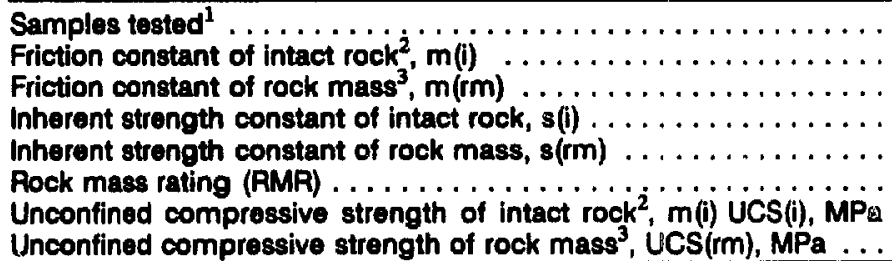 & $\begin{array}{r}8 \\
38 \\
8 \\
1.0 \\
0.0 \times 9 \\
58 \\
73 \\
\text { ND }\end{array}$ & $\begin{array}{r}6 \\
29 \\
5 \\
1.0 \\
0.004 \\
51 \\
37 \\
\text { ND }\end{array}$ & $\begin{array}{r}52 \\
15 \\
2 \\
1.0 \\
0.036 \\
\mathrm{ND} \\
91 \\
17\end{array}$ & $\begin{array}{r}6 \\
12 \\
2 \\
1.0 \\
0.004 \\
51 \\
49 \\
\mathrm{ND}\end{array}$ \\
\hline
\end{tabular}

ND Not determined.

IPanel 2 and 41 samples from 2315 level; others from 2615 level.

${ }^{2}$ Samples relatively free of discontinuities.

${ }^{3}$ Rock mass with discontinuities.

NOTE. - All data are rounded. 
Figune 9
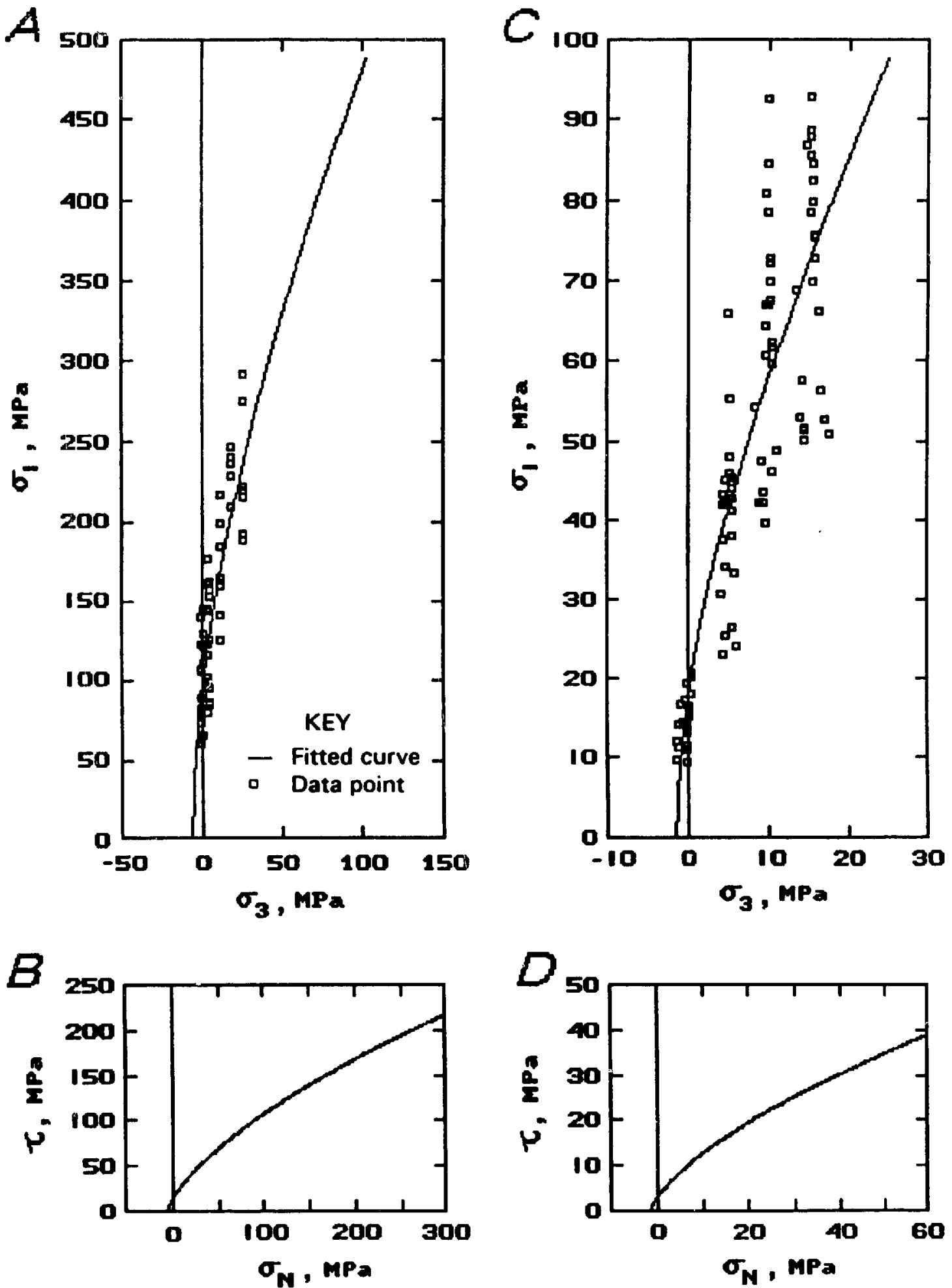

Hoek-Brown shear-failure parmeter values for intact rock and rock mass conditions by method $\boldsymbol{H}$. $A-B$, Labontary triasial tests on bonehole core samples; $C-D$, borehole shew tests in panels 2 and 11 on 2315 level. 
ROCKDATA provides an option to repeat the regression analysis to compute the $\mathrm{H}-\mathrm{B}(\mathrm{rm})$ parameter values for the rock mass. Two input data were required: (1) the borehole shear test data set $\left(\tau, \sigma_{n}\right)$, and (2) the unconfined compression strength from intact core sample UCS(i). Computed results are shown in figure 9 and table 2 , where $\mathrm{UCS}(\mathrm{rm})=17.3 \mathrm{MPa}(2,510 \mathrm{psi}) ; \mathrm{m}(\mathrm{rm})=2.2 ;$ and $\mathrm{s}(\mathrm{rm})$ $=0.036$.

ROCKDATA estimates the tensile strength values for intact and rock mass: $\sigma_{1}(\mathrm{i})=6 \mathrm{MPa}(870 \mathrm{psi})$, and $\sigma_{\imath}(\mathrm{rm})=1.48 \mathrm{MPa}(220 \mathrm{psi}$ ) (figures $9 A, 9 \mathrm{C}$ ).

\section{Data Analysis Method III}

Since no borehole shear test data existed from panels 3 and 11 on the 2615 level, data analysis method III was used to estimate Hoek-Brown rock mass parameters $\mathbf{m}(\mathrm{rm})$ and $\mathbf{s}(\mathrm{rm})$, when RMR values had been obtained from geological field surveys conducted in panels 3 and 11 on the 2615 level (8). RMR values, determined during the initial mine panel development were (1) RMR = 51 in panel 3, and (2) RMR = 58 in panel 11 (table 2).

The procedure for calculating Hoek-Brown material constants (12) is-
1. Compute UCS(i), and m(i), applying ROCKDATA to the set of intact triaxial test data, where $s(i)=1$ for intact rock.

2. Compute $m(\mathrm{rm})$ using Hoek-Brown's proposed relationship, where $\mathrm{m}(\mathrm{rm})=\mathrm{m}(\mathrm{i}) \times \mathrm{e}^{((\mathrm{RMR}-100) / 28)}$, for undisturbed rock mass.

3. Compute $s(r m)$ using Hoek-Brown's proposed relationship where $s(\mathrm{rm})=s(\mathrm{i}) \times \mathrm{e}^{((\mathrm{RMR}-100) / 9)}$, and $s(\mathrm{i})=1$ for intact rock.

Numerical results from this procedure are shown in table $\mathbf{2}$ for two rock types. For example, parameter values for quartz monzonite in panel 3 are $\mathrm{m}(\mathrm{i})=29, \mathrm{~m}(\mathrm{rm})=5$, and $\mathrm{s}(\mathrm{rm})=0.004$.

Hoek and Brown describe a ROCKDATA routine, derived by Bray (12), that comput $t$ s and plots a shearfailure envelope whenever Hoek-Brown material constants $\mathrm{UCS}(\mathrm{i}), \mathbf{m}(\mathrm{rm})$, and $\mathrm{s}(\mathrm{rm})$ are either specified or determined (figures $9 B, 9 D$ ). These plots may be used to compare envelopes derived from borehole shear tests (data analysis method I) with field RMR surveys (data analysis method III).

\section{MINE MODEL INPUT PARAMETERS AND SF COMPUTATION}

The EXAMINE ${ }^{2 D}$ program computes principal stresses and material damage SF for a selected grid of points, where each point represents a location within rock zones surrounding underground excavations. This section describes how the stress analysis package was used to construct the mine model excavation geometries (caving stages) prior to computing the material damage SF, and how ground instability may be inferred from mine model SF contour maps that indicate locations and extent of damaged rock zones.

The program accepts any consistent set of units of measure, but prompts the modeler for data in metric units. Compressive stresses are positive and tensile stresses are negative. The software package consists of (1) a modelbuilding module, (2) a compute module for calculating stresses and material damage SF, and (3) an interpretion module for generating contour maps that graphically display the location and extent of inferred damaged and/or undamaged rock zones.

\section{MODEL-BUILDING MODULE}

The model-building module is the preprocessing software used for entering the boundary excavation geometry, rock mass elastic property, shear-failure criterion parameter data, and initial premining field stresses. Steps for creating mine stress models and entering initial parameter input data are presented below.

\section{Boundary Excavation Data}

Figure 10 shows the connected line segments necessary to define the stage 2 excavation geometry and contour grid for the nonelevated trench drift mine model. For excavations, line segments are created by entering the beginning and ending coordinates, while proceeding counterclockwise around the opening until closure occurs. The coordinates may be entered using the key pad or cursor. Eight line segments were needed to create the boundaries. Tick marks, around the excavated boundaries, identify the length of each boundary-element used in the computing module. The large rectangular boundary around the mine openings defines a user-specified coordinate grid. It is used by the interpretion module to plot stress and material damage SF contour maps. Details of the stress theory and mathematical relations for boundary-elements are presented by Crouch (17) and Curran (12). 
Figure 10

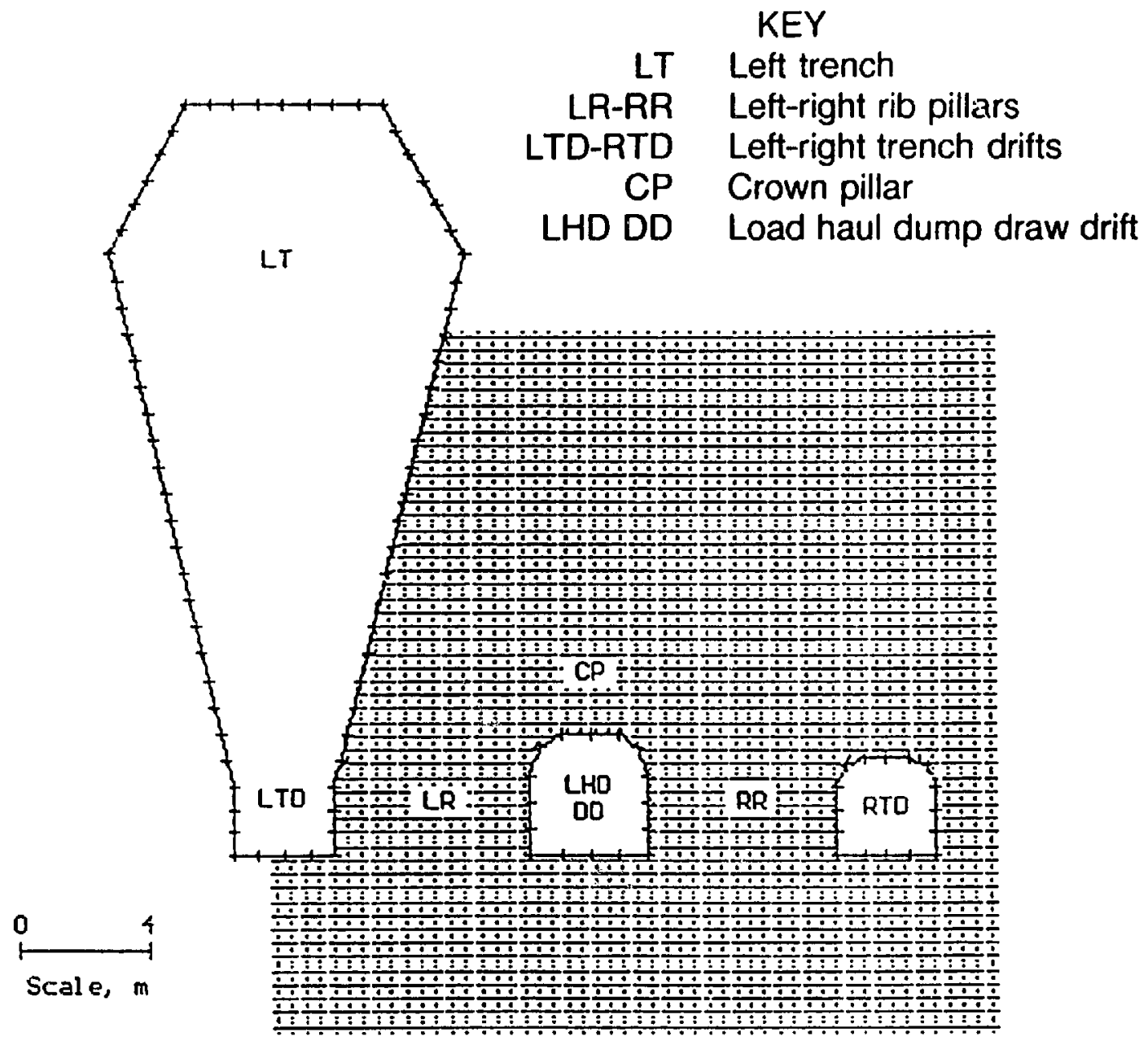

Miru model stage 2 excovation geometry for original nonelevated trench drift design, with SF contow grid to delineate zones of predicted material damage in test panels 18 and 19 on 2315 level.

\section{Elastic Material Property Data}

The Young's modulus and Poisson's values are averages from core sample tests reported in mine records (table 1): Young's modulus $(E)=32,000 \mathrm{MPa}\left(4.64 \times 10^{6} \mathrm{psi}\right)$. Poisson's ratio $(\nu)=0.17$.

\section{Rock Mass Shear-Failure Criterion Input Data}

Mohr-Coulomb rock mass (rm) shear-failure parameters (table 1):

Friction angle: $\phi(\mathrm{rm})=36.5^{\circ}$.

Cohesion intercept: $\sigma_{\text {coh }}(\mathrm{rm})=4.1 \mathrm{MPa}(592 \mathrm{psi})$.

Tensile strength: $\sigma_{1}(\mathrm{rm})=3.7 \mathrm{MPa}(540 \mathrm{psi})$.
The user-specified tension cut-off model input data is the average value determined by the Hoek-Brown data analysis method II (figure 9).

Hoek-Brown intact and rock mass strength parameters were derived from borehole shear tests conducted in panels 2 and 41 on the 2315 level (table 2):

$$
\begin{aligned}
& \operatorname{UCS}(\mathbf{i})=91.1 \mathrm{MPa}(13,210 \mathrm{psi}) \\
& \mathrm{m}(\mathrm{rm})=2.2, \mathrm{~s}(\mathrm{rm})=0.036
\end{aligned}
$$

\section{Initial Premining Field Stress Input Data}

The initial principal vertical stress was assumed to vary linearly with depth from the ground surface. With the rock unit weight of $0.0252 \mathrm{MN} / \mathrm{m}^{3}\left(160 \mathrm{lb} / \mathrm{ft}^{3}\right)$, the 
corresponding gravity gradient is $0.0252 \mathrm{MPa} / \mathrm{m}(1.11 \mathrm{psi} /$ $\mathrm{ft})$. The effect of $792 \mathrm{~m}(2,615 \mathrm{ft})$ of overburden above the 2615 level induces a premining vertical stress of about 19.8 MPa (2,870 psi). The initial principal horizontal stress is computed by multiplying the vertical stress value by the horizontal stress ratio (Ko) value. The model requires three input parameters to define the premining gravity stress field: (1) the unit weight of the rock $(\delta),(2)$ the vertical model coordinate (D) at the ground surface, where the vertical model coordinate at ground surface was $838 \mathrm{~m}(2,765 \mathrm{ft})$ and is based on the mine model coordinate system, and (3) the assumed horizontal stress ratio value (Ko).

Since the initial state-of-stress was not known in the San Manuel orebody, an initial horizontal stress sensitivity analysis was performed by varying the premining horizontal stress ratio (Ko) for a range of high, medium, and low values: $1.00,0.50$, and 0.25 . The lowest Ko value, 0.25 , approximates the horizontal stress effect produced by the Poisson's ratio, which is calculated by dividing Poisson's ratio of 0.17 by the quantity (1-0.17), yielding a Ko value of 0.205 . The high and medium stress ratios assume the possibility of tectonic stresses in the orebody (18). The purpose for the stress sensitivity analyses was to find a model with an initial premining stress that simulates the type of failures observed in the nonelevated trench drift test panels. Once this model was identified, it was used in a parametric analysis for two elevated trench drift designs and the modified stage 2 configuration.

\section{Stress and SF Grid Output Data}

Figure 11 shows the connected line segments needed to define the stage 2 excavation geometry and contour grid for the alternative elevated trench drift design mine model. Grid size, shape, and locations are specified by the user. Each grid is divided by evenly spaced horizontal and vertical lines to form a mesh of intersecting lines. Stress and SF output data are computed at each intersection. A multitude of grid point data assists the interpretation graphics display module in plotting smooth contour maps of principal stress and material damage SF output data.

\section{Computation of SF Data}

EXAMINE $^{2 D}$ computes the SF by dividing the maximum rock strength, $S_{\max }$ (strength), mobilized by the confining stress $(P)$ at a point, by the maximum induced shear stress existing at the same point, $S_{\text {mex }}$ (shear stress). In mathematical terms, the rock mass SF is defined-

$$
\mathrm{SF}=\mathrm{S}_{\max }(\text { strength }) / \mathrm{S}_{\max } \text { (shear stress), }
$$

where

$$
\begin{aligned}
& \mathrm{S}_{\max }(\text { strength })=\sigma_{\text {coh }}(\mathrm{rm}) \times \operatorname{Cos}(\phi(\mathrm{rm})) \\
& +\mathbf{P} \times \operatorname{Sin}(\phi(\mathrm{rm})) \text {, } \\
& \mathrm{S}_{\max }(\text { shear stress })=\left(\sigma_{1}-\sigma_{3}\right) / 2 \text {, } \\
& \mathrm{P}=\left(\sigma_{1}+\sigma_{3}\right) / 2 \text {. }
\end{aligned}
$$

\section{COMPUTE MODULE}

Once all modeling constructs and initial input parameter data are entered into a model input file, the compute module calculates stresses and SF at each of the specified grid points.

\section{INTERPRETATION MODULE}

Material damage prediction model cases are presented in terms of SF contour maps. SF contour ranges are displayed by distinctive textural patterns. Each pattern represents a stress condition that affected rock material by either tension or six ranges of shear stress intensity, e.g., figure 12. The SF legend is shown in all model case figures, where damaged material is indicated in range 0 $<\mathrm{SF} \leq 1$, and undamaged material is indicated when $\mathrm{SF}>1$. Tension zones, where $\mathrm{SF} \leq 0$, are dependent on the rock mass tensile strength cut-off value specified by the modeler.

\section{MINE MODEL MATERIAL DAMAGE PREDICTIONS}

Material damage predictions are presented in this section for nonelevated, elevated, and modified stage 2 trench drift design stress model cases. Each case stability analysis identifies rock zone locations, by key labels, and references the SF contour range legend to determine whether a zone is damaged or undamaged. Shear planes may be inferred where damaged and undamaged zones join.

The premining horizontal stress sensitivity analysis assumed high, medium, and low initial principal horizontal stresses. Results from this analysis determined which horizontal stress factor (Ko) would be selected and used in the 


\section{Figure 11}

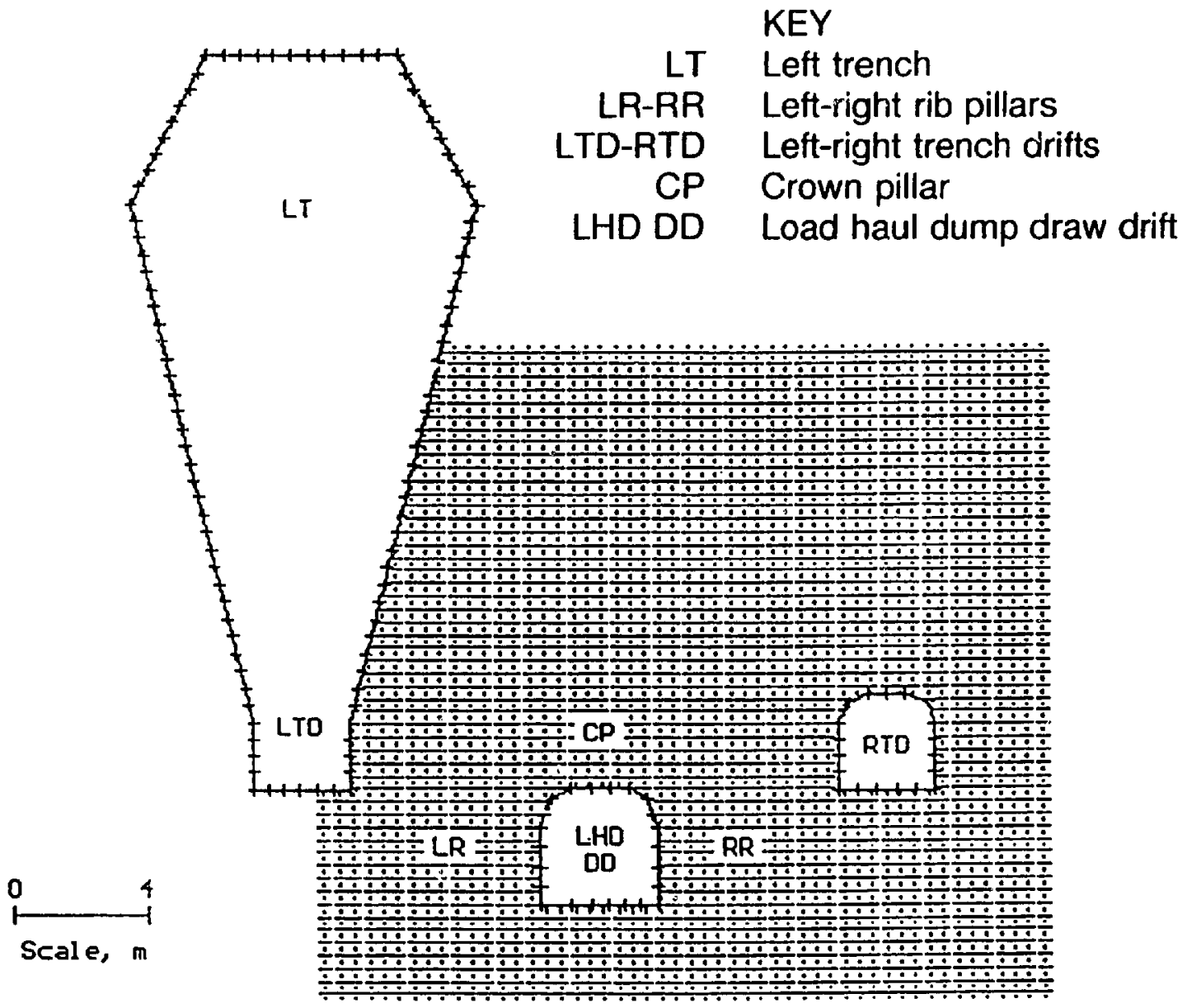

Mine model stage 2 axcavation geometry for altemative elevated bench dift design, with SF contour grid to delineate zones of predicted material damage in production panels 3 and 11 on 2615 level.

subsequent parametric analyses, in which the trench drifts were elevated $3.6 \mathrm{~m}(12 \mathrm{ft})$ and $5.5 \mathrm{~m}(18 \mathrm{ft})$ above the LHD production drift.

\section{RESULTS FROM PREMINING HORIZONTAL STRESS SENSITIVITY ANALYSES}

\section{High Stress Ratio: $K_{0}=1.00$}

Figure 12 shows the SF contours for the original nonelevated trecch drift design as a function of high stress ratio and $\mathrm{H}-\mathrm{B}(\mathrm{rm})$ strength parameter values. $A$ high shear failure is indicated in the left rib and narrow zone inclined up toward the left trench. A small tension zone appears above the right corner of the LHD draw drift. A stub-shaped undisturbed zone, inclined up to the right of the draw drift, is in a low shear stress state. The left rib pillar is disturbed, whereas the right rib pillar is undisturbed, since $1<$ SF $\leq 2$.

Figure 13 shows the SF contours for the original nonelevated trench drift design as a function of high stress ratio and $\mathrm{M}-\mathrm{C}(\mathrm{rm})$ strength parameter values. In general, the location, size, and contour shapes are similar to those in the previous H-B(rm) model. No tension zones exist; however, a larger shear zone is indicated in the right rib pillar. This model case predicts a large-scale failure in the left rib pillar. Once that occurs, the upper left rock mass zone (DD LT) could dislodge and displace obliquely into the LHD draw drift. The model does not simulate the observed events where both ribs failed locally into the draw drift, followed by a large-scale vertical displacement of the crown pillar (CP) into the draw drift. 
Figure 12

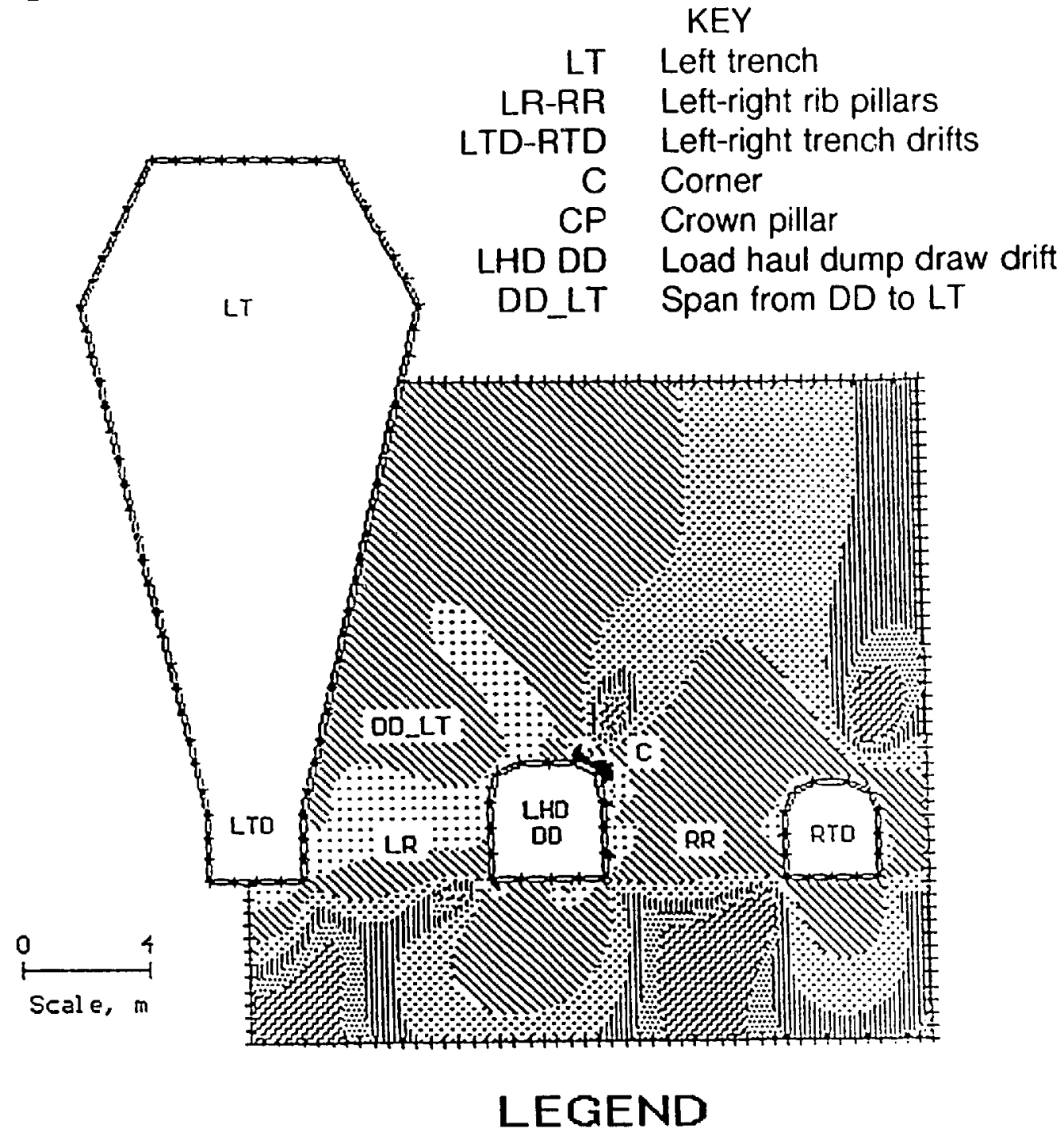

Strength factor (SF) contour ranges

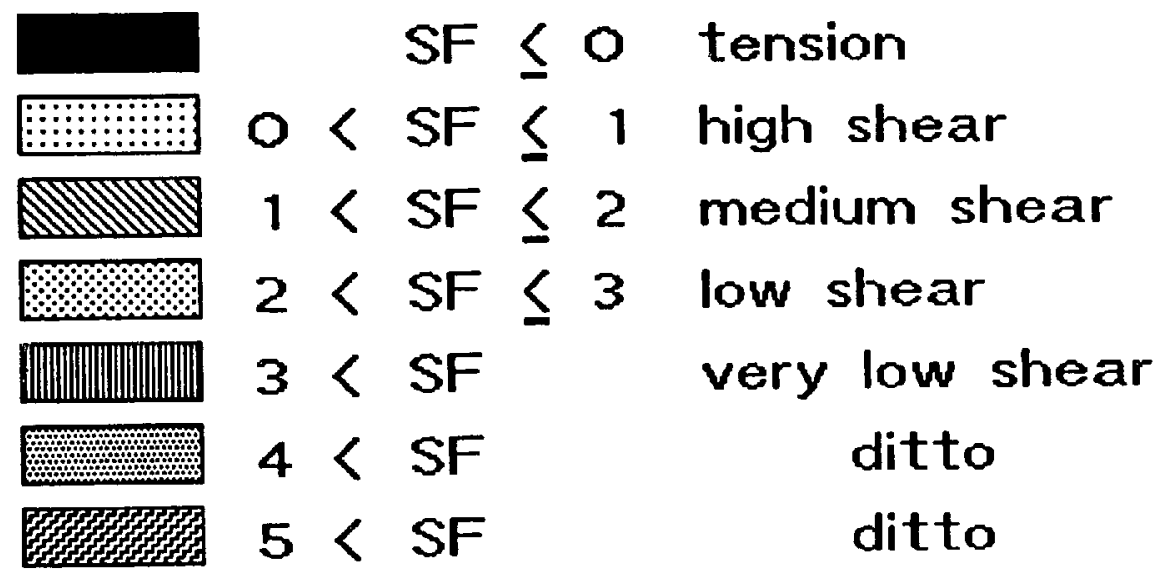

Stage 2 material damage predictions for nonelevated trenches as function of high stress ratio $(K o=1.00)$ and Hoek-Brown rock mass failure criterion model input parumetess: $U C S(i)=91.1 \mathrm{MPa}, m(m)=2.2 s(m)=0.036$ 
Figure 13

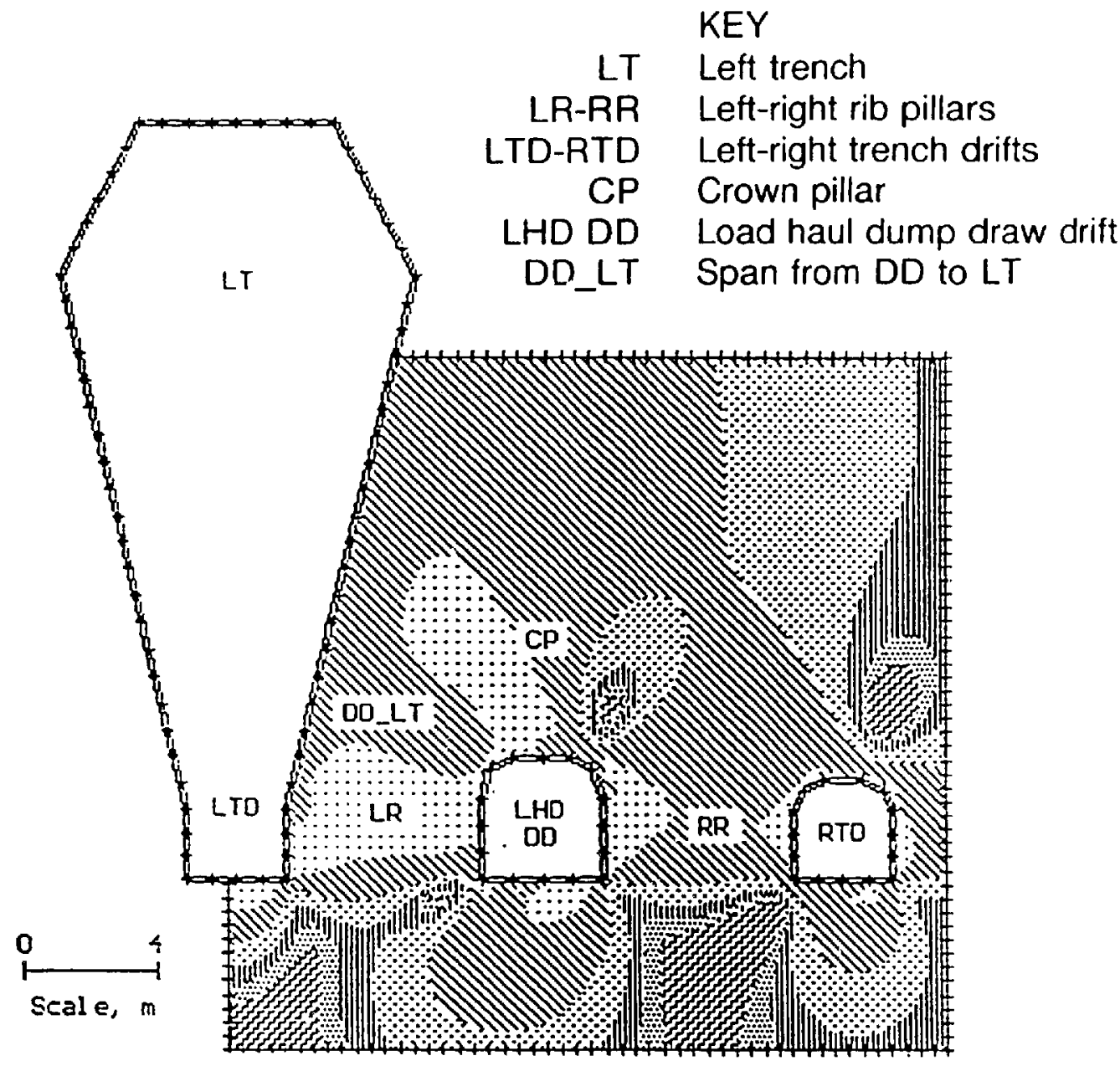

LEGEND

Strength factor (SF) contour ranges

$\begin{array}{rlrl} & \text { SF } \leq 0 & \text { tension } \\ 0<\mathrm{SF} \leq 1 & \text { high shear } \\ 1 & <\mathrm{SF} \leq 2 & \text { medium shear } \\ 2 & <\mathrm{SF} \leq 3 & \text { low shear } \\ 3 & <\mathrm{SF} & \text { very low shear } \\ 4 & <\mathrm{SF} & \text { ditto } \\ 5 & <\mathrm{SF} & \text { ditto }\end{array}$

Stage 2 material damage predictions for nonelevated trenches as function of high stress ratio $(K o=1.00)$ and Mohr-Coulomb rock mass failure criterion model input parameters: $\phi(m)$ $=36.5, \sigma_{\cos }(\mathrm{m})=4.1 \mathrm{MPa}, \sigma_{\mathrm{s}}(\mathrm{m})=3.7 \mathrm{MPa}$. 
Figure 14 shows the SF contours for the original nonelevated trench drift design as a function of high stress ratio and $\mathrm{H}-\mathrm{B}(\mathrm{i})$ intact rock strength parameter values. In general, the location, size, and contour shapes are not similar to those presented in the previous two models. The stub-shaped zone, inclined up to the right of the LHD draw drift, is in a very low shear stress state. This stress state infers this zone is not disturbed or damaged. Intact rock parameter values, chosen for this model, represent very good quality rock material, wher the RMR value is 100 and corresponds to the inherent intact strength value, $s(i)$ equal to $1.0(14)$.

\section{Medium Stress Ratio: $K_{0}=\mathbf{0 . 5 0}$}

Figure 15 shows the SF contours for the nonelevated trench drift design as a function of medium stress ratio and $\mathrm{H}-\mathrm{B}(\mathrm{rm})$ strength parameter values. The central portion of the left rib pillar indicates the material is in a marginally stable condition, since $1<\mathrm{SF} \leq 2$. The zone (DD_LT) is damaged from high shear stress. Mate tial zones beneath the drift floors are undisturbed. A nearvertical shear plane exists directly above the left corner of the LHD draw drift in the crown pillar. The left side of the crown pillar is damaged, whereas the right portion is undamaged. With these conditions, it is unlikely the roof rock-arch and crown pillar could dislodge and displace into the draw drift, since only one nearly vertical shear plane is indicated.

Figure 16 shows the contours for the nonelevated trench drift as a function of medium stress ratio and M-C(rm) strength parameter values. In general, the location and contour shapes are similar to the previous H-B(rm) model, except the size of the damaged zones increased. Shear failure is indicated in the left rib pillar. The rabbit-ear-shaped zone, above the right corner of the LHD draw drift, appears to be of significant length to induce dislodgement of the crown pillar subsequent to the shear failure in both rib pillars. This particular model begins to simulate the sequence of failures observed in test panels 18 and 19 on the 2315 level.

Figure 17 shows the SF contours for the nonelevated trench drift design as function of medium stress ratio and $\mathrm{H}$-B(i) intact rock strength parameter values. The intact rock parameter values represent a rock mass of very good quality, according to Hoek-Brown's quality categories that range from very poor, poor, fair, good, to very good. The very good RMR value of 100 is equivalent to HoekBrown's inherent strength s(i) parameter value, where s(i) $=1$. No material damage is predicted; however, stress patterns show a stub-shaped zone in the crown pillar region, and a zone (DD_RTD) that connects the LHD draw drift to the right trench drift.

\section{Low Stress Ratio: $K_{0}=0.25$}

Figure 18 shows the SF contours for the original nonelevated trench drift design as a function of low stress ratio and $H-B(r m)$ strength parameter values. Major areas of the left and right rib pillars are undamaged and stable, since $1<\mathrm{SF} \leq 2$. Similarly, the stub-shaped region above the draw drift in the crown pillar zone is undamaged and marginally stable. Small-scale rib damage is indicated in both ribs.

A sizeable damaged shear zone (DD_LT) angles up from the left corner of the draw drift toward the left trench. The roof rock-arch zone has decompressed, having sustained tensile strain. The contours reflect that the absolute tensile stress exceeded the Hoek-Brown rock mass tensile strength of $1.48 \mathrm{MPa}$ (220 psi). A large zone (DD_RTD) connerts the right corner of the draw drift over to the left corner of the right trench drift. Conjugate shear planes exist on either side of the crown pillar zone. A near-vertical shear plane is located directly above the left corner of the draw drift, and the second shear plane is inclined up over the right rib pillar. Despite relatively small areas of shear damage in both draw drift ribs, the indicated damaged zones in the rocf-arch and upward along vither side of the stub-shaped crown pillar suggest this stub could dislodge and displace vertically into the draw drift. Drillers, ring-drilling in the right trench prior to stage 4 cave initiation blasting, reported reduced drilling rates and subsequent closure of the blast holes before they could load and shoot the ring. This effect may have been caused by the development of the high shear zone (DD_RTD) that connects to the left corner of the right trench. This low-horizontal stress model simulates the failure events observed by the Magma engineers, based on the indicated damage zones and kinematics that might occur (figure 4).

Figure 19 shows the SF contours from the nonelevated trench drift design as a function of low stress ratio and M-C(rm) strength parameter values. In general, the location and contour shapes are similar to those shown in the previous H-B(rm) model, except the size (extent) of the damaged zones increased slightly. A sizeable damaged shear zone (DD LT) angles upward from the left corner of the draw drift toward the left trench slope surface. In the two test panels on the 2315 level, a fan of drill holes had been drilled up into the crown pillar to define the trench slope inclination after full-production caving (stage 3) was achieved. Slope crosion was found to vary around the $60^{\circ}$ design value. In some locations, the trench slope surface retained the design value, whereas in other locations either higher or lower slopes developed $(8)$. This model predicts erosion is likely to occur in the right rib of the left trench drift. Some floor heave is indicated, though 
Figure 14

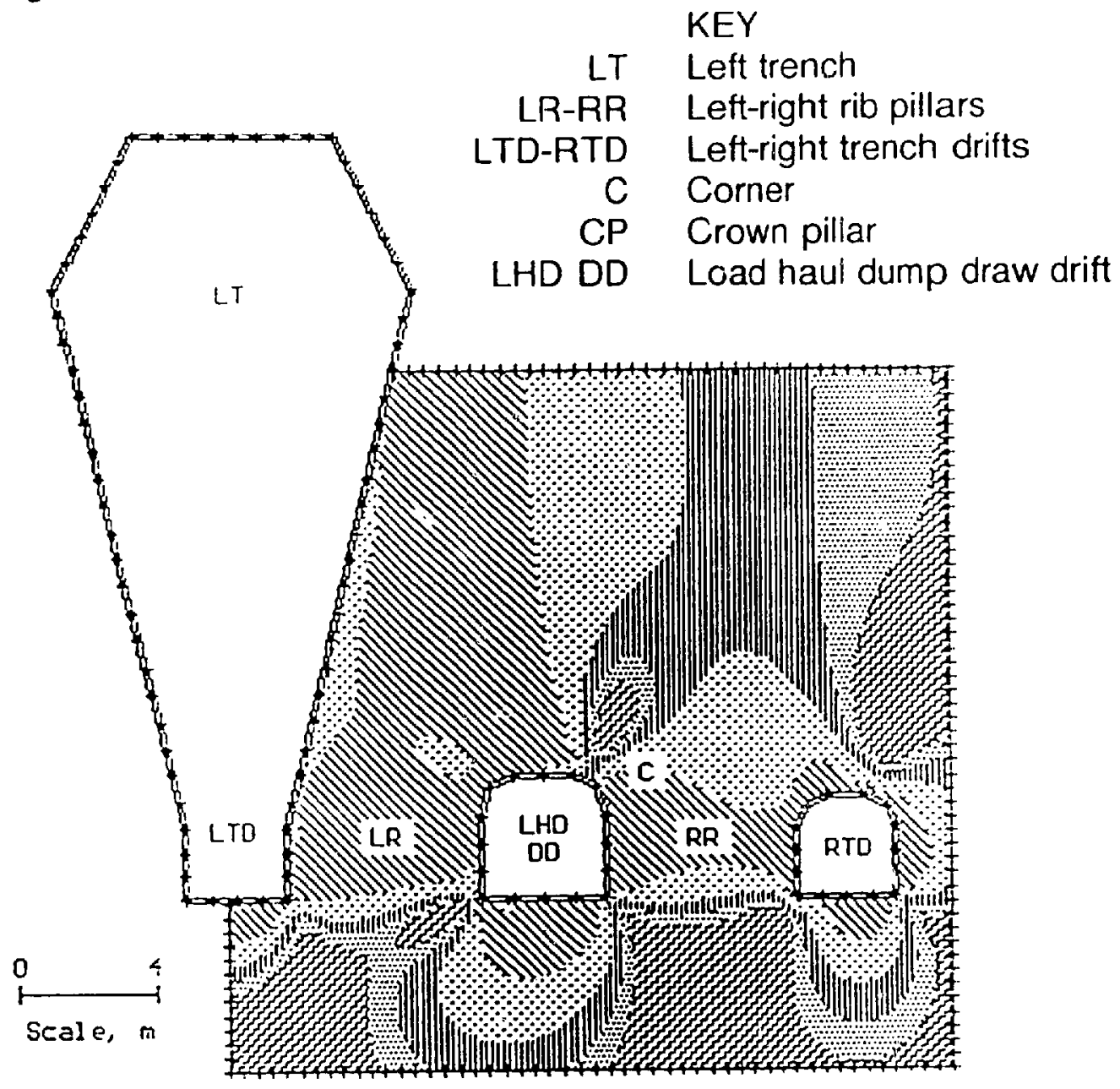

LEGEND

Strength factor (SF) contour ranges

$\begin{array}{rlrl}0 & \text { SF } \leq 0 & \text { tension } \\ 1 & <\mathrm{SF} \leq 1 & \text { high shear } \\ 2 & <\mathrm{SF} \leq 2 & \text { medium shear } \\ 3 & <\mathrm{SF} & \text { low shear } \\ 4 & \text { very low shear } \\ 50 \mathrm{SF} & \text { ditto } \\ 5<\mathrm{SF} & \text { ditto }\end{array}$

Stage 2 material damage predictions for nonelevated trenches as function of high stress ratio $(K o=1.00)$ and Hoek-Brown intact rock failure criterion model input parametess: UCS(i)

$=91.1 \mathrm{MPa}, \mathrm{m}(i)=15.1, \mathrm{~s}(\mathrm{i})=1$. 
Figure 15

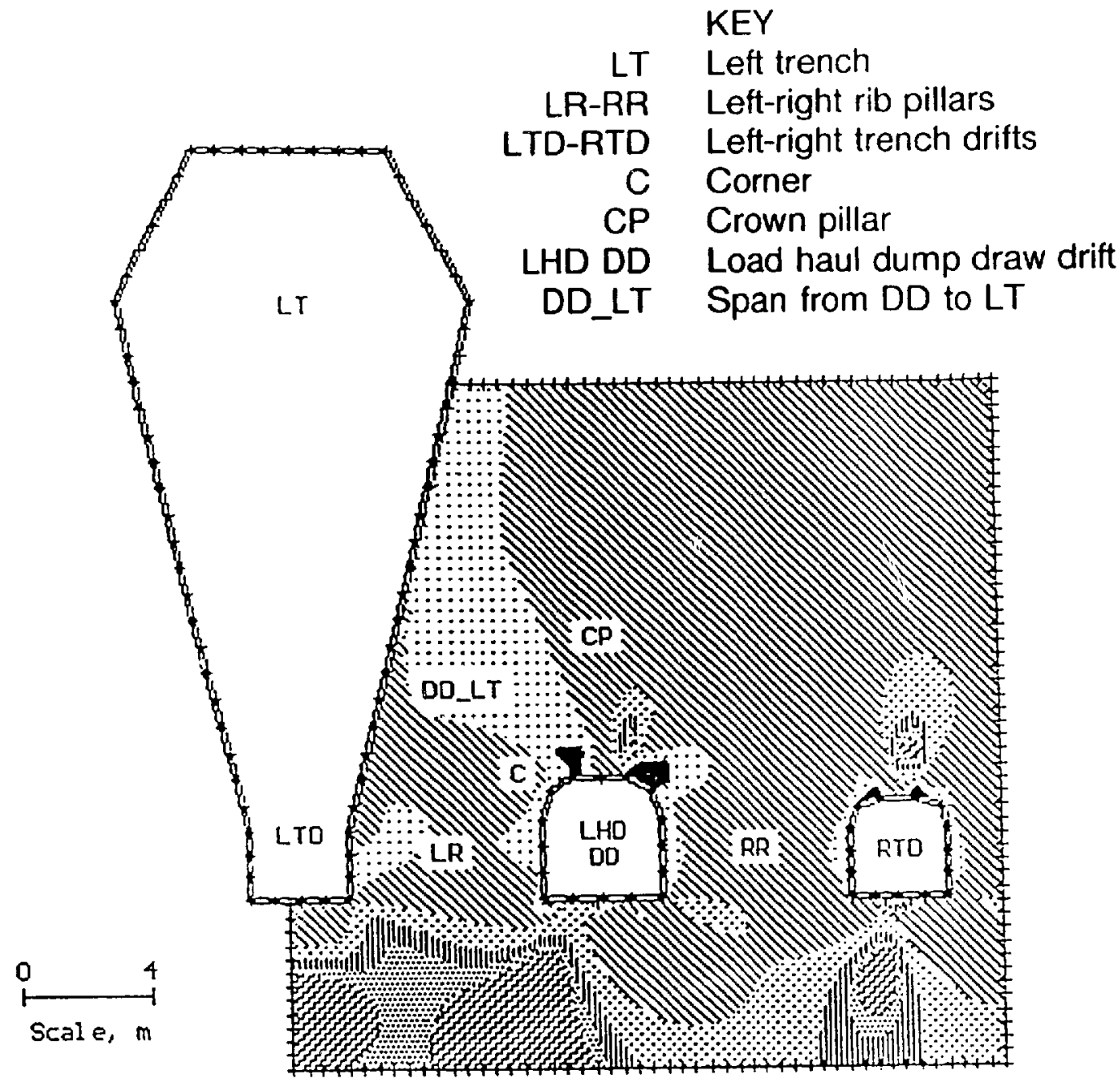

\section{LEGEND}

Strength factor (SF) contour ranges

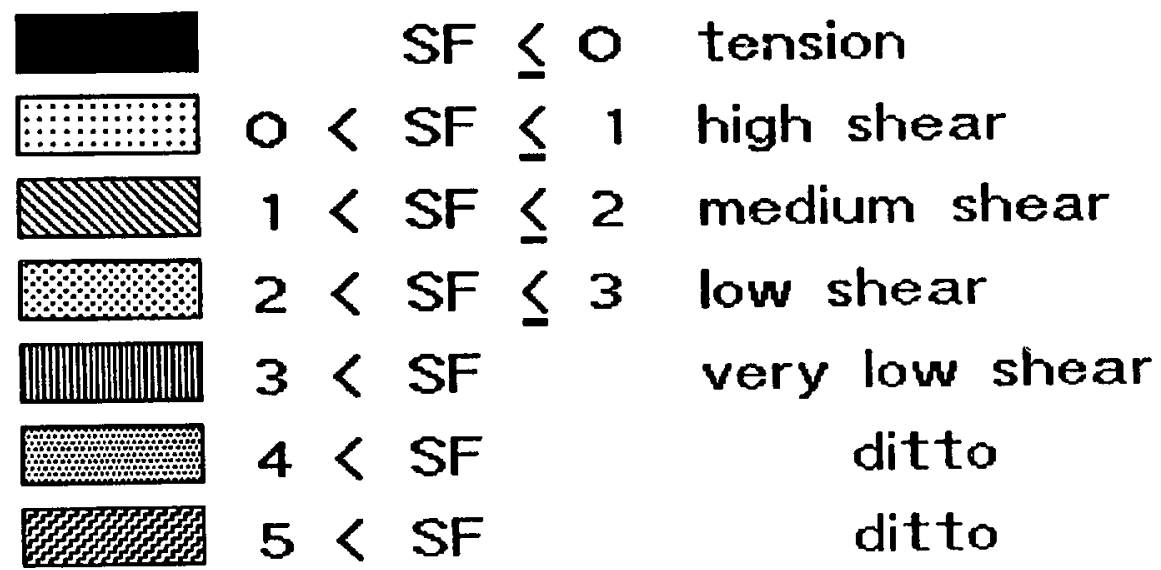

Stage 2 material damage predictions for nonelevated trenches as function of medium stress natio $(K o=0.50)$ and Hoek-Bnown rock mass faihure criterion model input parametess: $U C S(i)=91.1 \mathrm{MPa}, m(m)=22, \mathrm{~s}(\mathrm{~m})=0.036$ 
Figure 16

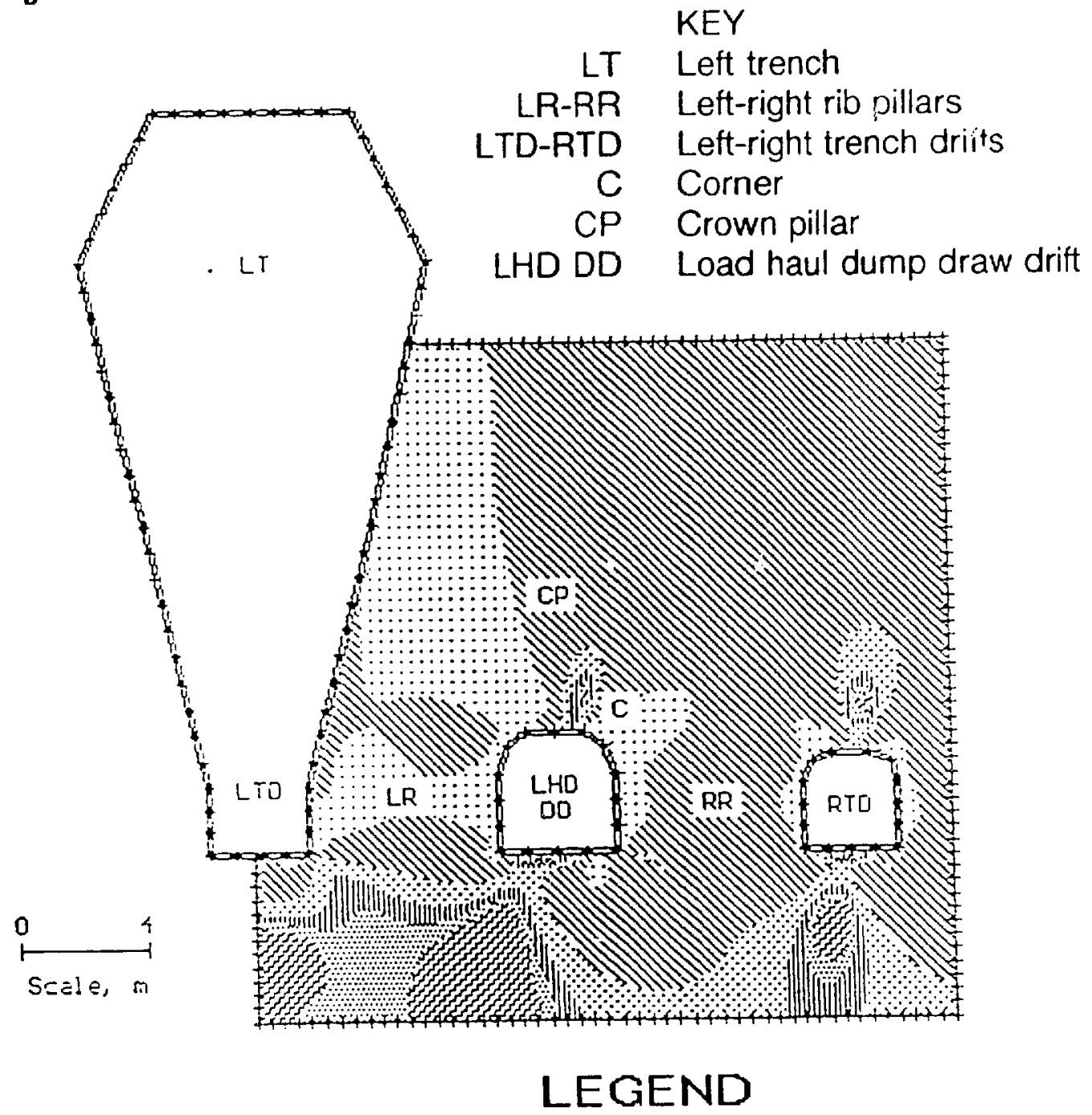

Strength factor (SF) contour ranges

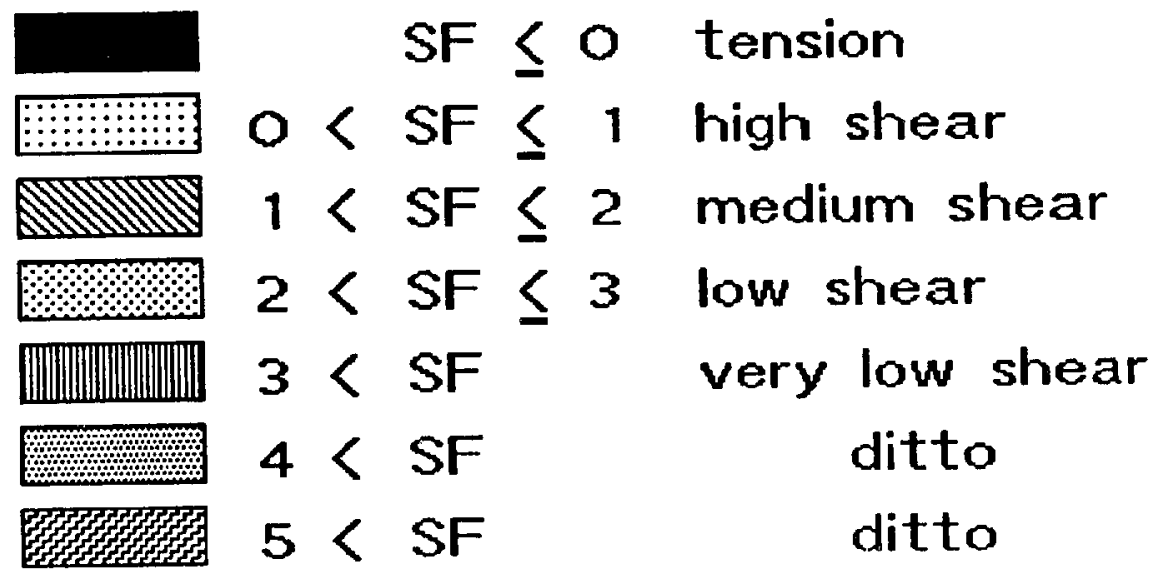

Stage 2 material damage predictions for nonelevated trenches as function of medium stress ratio $(K o=0.50)$ and Mohr-Coulomb rock mass failure criterion model input parameters: $\phi(m)=36.5, \sigma_{\text {coh }}(m)=4.1 \mathrm{MPa}, \sigma_{\mathrm{t}}(m)=3.7 \mathrm{MPa}$ 
Figure 17

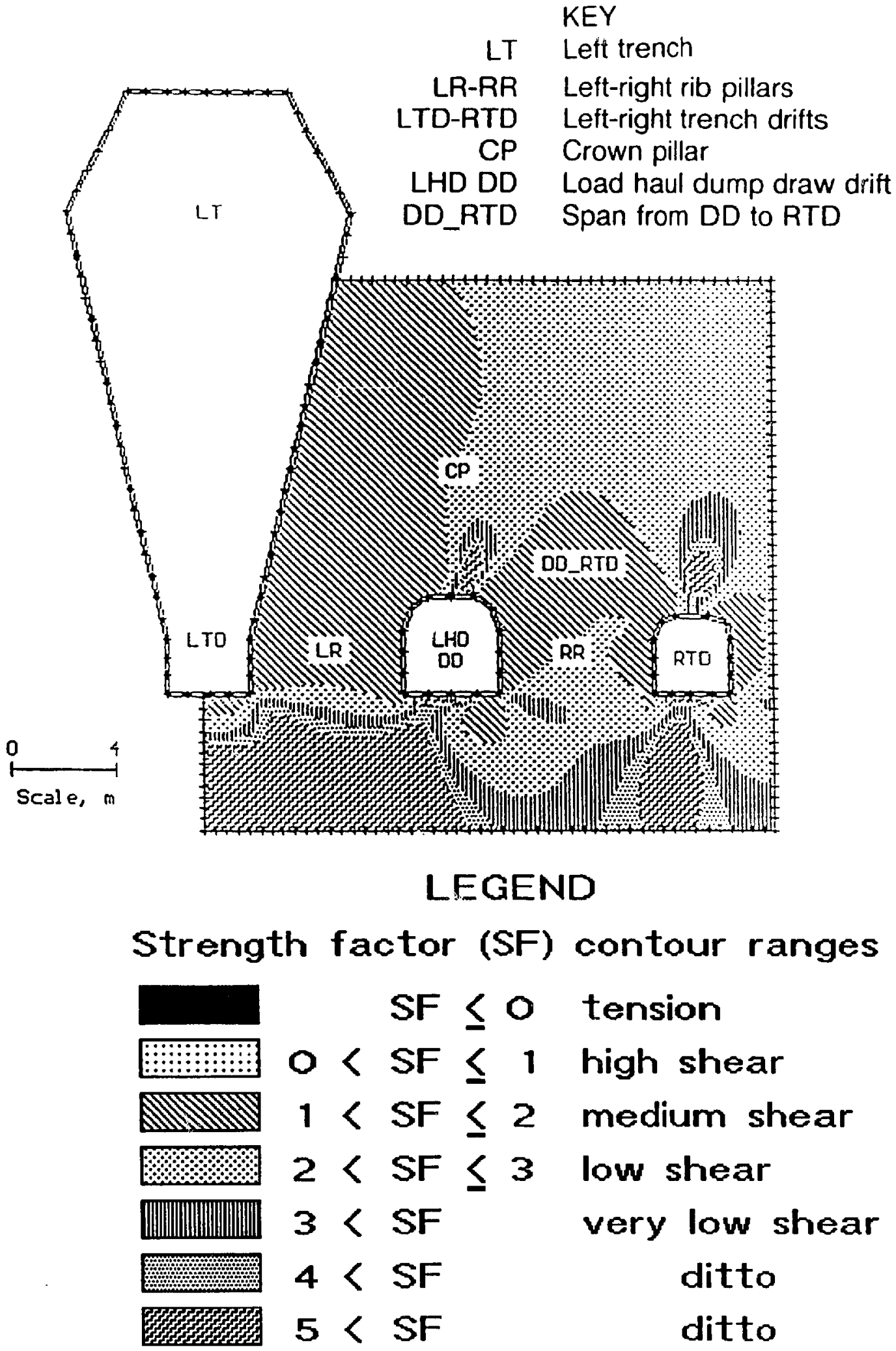

Stage 2 material damage predictions for nonelevated trenches as function of medium stress ratio $(K o=0.50)$ and Hoek-Brown intact rock failure criterion model input parameters: $U C S(i)=91.1 \mathrm{MPa}, m(i)=15.1, s(i)=1$. 
Figure 18

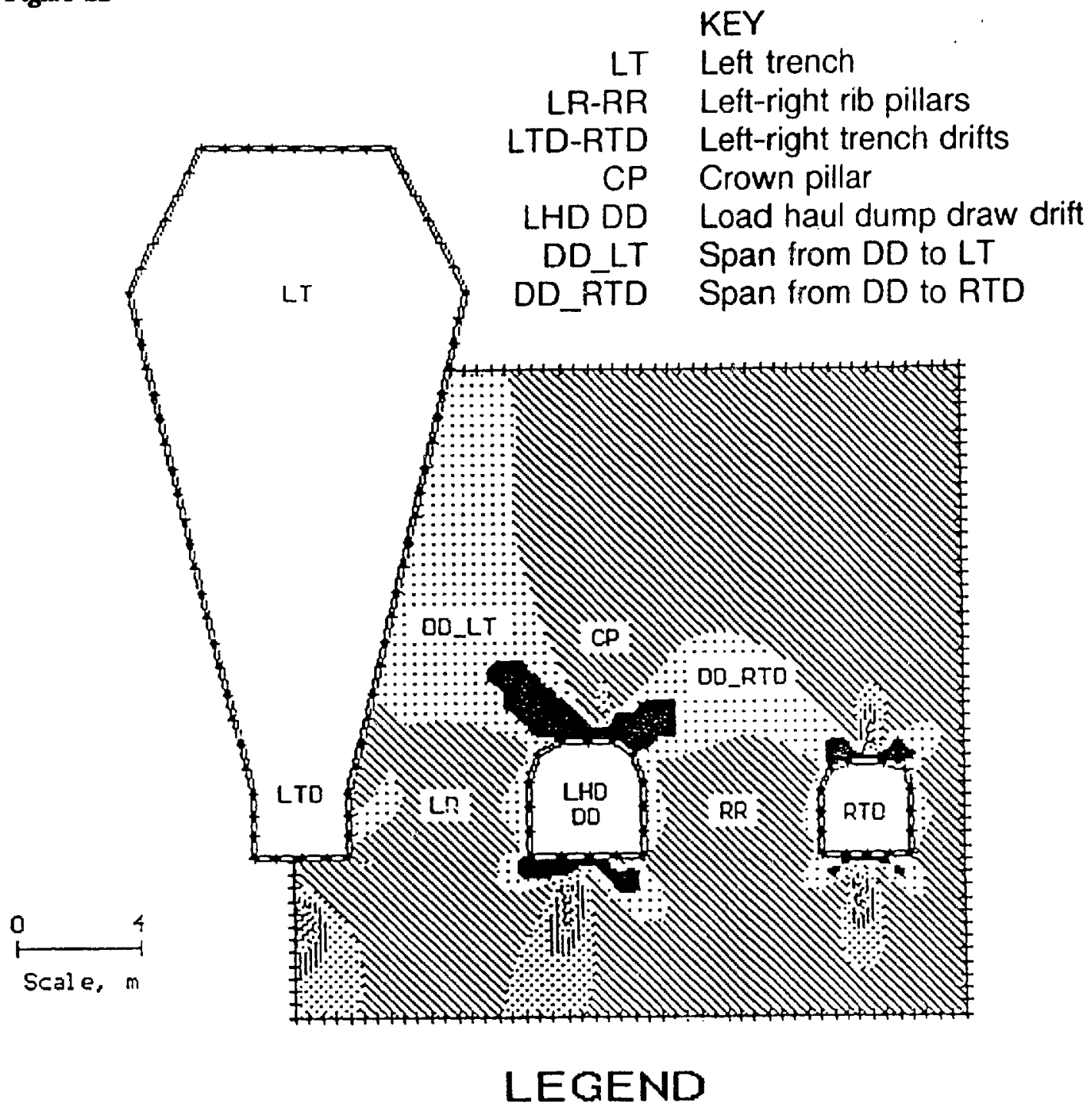

Strength factor (SF) contour ranges

\begin{tabular}{|c|c|c|c|c|}
\hline & & SF & $\leq 0$ & tension \\
\hline 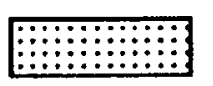 & 0 & SF & $\leq 1$ & high shear \\
\hline & 1 & SF & $\leq 2$ & medium shear \\
\hline & 2 & SF & $\leq 3$ & low shear \\
\hline (m) & 3 & $\mathrm{SF}$ & & very low shear \\
\hline W= & 4 & $\mathrm{SF}$ & & ditto \\
\hline & & $\mathrm{SF}$ & & ditto \\
\hline
\end{tabular}

Stage 2 material damage predictions for nonelevated trenches as function of low stress ratio $(K o=0.25)$ and Hoek-Brown rock mass failure criterion model input parameters: UCS(i) $=91.1, M P a, m(m)=2.2 s(m)=0.036$. 
Figure 19

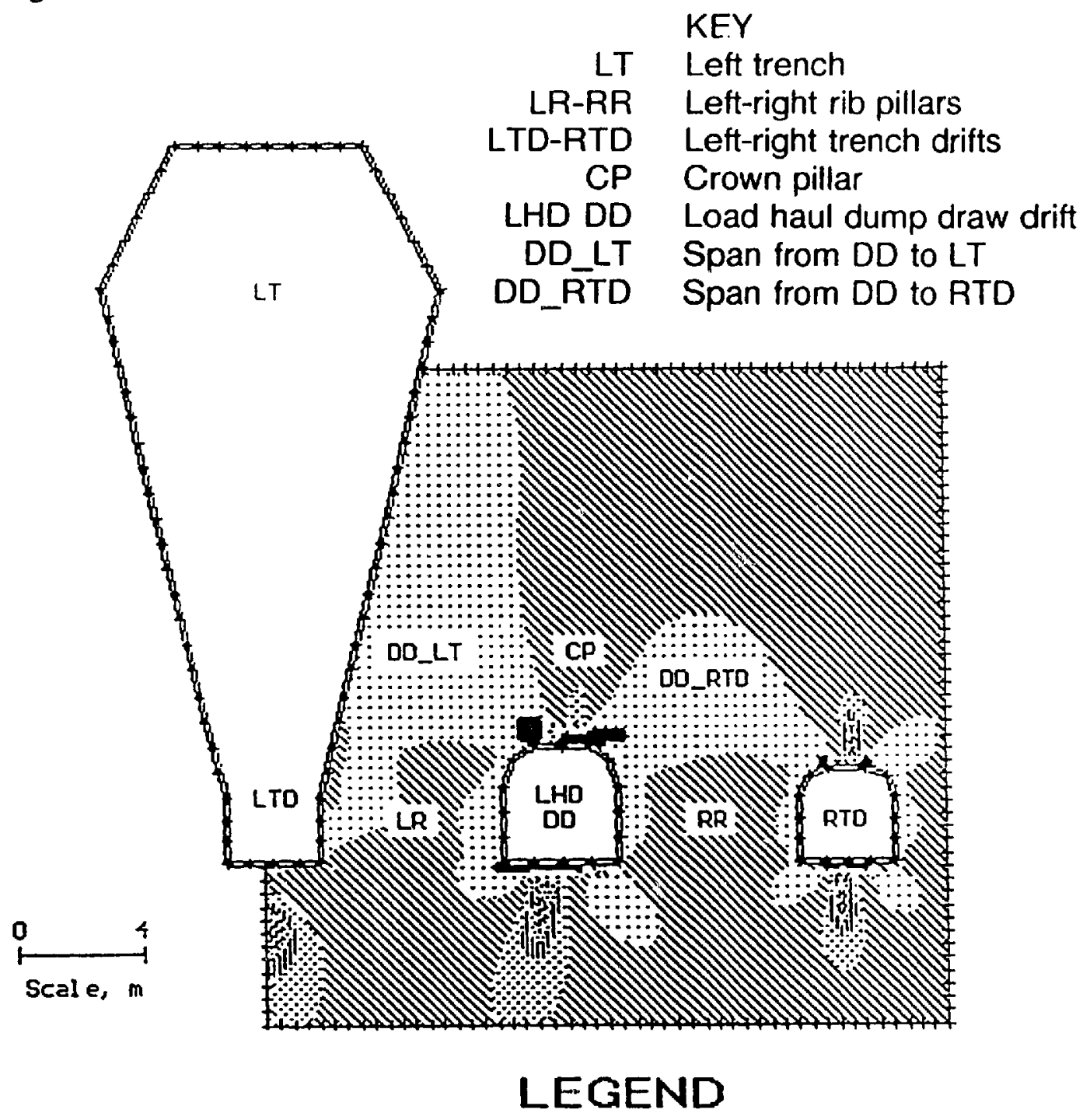

Strength factor (SF) contour ranges

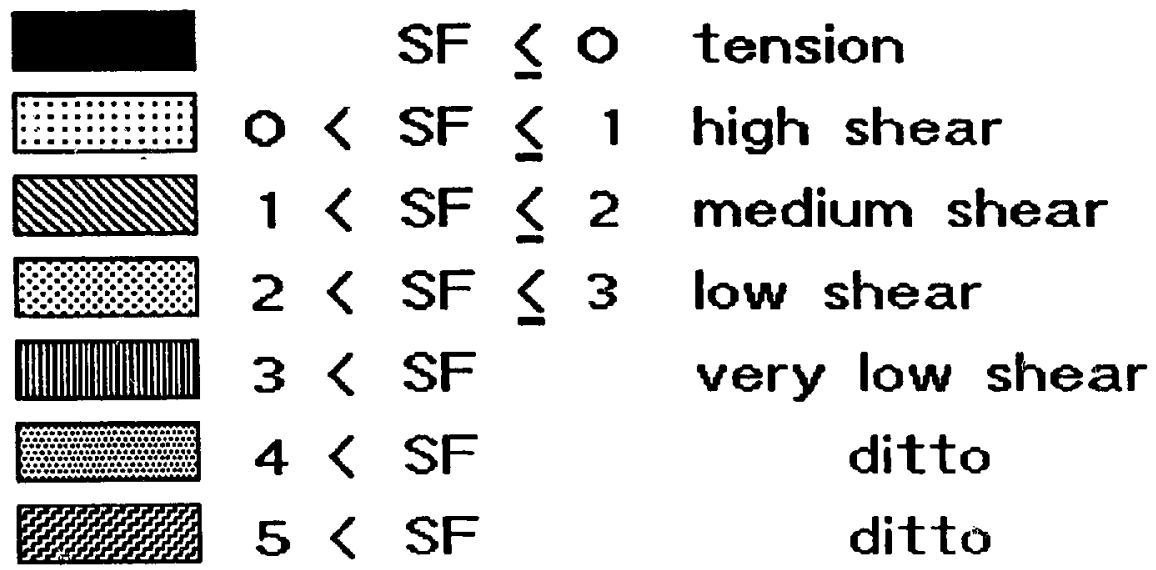

Stage 2 material damage predictions for nonelevated trenches as function of low stress ratio $(K O=0.25)$ and Mohr-Coulomb nock mass failure criterion model input parameter: $\phi(\mathrm{m})$ $=36.5^{\circ}, \sigma_{\text {col }}(m)=4.1 \mathrm{MPa}, \sigma_{\mathrm{t}}(\mathrm{m})=3.7 \mathrm{MPa}$. 
no instances were found in available mine reports. The roof rock-arch zone has decompressed and sustained tensile strain. The absolute tensile stress exceeded the M-C(rm) rock mass strength cut-off value of $3.7 \mathrm{MPa}$ (540 psi).

This low-stress model simulates the failure events ubserved by Magma engineers. Therefore, this model case was selected for subsequent parametric model case studies to investigate the stability of rock mass surrounding elevated trench drift designs and a modified stage 2 configuration.

Figure $\mathbf{2 0}$ shows the SF contours for the nonelevated trench drift design as a function of low stress ratio and $H$-B(i) intact strength parameter values. Results from this "very good" intact rock quality model may be compared to the results from the (good) rock mass quality model (figure 18). All rock mass zones around the LHD draw drift are marginally stable. The variance in SF contours is caused by the difference in the condition and rated quality of the rock material. The condition of the rock mass, in panels 2 and 41 on 2315 level, was rated good, and the laboratory intact rock samples were rated very good.

\section{RESULTS FROM PARAMETRIC ANALYSES}

\section{Stage 2 Elevated Trench Drift Design Model Cases}

Figure 21 shows SF contours for elevated trenches as a function of low stress ratio and $\mathrm{H}-\mathrm{B}(\mathrm{rm})$ strength parameter values. The SF contour range values suggest that both ribs and crown pillar might remain stable for trench drifts elevated $3.6 \mathrm{~m}(12 \mathrm{ft})$ above the LHD draw drift level. However, a high shear zone (DD_LT) angles up toward the left trench, similar to the zone that appeared in previous nonelevated trench drift models.

This model predicts slope erosion in a manner similar to previous models. The crown pillar is undisturbed and appears unlikely to become dislodged and displace into the draw drift. The high shear zone (DD_RTD) that existed in the nonelevated model cases does not exist here, inferring stability of the crown pillar may be enhanced. Tension zones, in the draw drift floor, may pose problems for specific geological conditions, involving steeply dipping joint and/or fault systems.

Figure 22 shows the SF contours for the elevated trenches as a function of low stress ratio and $M-C(r m)$ strength parameter values. In general, the location and contour shapes are similar to the previous H-B(rm) model, except the size (extent) of the damaged zones increased. The left rib pillar is marginally stable and only minor shear failure occurs in the left rib of the draw drift. A near-vertical shear plane exists directly above the left corner of the draw drift, and a high shear zone has developed above the right corner of the draw drift. Crown pillar displacement would probably occur should the medium shear zone (DD_RTD) fail.

Elevating trench drifts $3.6 \mathrm{~m}$ (12 ft) above the LHD level would not significantly enhance the stability of the draw and trench drifts. Strike, dip, and spacing data on fault and joint systems identified in panel 3 indicate a dip range from $50^{\circ}$ to $70^{\circ}$ with a mean joint spacing of $0.33 \mathrm{~m}$ $(1 \mathrm{ft})$. Given these joint orientations, it is possible that joint slip in zone (DD_RTD) could result in a portion of the crown pillar dislodging and invading the draw drift. Since the rock bolting design included 3.6-m (12-ft) long bolts on 11.2-m (4ft) centers into the roof rock-arch, one might expect a portion of the crown pillar to displace en masse into the draw drift.

Figure 23 shows SF contours for elevated trenches as a function of low stress ratio and estimated H-B(rm) strength parameter values. RMR values were averaged to represent combined material constant properties of panels 3 and 11 on 2615 level. The values are UCS(i) $=53 \mathrm{MPa}$ $(7,689 \mathrm{psi})$; the friction parameter $m(53)=5$; the inherent strength $s(53)=0.006$ (table 2).

Figure 24 shows SF contours for elevated trenches as a function of low stress ratio and estimated H-B(rm) strength parameter values. These values were obtained from triaxial test data on intact core samples and RMR field surveys performed in the southern region of panel 3 on the 2615 level during initial stage 1 development. The values are UCS(i) $=43 \mathrm{MPa}(6,260 \mathrm{psi})$; average friction parameter $m(51)=3.5$; the average inherent strength $s(51)=0.004$ (table 2). From this field RMR survey value, the rock mass quality was rated as fair. Model predictions indicated shear damage is extensive and surrounds the crown pillar region. The model simulates the observed failure sequence, where both LHD draw drift ribs fail in shear followed by a large-scale displacement of the roof rock-arch from the crown pillar location.

Figure 25 shows SF contours for elevated trenches as a function of low stress ratio and estimated $H-B(r m)$ strength parameter values by data analysis method III for panel 11 on 2615 level. Since the field RMR survey value equals 58 , the initial undisturbed rock quality was rated as good (12). Estimated H-B(rm) parameter values for this model are UCS $(\mathrm{i})=72.7 \mathrm{MPa}(10,540 \mathrm{psi})$; the friction constant $m(58)=8$; the inherent strength $s(58)=0.009$ (table 2). Results show that most of the rock mass zones surrounding the LHD draw drift are marginally stable, and the draw and right trench drifts sustained tensile strain. Tensile strain occurred in both the floor and roof rockarch zones. Geologists reported fewer ground instability 
Figure 20

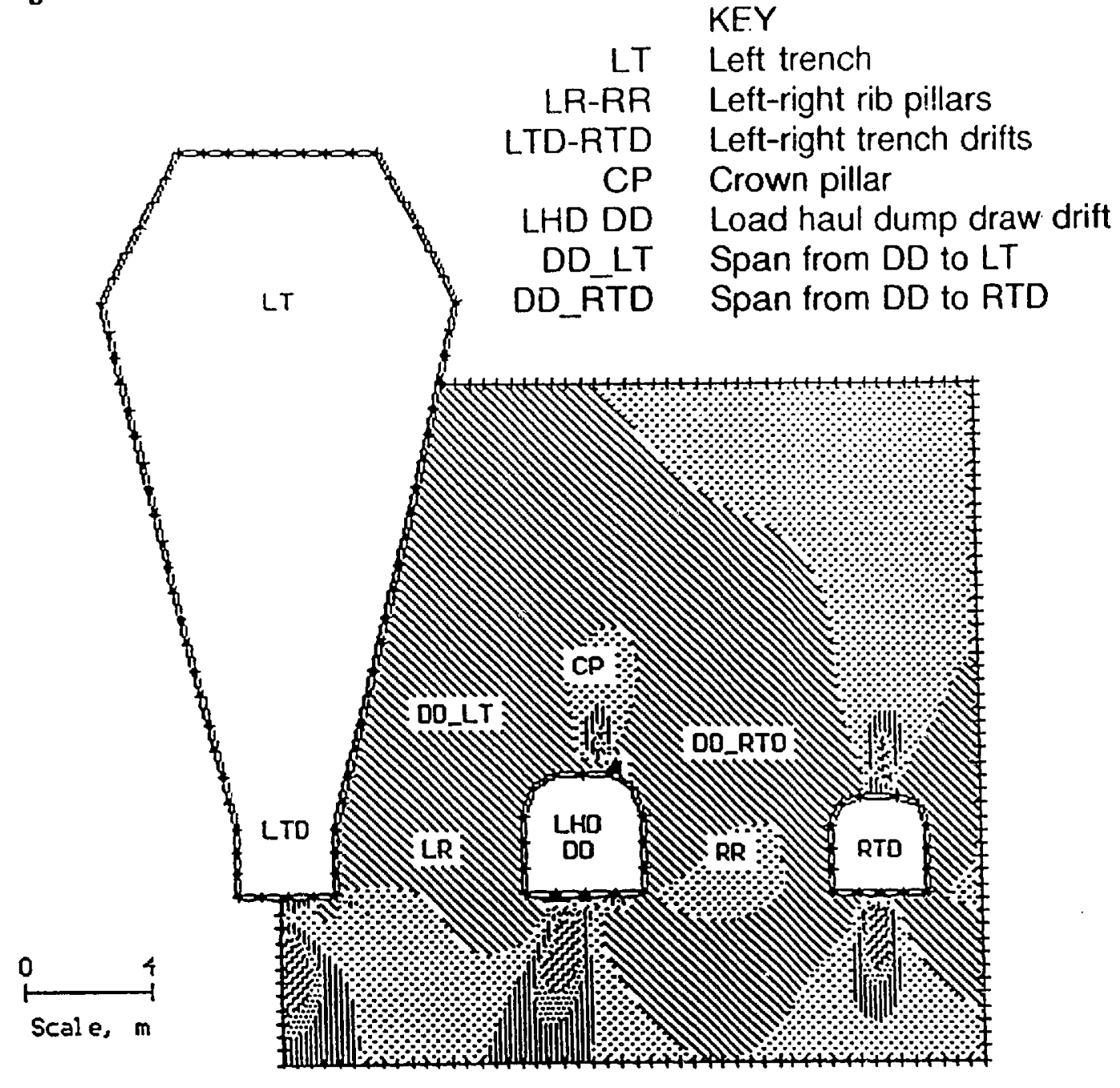

\section{LEGEND}

Strength factor (SF) contour ranges
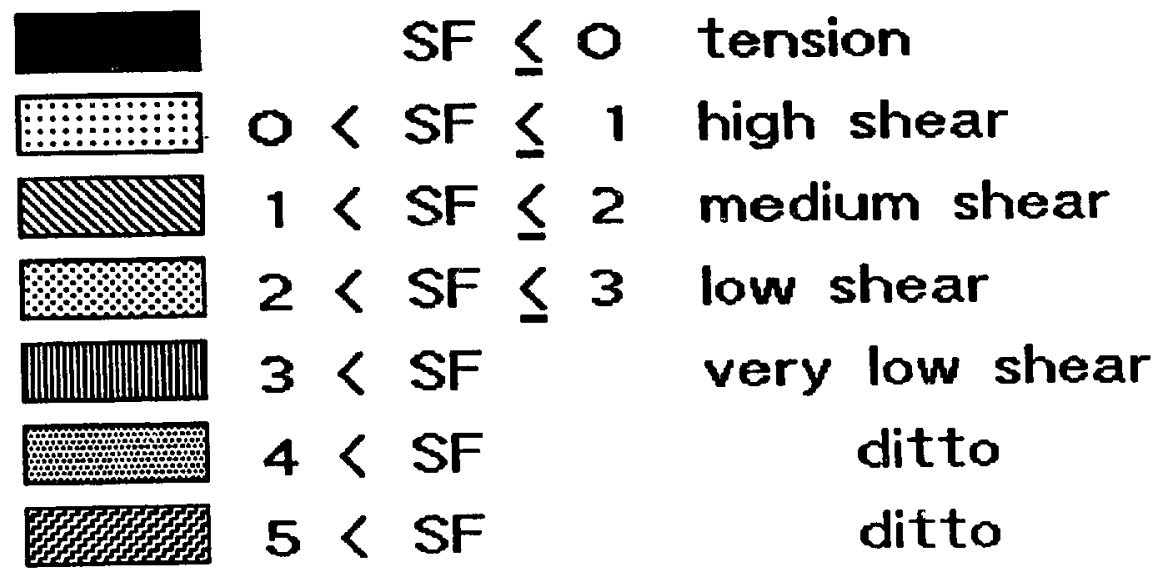

Stage 2 material damage predictions for nonelevated thenches as function of low stress ratio $(K o=0.25)$ and Hoek-Brown intact rock faihure criterion model input panametess: UCS(i) $=91.1 \mathrm{MPa}, m(i)=15.1, s(i)=1$. 
Figure 21

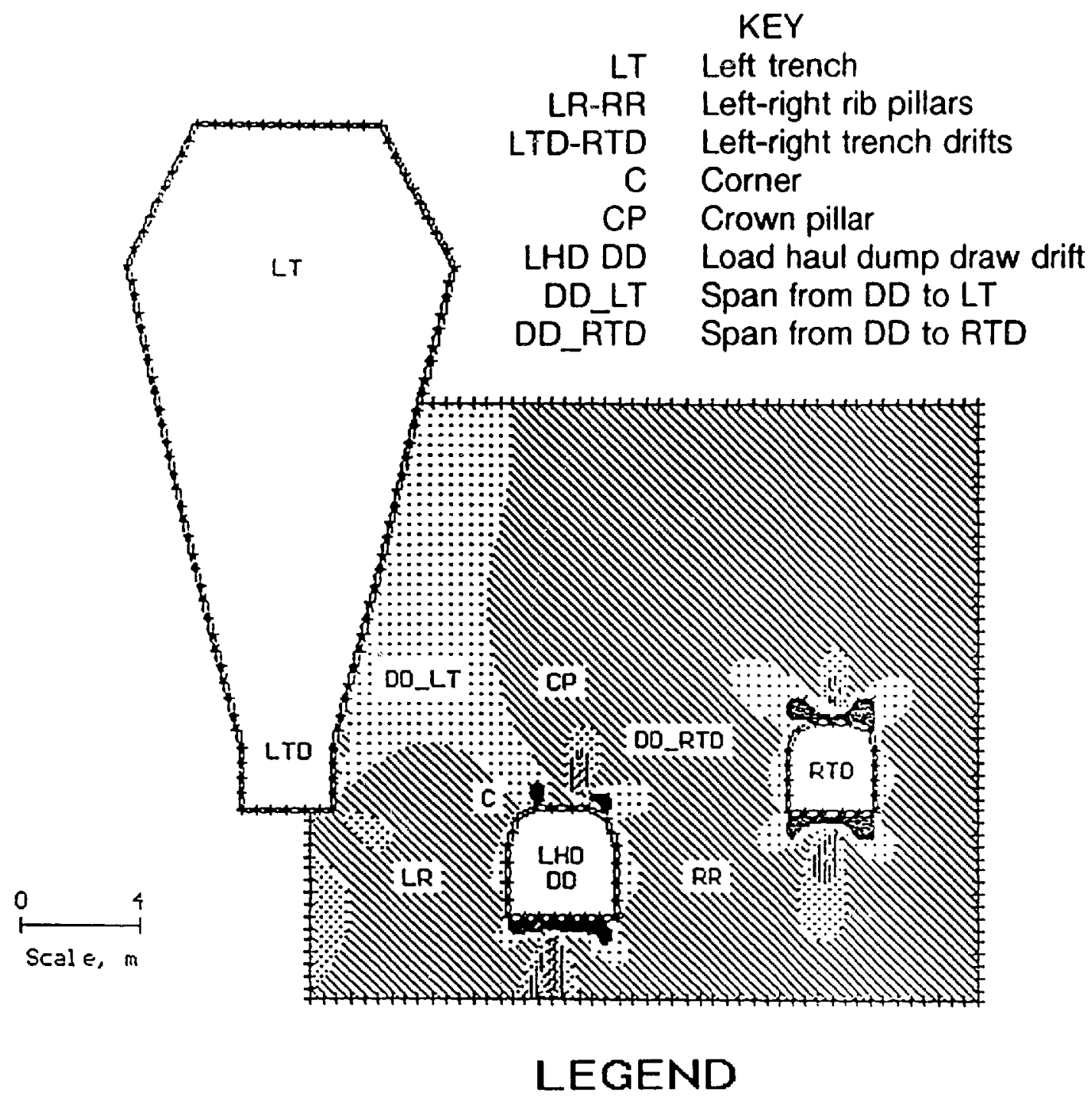

Strength factor (SF) contour ranges

\begin{tabular}{|c|c|c|c|c|}
\hline & & & $\mathrm{SF} \leq 0$ & tension \\
\hline & & & $S F \leq 1$ & high shear \\
\hline & 1 & $<$ & $S F \leq 2$ & medium shear \\
\hline & 2 & $<$ & $S F \leq 3$ & low shear \\
\hline & & & SF & very low shea \\
\hline
\end{tabular}

Stage 2 material damage predictions for elewated thenches ( $3.6 \mathrm{~m}$ (12 ft)) as function of low stress ratio (Ko $=0.25$ ) and Hoek-Brown rock mass faibure criterion parumeter vahues from bonehole shear tests in panels 2 and 41 on 2315 level by method II: UCS(i) $=91.1 \mathrm{MPa}$, $m(m)=2.2 \mathrm{~s}(\mathrm{~mm})=0.036$ 
Figure 22

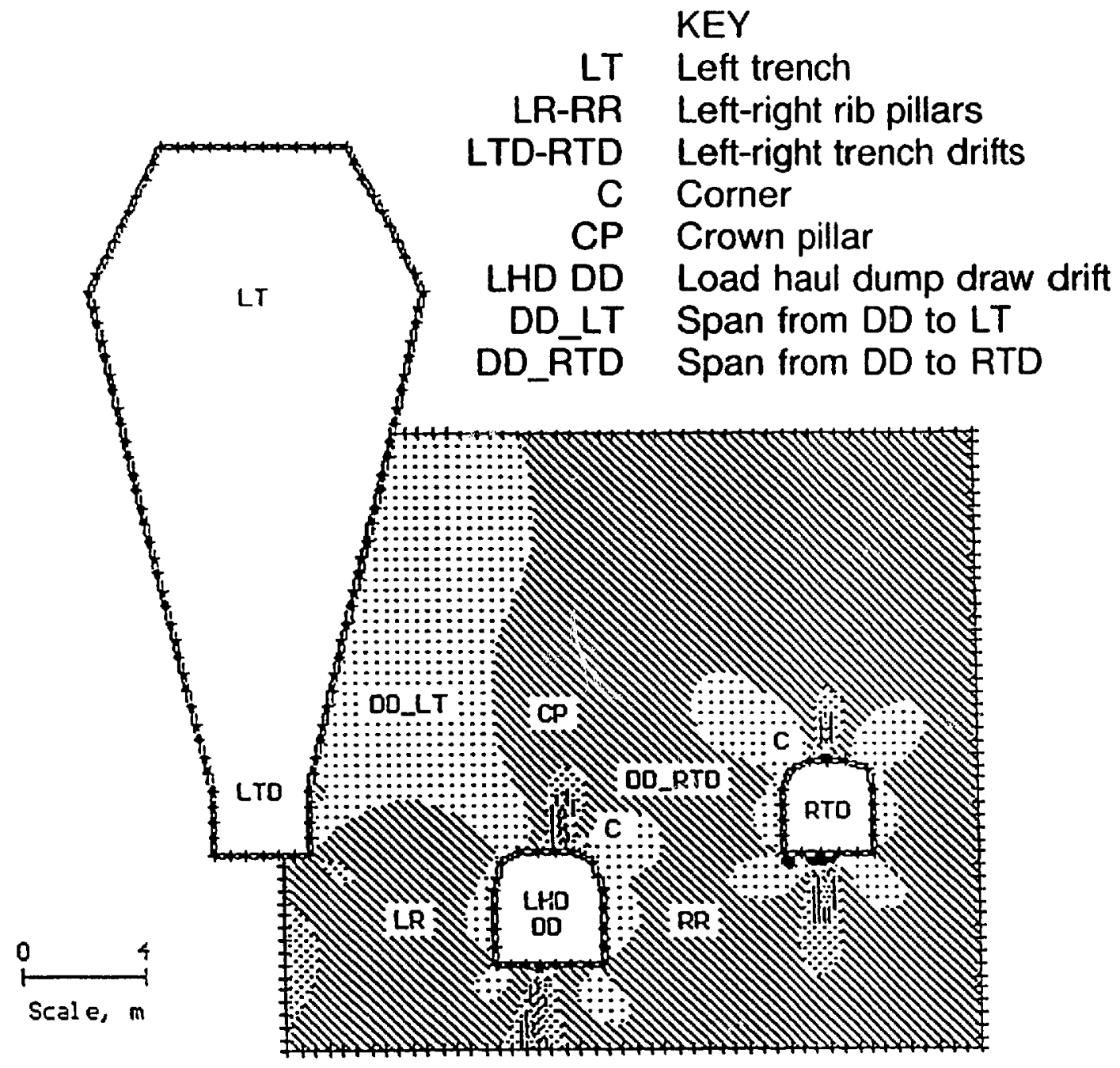

LEGEND

Strength factor (SF) contour ranges

$\begin{array}{lll}0 & \text { SF } \leq 0 & \text { tension } \\ 1 & <\text { SF } \leq 1 & \text { high shear } \\ 2 & <2 \text { SF } \leq 3 & \text { low shear } \\ 3<\text { SF } & \text { very low shear }\end{array}$

Stage 2 material damage predictions for elevated thenches $(3.6 \mathrm{~m}(12 \mathrm{ft}))$ as function of low stress ratio $\left(K_{0}=0.25\right)$ and Mohr-Coulomb nock mass failure criterion parumeter values from borehole shear tests in panels 2 and 41 on 2315 level by method $I: \phi(m)=36.5^{\circ}$; $\sigma_{\mathrm{m}}(\mathrm{m})=4.1 \mathrm{MPa}, \sigma_{1}(\mathrm{~m})=3.7 \mathrm{MPa}$ 
Figure 23

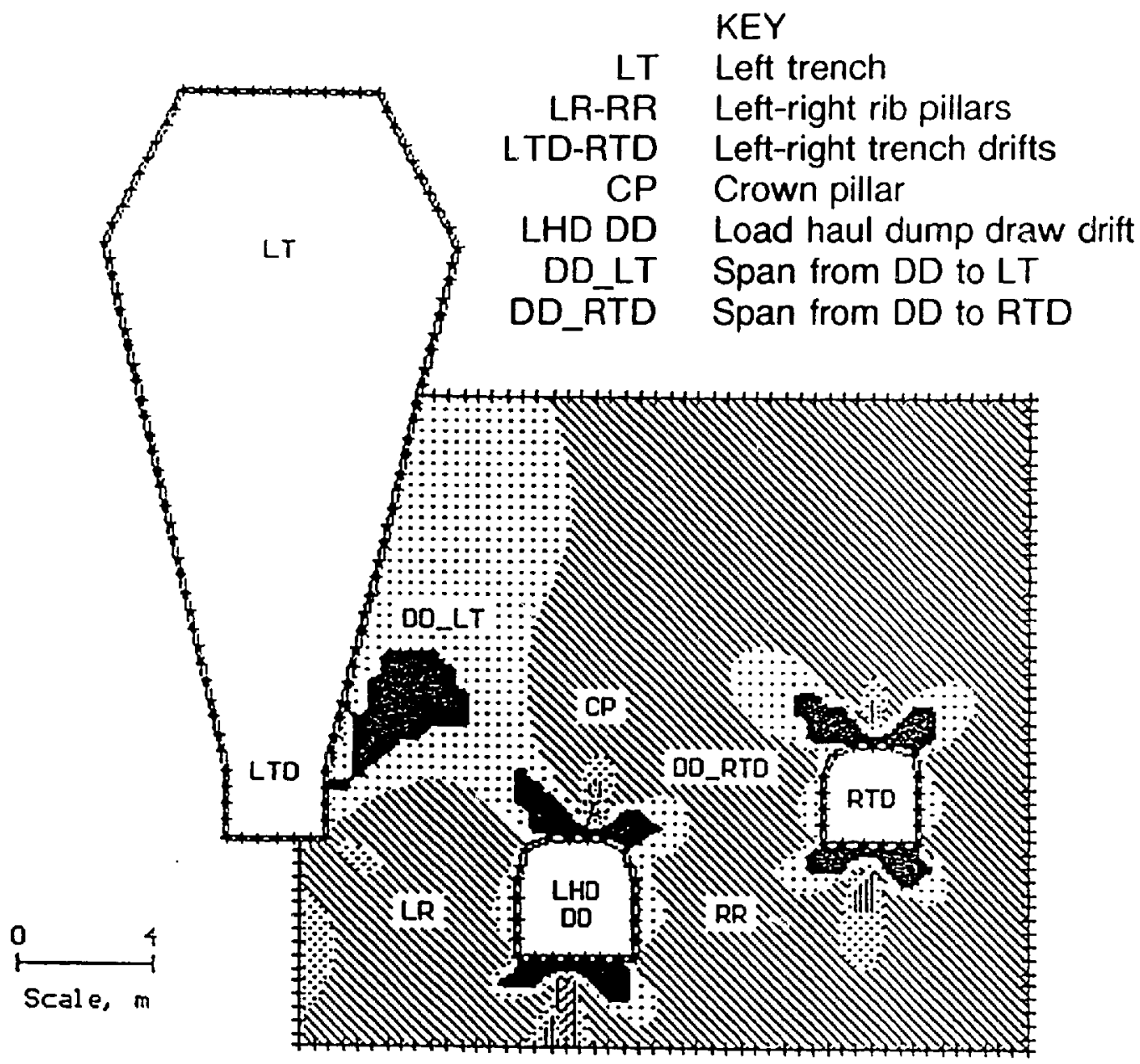

LEGEND

Strength factor (SF) contour ranges

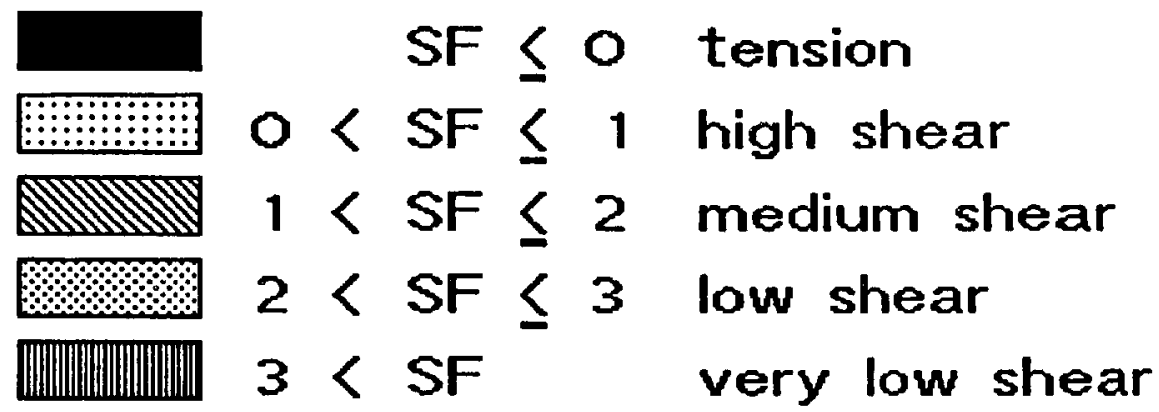

Stage 2 material damage predictions for elevated trenches (3.6 $\mathrm{m}(12 \mathrm{ft})$ ) as function of low stress ratio (Ko $=0.25)$, avenage geological rock mass rating $(R M R=53)$ in panels 3 and 11 on 2615 level, and extimated Hoek-Brown rock mass strength parameter values by method III: $U C S(i)=53 \mathrm{MPa} m(\mathrm{~m})=5$, and $s(\mathrm{~m})=0.006$ 


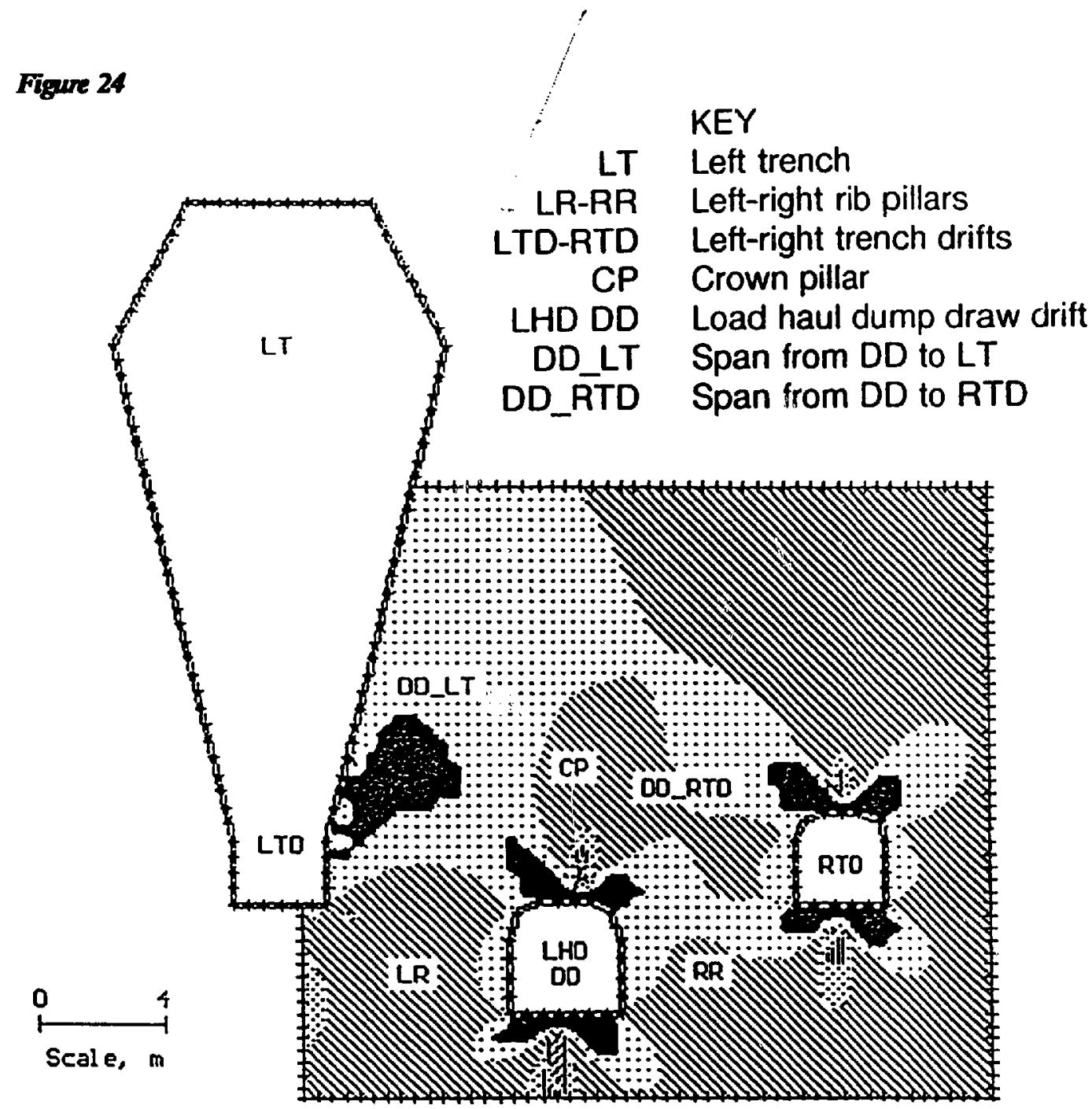

LEGEND

Strength factor (SF) contour ranges

$0<\mathrm{SF} \leq 0 \quad$ tension
$1<\mathrm{SF} \leq 2$ high shear
$2<\mathrm{SF} \leq 3$ low shear
$3<\mathrm{SF} \quad$ very low shear

Stage 2 material damage predictions for elevated trenches $(3.6 \mathrm{~m}(12 \mathrm{ft})$ ) as function of low stress ratio $\left(K_{0}=0.25\right)$ average geological rock mass reting $(R M R=51)$ in parel 3 on 2615 level, and estimated Hoek-Brown rock mass strength parwmeter values by method III: UCS $(i)=43.2 \mathrm{MPa}, m(m)=3.5, s(m)=0.004$. 
Figure 25

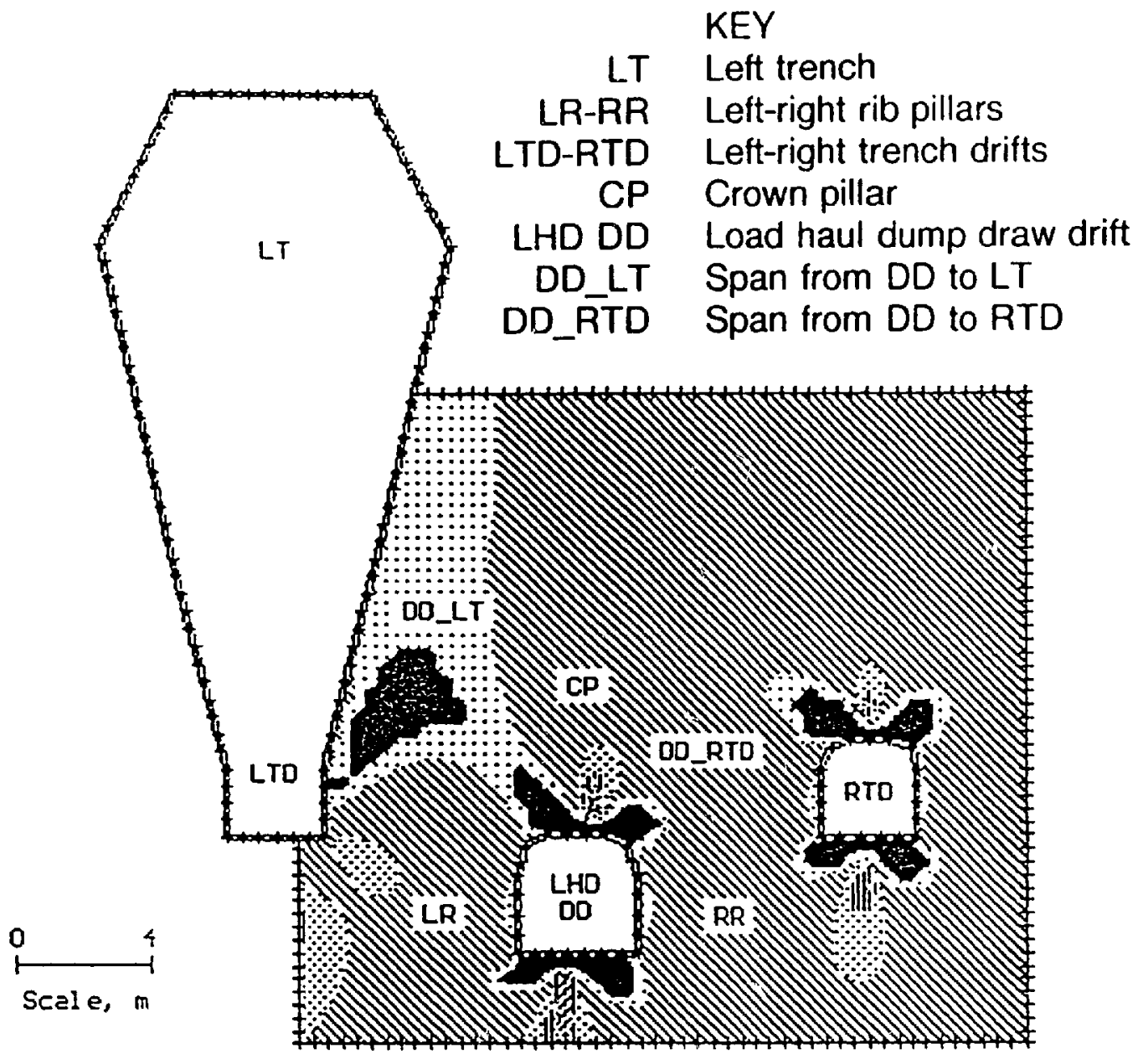

LEGEND

Strength factor (SF) contour ranges

$\begin{array}{lll} & \text { SF } \leq 0 & \text { tension } \\ 0<\mathrm{SF} \leq 1 & \text { high shear } \\ 1 & <\mathrm{SF} \leq 2 & \text { medium shear } \\ 2<\mathrm{SF} \leq 3 & \text { low shear } \\ 3<\mathrm{SF} & \text { very low shear }\end{array}$

Stage 2 material damage predictions for elevated trenches $(3.6 \mathrm{~m}(12 \mathrm{ft}))$ as function of low stress rutio (Ko $=0.25$ ) geological nock mass rating ( $R M R=58$ ) in panel 11 on 2615 level, and extimated Hoak-Brown nock mass strength parameter wahues by method III: UCS(i)

$=72.7 \mathrm{MPa} m(\mathrm{~m})=8 \mathrm{~s}(\mathrm{~m})=0.009$. 
problems had occurred in panel 11, which was located $303 \mathrm{~m}$ $(1,000 \mathrm{ft})$ west of panel 3 . The field survey site in panel 3 was located near the intersection of two large fault systems, the northwest and vent raise systems. The amount of rib sloughing that occurred in panel 11 was notably less than observed and reported in panel $3(8)$. With more sample data for rock strength data analyses, the data analysis method III could be used to assist in characterizing rock mass zones throughout an orebody.

Figure 26 shows SF contours for a hypothetical elevated trench drift design as a function of low stress ratio and $\mathrm{H}-\mathrm{B}(\mathrm{rm})$ strength parameter values from borehole shear tests in panels 2 and 41 on 2315 level. Results suggest some stabilizing advantages might be achieved by elevating the trench drift $5.4 \mathrm{~m}(18 \mathrm{ft})$ above the LHD production level. Rock mass zones around the draw drift are marginally stable. Tension zones, in the immediate roof and floor of the draw and right trench drifts, should pose no problems.

Using $\mathrm{M}-\mathrm{C}(\mathrm{rm})$ parameter values, figure 27 shows SF contours similar to those predicted in the previous H-B(rm) model with one notable exception. A high shear zone (DD RTD) connects the upper right corner of the LHD draw drift to the lower left corner of the right trench drift (RTD). Since this particular trench design leaves $35 \%$ to $45 \%$ of unmined rock to serve as supporting rib pillars, other damaged areas, such as this zone, would probably pose instability problems around these drifts. The existence of steeply dipping joint systems may also have an effect on the stability of the openings.

\section{Modified Stage 2 Delayed Excavation of Trench Drift Model Case}

Magma had modified the elevated trench drift design by delaying the excavation of the adjacent right trench drift for as long as possible. The purpose of this model case was to determine if the delayed excavation strategy might reduce rib sloughing and subsequent displacement of the roof rock-arch at the chamber drift brow (CDB) (figure 7). Rock mass zones at the brow are typically vulnerable to overpressure, e.g., Barla and Boshkov reported ground control problems and steel support failures along draw drifts during initial undercutting and caving. The model case geometry includes the end of the chamber drift at the brow (CDB).

Figure 28 shows SF contours for the modified stage 2 geometry as a function of low stress ratio and $\mathbf{H}-\mathrm{B}(\mathrm{rm})$ strength parameter values. Model case results predict a damage zone (DD_LT) that angles up from the left corner of the LHD draw drift to the left trench. A second damaged zone (DD_RTD) originates at the upper-right corner of the LHD draw drift and connects to the left corner of the chamber draw drift at the brow.

Figure 29 shows the SF contours for the modified stage 2 geometry as a function of $\mathrm{M}-\mathrm{C}(\mathrm{rm})$ strength parameter values. In general, the location and contour shapes are similar to the previous H-B(rm) model, except the area extent of the damaged zones increased. The amount of disturbed rock mass in the right rib pillar increased and suggests unstable conditions may exist there.

Figure 30 shows the SF contours for the modified stage 2 geometry as a function of low stress ratio and estimated H-B(rm) strength parameter values. Material damage prediction results are similar to the previous models except for the indicated tension failure. Contours indicate that computed model stress exceeded the Hoek-Brown rock mass tensile strength. The possibility of floor heave is displayed by this model. In fact, several large-scale floor heaves had occurred in panel 3 in LHD production drifts located north of the TV camera field survey site.

\section{FIELD SURVEY SITE RESULTS}

\section{USBM BOREHOLE TV CAMERA OBSERVATIONS}

TV camera surveys were conducted 3 months apart in an array of four, 75-mm (3-in) diam boreholes drilled in panel 3 draw drift 7 (DD 7) near chamber draw drift 5 south (CD 5S) on the 2615 level (figure 31). A horizontal hole was drilled $5.1 \mathrm{~m} \mathrm{(17} \mathrm{ft)} \mathrm{into} \mathrm{the} \mathrm{south} \mathrm{rib} \mathrm{pillar,}$ and an inclined hole $\left(45^{\circ}\right)$ was drilled $8.5 \mathrm{~m}(28 \mathrm{ft})$ into the south arch zone. Two vertical holes, $2.7 \mathrm{~m}(9 \mathrm{ft})$ apart, were drilled $8.5 \mathrm{~m}$ ( $28 \mathrm{ft}$ ) into the crown pillar (figures 5A, 31). Typical ground support in LHD draw drifts consisted of pretensioned, grouted bolts $3.6 \mathrm{~m}$ (12 ft) long and spaced on 1.2-m (4-ft) centers.
The first survey recorded audio descriptions and video images of rock conditions inside the boreholes during the modified stage 2 configuration. Modified stage 2 excavation geometry was necessary because the adjacent right trench drift 7 (TD 7) had not yet been excavated. The second survey was conducted after the right trench drift 7 (TD 7) was excavated, blasted, and achieved fullproduction caving (stage 5) status (figures $5 A, 31$ ).

Borehole surface conditions were described in terms of cracks, fractures, voids (vugs), veinlets, and disturbed (rubble) material. The first survey recorded cracks, fractures,

\footnotetext{
${ }^{4}$ Work cited in footnote 3 .
} 
Figure 26

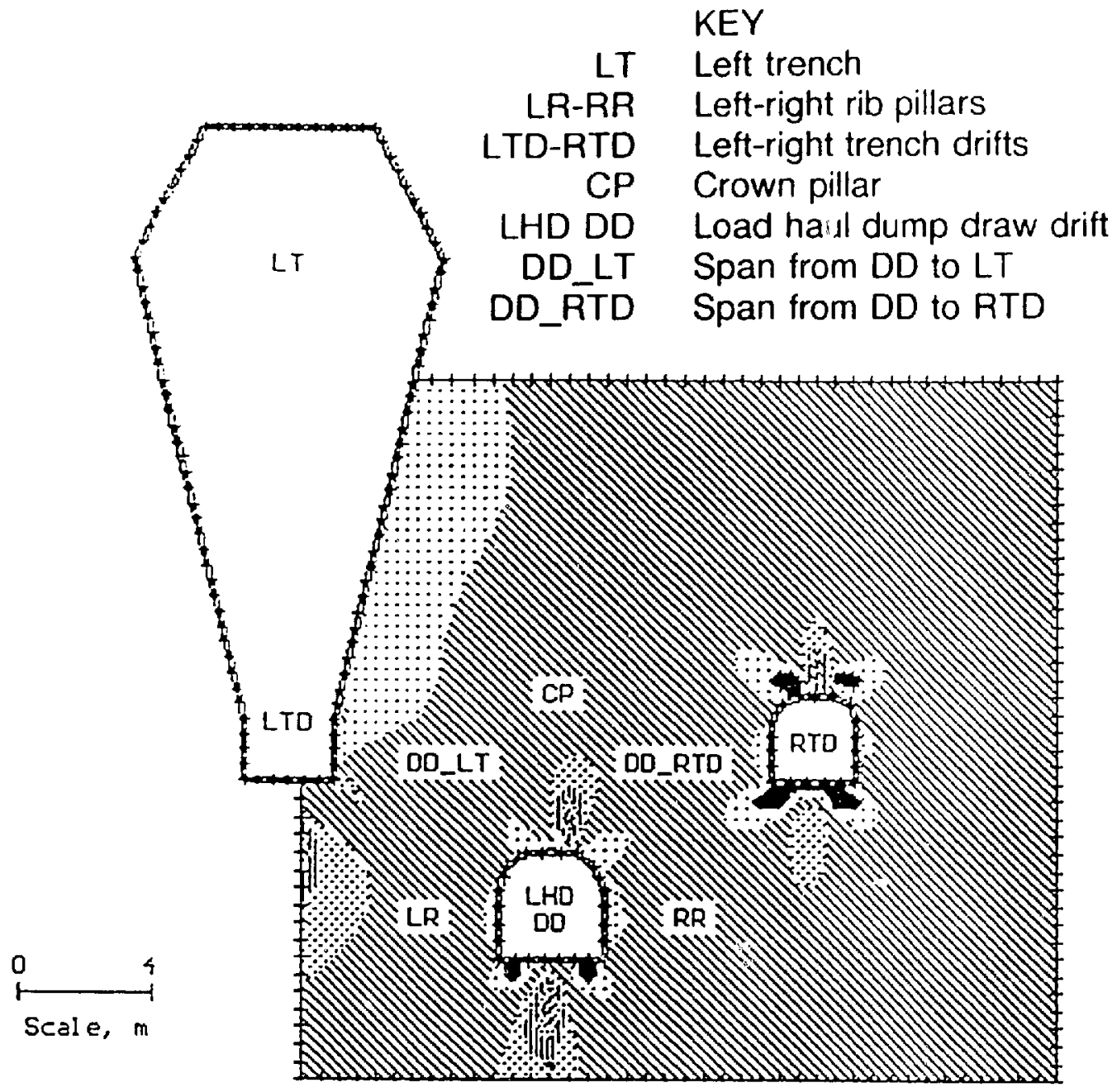

\section{LEGEND}

Strength factor (SF) contour ranges

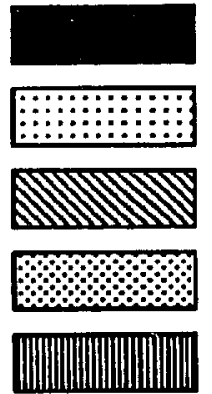

$\begin{array}{ll}\text { SF } \leq 0 & \text { tension } \\ 0<\mathrm{SF} \leq 1 & \text { high shear } \\ 1<\mathrm{SF} \leq 2 & \text { medium shear } \\ 2<\mathrm{SF} \leq 3 & \text { low shear } \\ 3<\mathrm{SF} & \text { very low shear }\end{array}$

Stage 2 material damage predictions for hypothetical elevated trench dift design $15.5 \mathrm{~m}$ $(18 \mathrm{ft})$ ) as functiont of low stress ratio $\left(K_{0}=0.25\right)$ and Hoek-Brown rock mass strength parameter values from panels 2 and 41 on 2315 level by method III: UCS(i) = 91.1 MPa, $m(m)=2.2, s(m)=0.036$ 
Figure 27

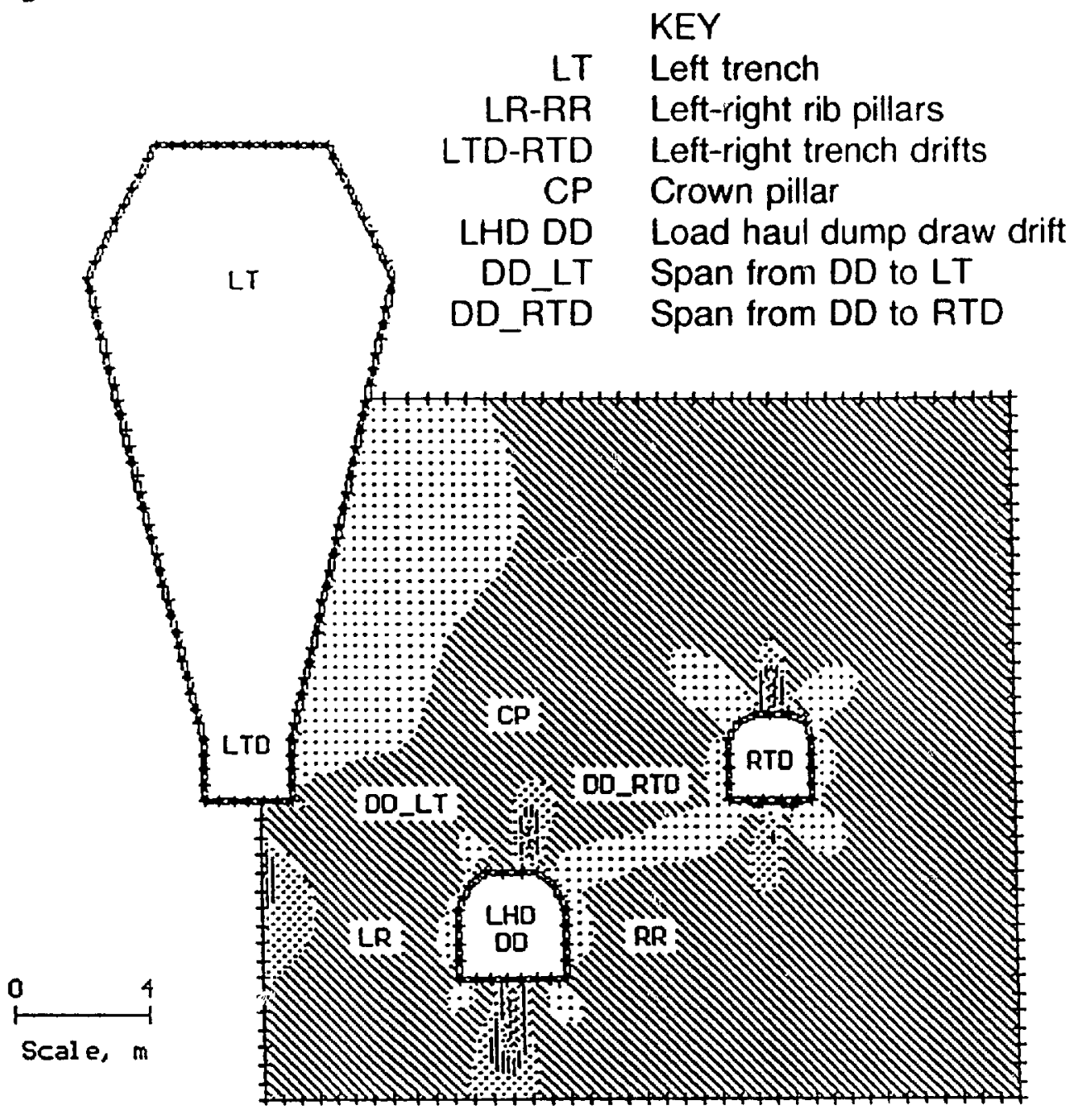

LEGEND

Strength factor (SF) contour ranges

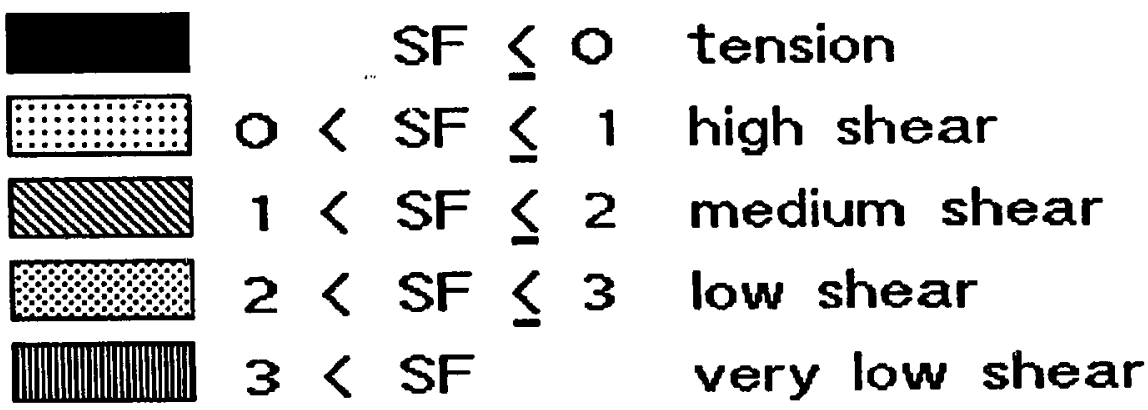

Stage 2 material damage predictions for hypothetical elevated trench difft design $(5.5 \mathrm{~m}$ $(18 \mathrm{ft})$ ) as function of low stress rutio $(K o=0.25)$ and Mohr-Coulomb rock mass strength parameter values from parels 2 and 41 on 2315 level by method $I: \phi(m)=365$, $\sigma_{\cos }(m)=4.1 \mathrm{MPa}, \sigma_{\mathrm{t}}(\mathrm{m})=3.7 \mathrm{MPa}$ 
Figure 28

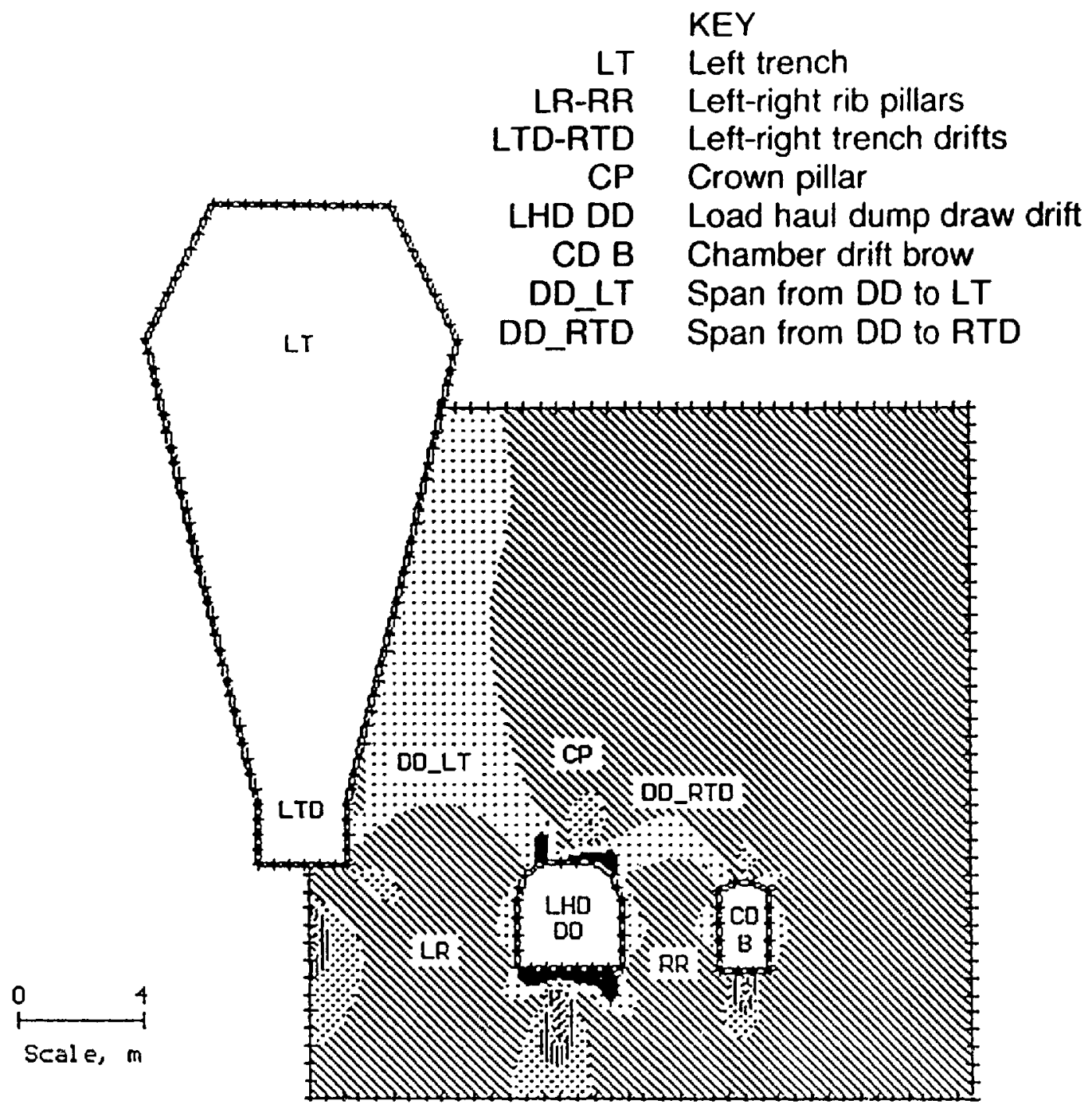

LEGEND

Strength factor (SF) contour ranges

$\begin{array}{lll}0 & \text { SF } \leq 0 & \text { tension } \\ 1 & <\text { SF } \leq 1 & \text { high shear } \\ 2 & <\text { SF } \leq 3 & \text { low shear } \\ 3 & <\text { SF } & \text { very low shear }\end{array}$

Modified stage 2 material damage predictions around chamber diff brow for delayed arcavation of right trench drift as function of low stress ratio $(K o=0.25)$ and Hoek-Brown rock mass strength parameters: $U C S(i)=91.1 \mathrm{MPa}, m(m)=2.3 \mathrm{~s}(\mathrm{~m})=0.036$ 
Figure 29
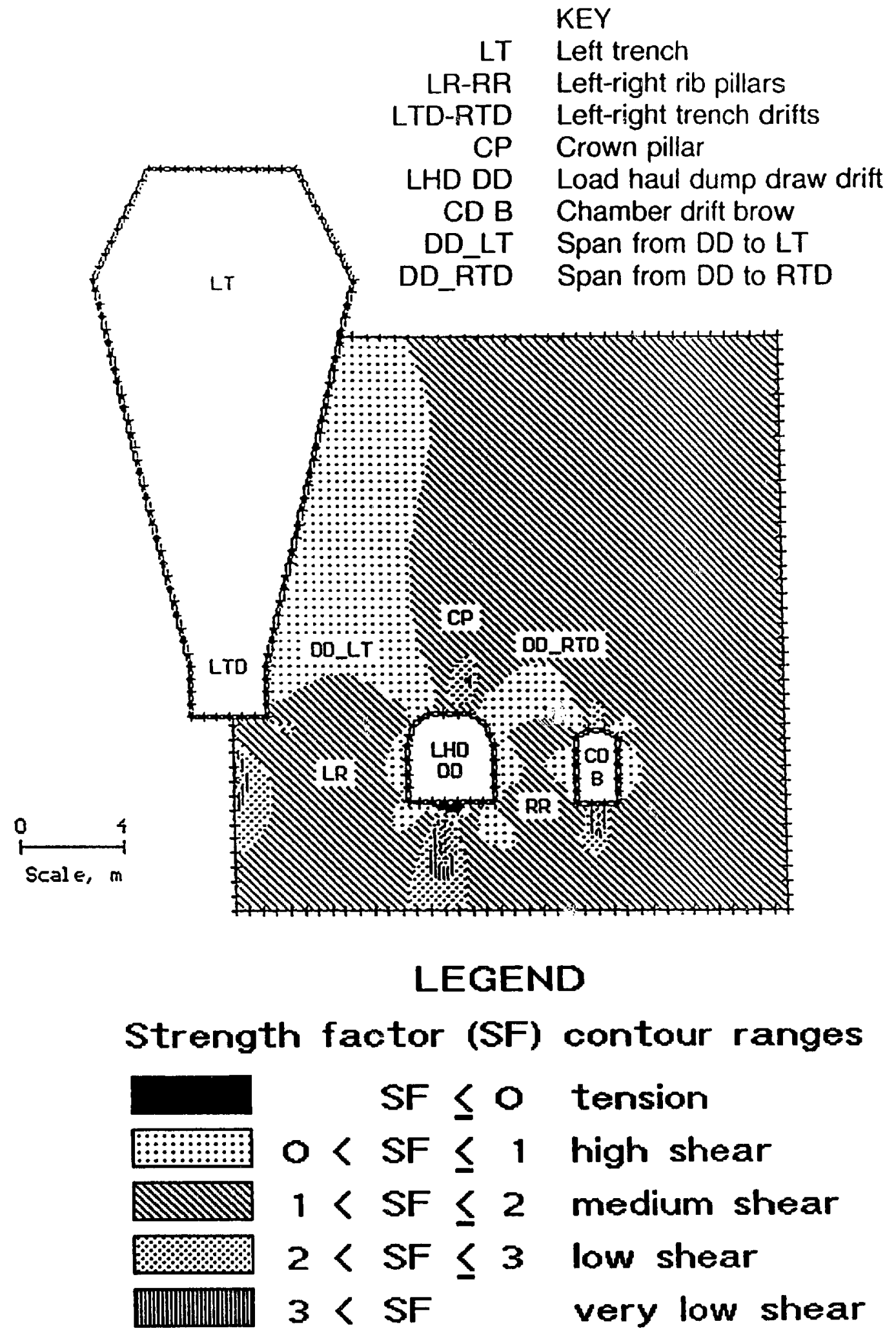

Modified stage 2 material damage predictions around chamber drift brow for delayed excavation of right trench abift as function of low stress ratio $(K o=0.25)$ and Mohr-Coulomb rock mass strength parameters: $\phi(m)=36.5, \sigma_{\text {col }}(m)=4.1 \mathrm{MPa} \sigma_{\mathrm{l}}(\mathrm{m})=3.7 \mathrm{MPa}$ 
Figure 30

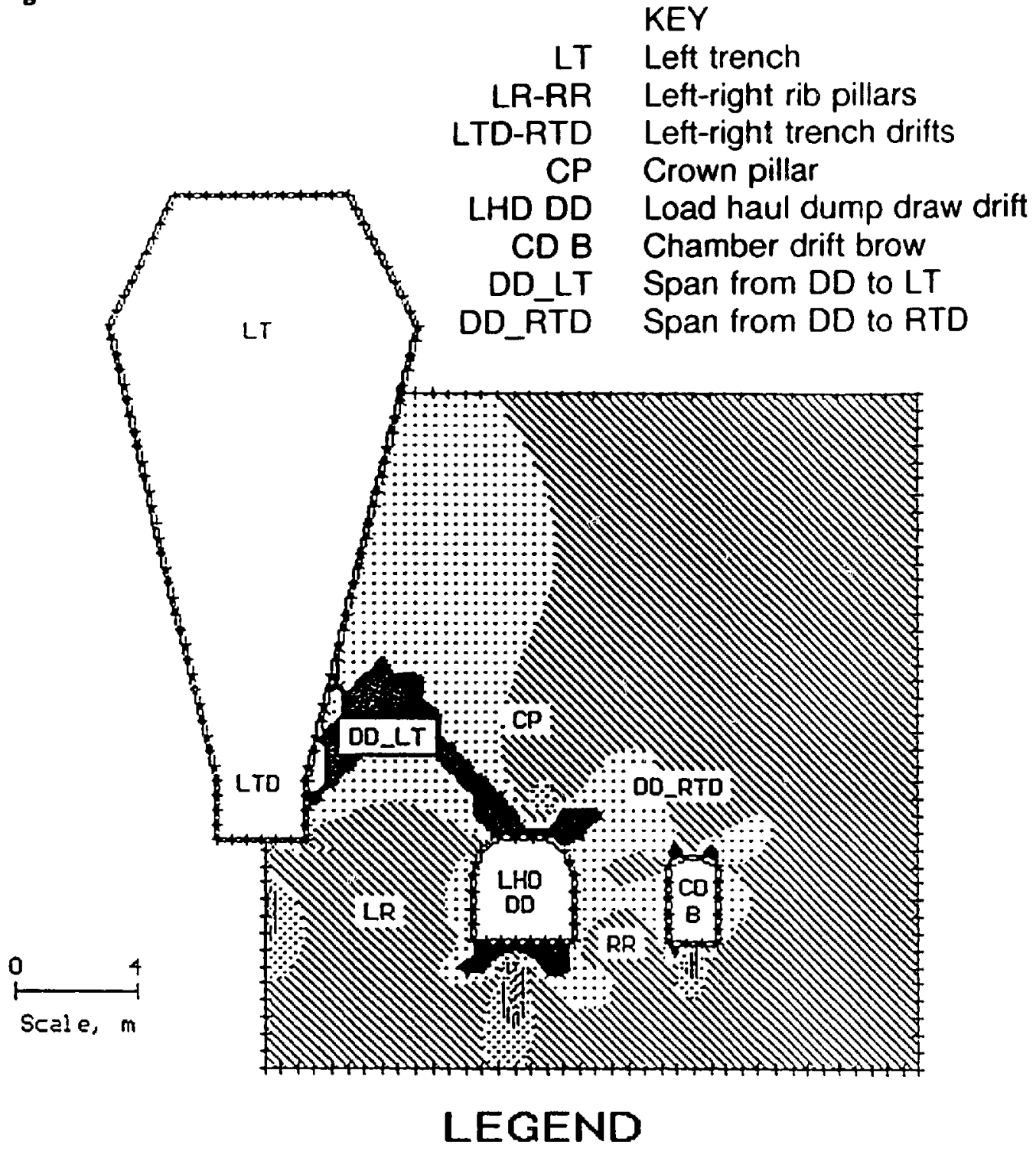

Strength factor (SF) contour ranges

SF $\leq 0$ tension
$0<$ SF $\leq 1$ high shear
$1<$ SF $\leq 2$ medium shear
$2<$ SF $\leq 3$ low shear
$3<$ SF $\quad$ very low shear

Modified stage 2 material damage predictions around chamber dift brow for delayed excavation of right trench dijft as function of low stress ratio $(K o=0.25)$, average geological rock mass rating $(R M R=51)$ in panel 3 on 2615 level, and extimoted Hoek-Brown rock mass strongth parameters: $U C S(i)=43.2 \mathrm{MPa}, m(m)=3.5$, $s(m)=0.004$ 
Figure 31
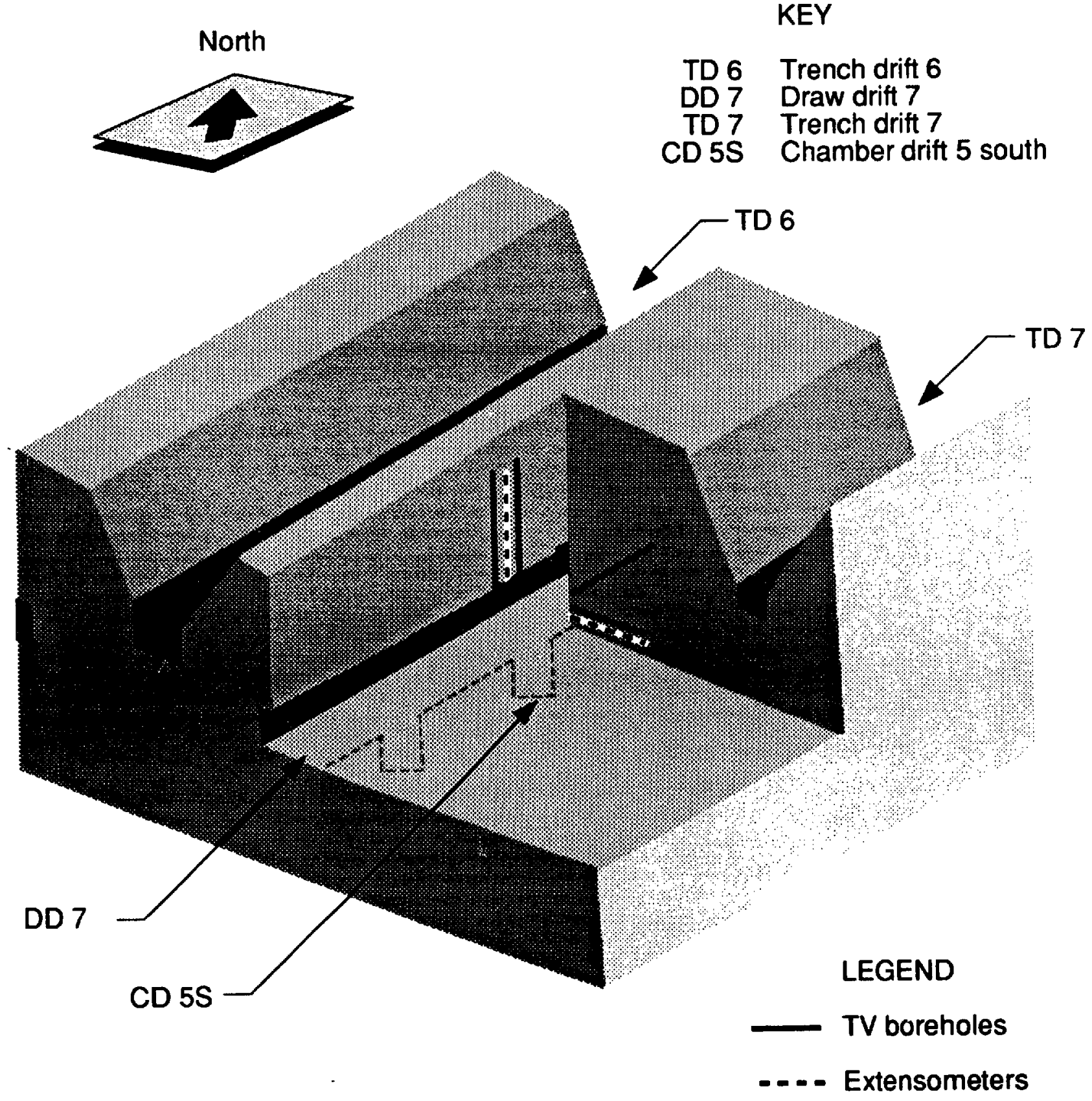

Not to scale

Locations of TV camena boreholes and convengence extensometers at survey site in pand 3 on 2615 level. 
and disturbed material with increasing frequency from the deep end of the holes out to the drift opening. In the two vertical holes, veinlets and open fractures were observed at $1.8 \mathrm{~m}$ (6 ft) and $7.3 \mathrm{~m}(24 \mathrm{ft})$. Some disturbed material was observed within the first $1.8 \mathrm{~m}$ (6 ft) of both vertical holes. In the inclined hole, extensive cracks were recorded

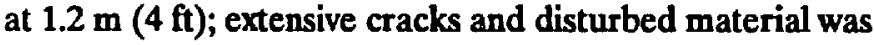
detected between $1.8 \mathrm{~m}(6 \mathrm{ft})$ and $4.2 \mathrm{~m}(14 \mathrm{ft})$; open

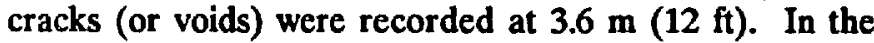
horizontal hole directly below the inclined hole, extensive open fractures were reported between $2.4 \mathrm{~m}(8 \mathrm{ft})$ and $3.6 \mathrm{~m}$ (12 ft), with extensive fractures recorded from $3 \mathrm{~m}$ (10 ft) to $4.5 \mathrm{~m}(15 \mathrm{ft})$ into the rib.

Results from the second survey indicated the vertical hole, west of the extensometers, was blocked at $7.3 \mathrm{~m}$ (24 $\mathrm{ft}$ ); the vertical hole, nearest the inclined hole, was blocked at $3.6 \mathrm{~m} \mathrm{(12} \mathrm{ft);} \mathrm{the} \mathrm{inclined} \mathrm{hole} \mathrm{was} \mathrm{blocked} \mathrm{at}$ $6.4 \mathrm{~m}$ (21 ft); and the horizontal hole was blocked at $2.4 \mathrm{~m}$ $(8 \mathrm{ft})$ into the south rib. Blockages indicate material damage and movement occurred and correlated well to the damage zones predicted by either stage 2 or the modified stage 2 stress model.

Borehole TV surveys illustrated the utility of this camera system for detecting the onset of internal rock mass material disturbance and assessing conditions for rock bolting design requirements (19).

\section{MAGMA CONVERGENCE MONITORING MEASUREMENTS}

Vertical convergence extensometers, $3 \mathrm{~m}(10 \mathrm{ft}), 5.1 \mathrm{~m}$

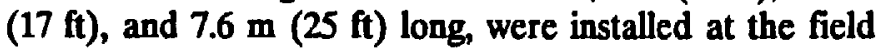
survey site (figure $5 \mathrm{~A}$ ). Convergence measurements confirmed vertical displacements occurred at each extensometer and continued during the 3-month period. Horizontal extensometers, $2.8 \mathrm{~m}$ (9.4 ft), and $1.6 \mathrm{~m}$ (5.3 ft) long, had been installed near the chamber drift 5 south (CD 5S) rib (figure 31). Initially, these units detected horizontal rib convergence, but became inoperable during the modified stage 2 mining cycle.

\section{INVESTIGATION SUMMARY}

Results from the two-dimensional boundary-element structural stress analyses indicate significant rock mass damage could occur around the LHD draw drift at the start of each repeated mining cycle (stage 2) when the first of two adjacent trench drifts was ring-drilled and blasted. The extent of material damage was extensive for the nonelevated trench drift design, but was reduced marginally when the trench drifts were elevated to the height equal to the height of the LHD draw drift and higher. Two types of analyses were used to investigate the effects of premining stress and elevated trenches on the development of unstable rock mass zones.

In the first analysis, a premining horizontal stress sensitivity study was performed to find a mine stress model that simulated the type of failures observed for the nonelevated trench design. The model, which assumed a relatively low horizontal premining stress of one-quarter the value of the premining vertical stress, simulated reasonably well the failure events that frequently occurred in the nonelevated trench panels. In the second analysis, a parametric study was performed by varying only the elevation of the trench drifts above the LHD production drift elevation. Of all the mine stress cases, the critical mining cycle, at which considerable material damage was predicted by the model, occurred at stage 2 and/or the modified stage 2 configuration.
For both analyses, a secondary rock-quality sensitivity analysis was performed, based on three sets of shearfailure rock mass and intact rock parameter values, where (1) the Mohr-Coulomb parameters were obtained directly from borehole shear tests previously conducted at the mine by USBM; (2) the Hoek-Brown parameters were obtained indirectly using Hoek-Brown's empirical analysis methods on laboratory triaxial and the borehole shear test data; and (3) the Hoek-Brown parameter values were estimated from field RMR survey values and the laboratory triaxial test data on intact core samples. In general, the locations and contour shapes of predicted material damage zones were quite similar between the Hoek-Brown and the Mohr-Coulomb rock mass parameter values. The main difference was that the extent of material damage was slightly larger using the Mohr-Coulomb parameter values. Models using the Hoek-Brown intact rock strength parameter values indicated marginally stable to stable zones around the LHD draw drift.

Crack development was detected inside the TV camera boreholes during the initial modified stage 2 mining cycle, with voids appearing from $1.8 \mathrm{~m}(6 \mathrm{ft})$ to $3.6 \mathrm{~m} \mathrm{(12ft)} \mathrm{into}$ the camera boreholes. Closed holes blocked the TV camera during the second survey. 
From the field inspection and review of the mine reports, a number of factors were identified that contributed to the ground instabilities encountered in the test panels on the $\mathbf{2 3 1 5}$ level and in the production panels on the $\mathbf{2 6 1 5}$ level. Geological conditions varied considerably in each panel. Mining in steeply dipping joint systems and altered material in fault zones adversely affected the safety and productivity of the operation. A design that requires $35 \%$ to $45 \%$ of the remaining unmined rock to sustain induced overpressure from initial caving depends on good quality rock mass in the remaining rib pillars. Failure of one rib pillar would likely impose excessive loads onto neighboring rib and crown pillars.

The study was based on ideal, linear-elastic, homogeneous, and isotropic material behavior assumptions. These limitations were considered reasonable for conducting a preliminary structural stress analysis to investigate the possible causes of the rib and roof rock-arch failures.

\section{CONCLUSIONS AND RECOMMENDATIONS}

Results from this study indicate that elevated trench drifts do not significantly minimize internal material damage or reduce the large-scale ground movements frequently encountered at this particular minesite using the mechanized LHD trench undercut panel caving system. Damage zones and shear planes, predicted by the mine structural stress analysis model, were consistent with the borehole TV observations and mine convergence monitoring measurements conducted at the survey site during a complete modified stage 2 mining cycle. The critical excavation stage, at which extensive material damage was predicted by the model, occurred for both the stage 2 and modified stage 2 configurations. Extensive cracks, open fractures, and voids were observed for the modified stage 2 configuration.
Though most block caving problems are associated with jointed, faulted, and broken (discontinuous) rock masses, the boundary-element method can be used to initially investigate what effect the premining stress state and rock mass geotechnical parameters could have on the stability of rock mass structures. Once material damage zones and shear planes are delineated from the boundary-element model, a distinct (or discrete) element stress analysis model may be constructed to further analyze what effects faults, geometry, gravity, and excavation sequences may have on rock mass movements, similar to the study by Jing and Stephansson (20).

Prior to conducting field demonstration tests, computeraided mine design and geotechnical analysis methods should be used to evaluate site conditions and design aiternatives.

\section{ACKNOWLEDGMENTS}

The author thanks Louis Sandbak and James Hunter, mining engineers, Magma Copper Co., San Manuel, AZ, for providing mine reports and assisting with the borehole TV camera surveys. Special thanks to Evert Hoek, professor, Department of Civil Engineering, University of
Toronto, Toronto, Ontario, Canada, for providing the rock strength data analysis software ROCKDATA and the twodimensional boundary-element stress analysis computer program package EXAMINE ${ }^{2 D}$.

\section{REFERENCES}

1. Merino, L. A., and M. A. Mahtab. Review of Major Problems in Block Caving. Ch. in Geomechanics Applications in Underground Hardrock Mining, ed. by W. G. Pariseau, Soc. Min. Eng. AIME, New York, NY, 1984, pp. 189-202.

2. Panek, L. A. Geotechnical Factors in Undercut-Cave Mining. Sec. in Underground Mining Methods Mandbook, Soc. Min. Eng. AlME, 1982, pp. 1456-1465.

3. Mahtab, M. A., and J. D. Dixon. Influence of Rock Fractures and Block Boundary Weakening on Cavability. Trans. SME-AIME, v. 260, 1976, pp. 6-12.

4. Jude, C. V. The Distribution of Stress Around the Initial Cave Induction Structure in a Deep Mine. Internal Report, American Metals Climax, Inc., Henderson Mine, Empire, Co, 1976, 71 pp.

5. Magma Copper Co. The Mine, General Information. 1980, 36 pp.
6. Allum, R. Modemization at Magma's San Manuel Underground Mine. Soc. Min. Eng. AIME preprint 88-316, 1988, 8 pp.

7. Stevens, C. R, L. A. Sandbak, and J. J. Hunter. LHD Production and Design Modifications at the San Manuel Mine. Paper in Proceedings of the 28th U.S. Symposium on Rock Mechanics (Tucson, AZ, June 29-July 1, 1987), Balkema, Rotterdam, 1987, pp. 1175-1185.

8. Sandbak, L. A. Rock Mass Classification in LHD Mining at San Manuel, Arizona. Soc. Min. Eng. AIME preprint 88-26, 1988, 20 pp.

9. Walenga, K. Magma to Limit Mechanized Mining of San Manuel Orebody. Southwestern PAY DIRT, Aug. 1988, p. 9A.

10. Curran, J. H., and B. T. Corkum. Excavation Analysis for Mines, EXAMINE $^{2 D}$, User's Manual Revision 3.1. Univ. of Toronto, Toronto, Ontario, Canada, 1991, 60 pp. 
11. Crandall, M. Modern Mining at San Manuel (advertisement). 1986, 22 pp.

12. Hoek, E., and E. T. Brown. The Hoek-Brown Failure CriterionA 1988 Update. Paper in Procecdings of the 15th Canadian Rock Mechanics Symposium, Toronto, Dep. Min. Eng., Queens Univ., Kingston, Ontario, Canada, 1988, pp 31-38.

13. Empirical Strength Criterion for Rock Masses. J. Geotech. Eng. Div., Proceedings of the American Society of Civil Engineers, v. 106, No. GT9, Sept. 1980, pp. 1012-1035.

14. Hoek, E. 23 Rankine Lecture, Strength of Jointed Rock Masses. Geotechnique, v. 33, No. 3, 1983, pp. 187-223.

15. Panek, L. A. Criterion of Failure for Design of Rock Nass Structures as Determined by Borehole Shear Tests. Paper in Proceedings of the 4th Congress of the International Society for Rock Mechanics (Montreaux, Switzerland, Sept. 2-8, 1979), v. 2, Balkema, Rotterdam, 1979, pp. 509-515.

16. Bieniawski, Z. T. Rock Mass Classifications in Rock Engineering. Paper in Proceedings of the Symposium on Exploration for Rock
Engineering (Johannesburg, So. Afr., Nov. 1-5, 1976), v. 1, Balkema, Rotterdam, 1976, pp. 97-106.

17. Crouch, S. L, and A. M. Starfield. Boundary Element Methods in Solid Mechanies. George Allen and Unwin, London, 1984, 322 pp.

18. White, D. Premining Stress and Its Impact on Block Caving. Ch. in Geomechanics Applications in Underground Hardrock Mining, ed. by W. G. Pariseau, Soc. Min. Eng. AIME, New York, NY, 1984, pp. 213-224.

19. Milne, D., and A. Gendron. Borehole Camera Monitoring for Safety and Design. Paper in Proceedings of the 92nd A.G.M. Canadian Institute of Mining and Metallurgy, Ottawa, May 6-10, 1990, preprint, 13 pp.

20. Jing, L., and O. Stephansson. Numerical Modeling of Sublevel Stoping for the Oscar Project Using a Three-Dimensional Distinct Element Method. Univ. of Sweden, Luleå, Sweden, 1990, 86 pp. 